\title{
Primary prophylactic colony-stimulating factors for the prevention of chemotherapy-induced febrile neutropenia in breast cancer patients (Review)
}

\author{
Renner P, Milazzo S, Liu JP, Zwahlen M, Birkmann J, Horneber M
}

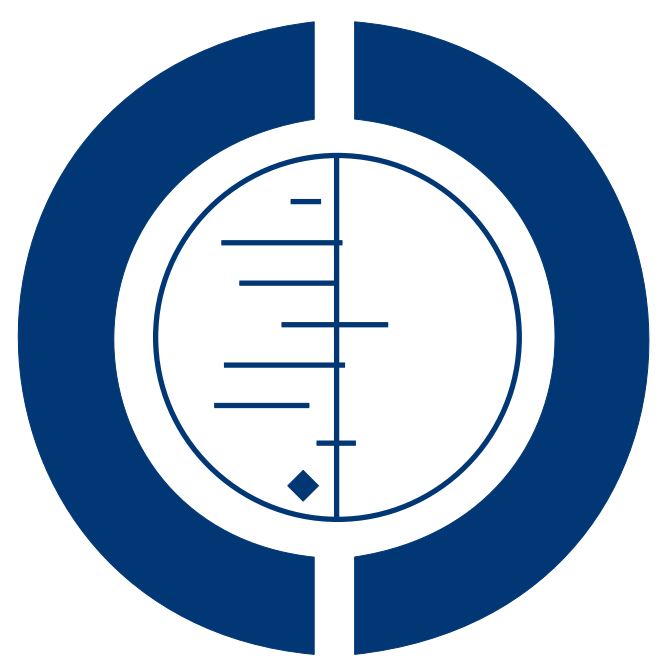

\section{THE COCHRANE COLLABORATION $^{\circledR}$}

This is a reprint of a Cochrane review, prepared and maintained by The Cochrane Collaboration and published in The Cochrane Library 2012, Issue 10

http://www.thecochranelibrary.com

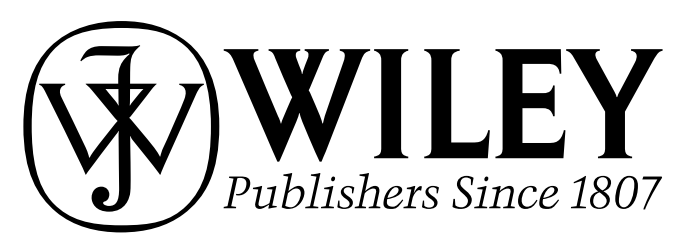

Primary prophylactic colony-stimulating factors for the prevention of chemotherapy-induced febrile neutropenia in breast cancer patients (Review)

Copyright $\odot 2012$ The Cochrane Collaboration. Published by John Wiley \& Sons, Ltd. 
TABLE OF CONTENTS

HEADER . . . . . . . . . . . . . . . . . . . . . . . . . . . . . . . . . . . . . . . 1

ABSTRACT . . . . . . . . . . . . . . . . . . . . . . . . . . . . . . . . . . . . . . .

PLAIN LANGUAGE SUMMARY . . . . . . . . . . . . . . . . . . . . . . . . . . . . . . . . . . . . . . . . . . . . .

SUMMARY OF FINDINGS FOR THE MAIN COMPARISON $\quad$. . . . . . . . . . . . . . . . . . . . . . . . . .

BACKGROUND . . . . . . . . . . . . . . . . . . . . . . . . . . . . . . . . . . . . . 6

OBJECTIVES . . . . . . . . . . . . . . . . . . . . . . . . . . . . . . . . . . . . . . . . . . . . . . . . . .

METHODS . . . . . . . . . . . . . . . . . . . . . . . . . . . . . . . . . . . . . . 7

RESULTS . . . . . . . . . . . . . . . . . . . . . . . . . . . . . . . . . . . . . . . 9

Figure 1. . . . . . . . . . . . . . . . . . . . . . . . . . . . . . . . . . . . . 10

Figure 2. . . . . . . . . . . . . . . . . . . . . . . . . . . . . . . . . . . . . . 13

Figure 3. . . . . . . . . . . . . . . . . . . . . . . . . . . . . . . . . . . . . . . . . .

Figure $4 . \quad$. . . . . . . . . . . . . . . . . . . . . . . . . . . . . . . . . . . . . 15

Figure 5. . . . . . . . . . . . . . . . . . . . . . . . . . . . . . . . . . . . . . 417

Figure 6. . . . . . . . . . . . . . . . . . . . . . . . . . . . . . . . . . . . . . . .

ADDITIONAL SUMMARY OF FINDINGS . . . . . . . . . . . . . . . . . . . . . . . . . . .

DISCUSSION . . . . . . . . . . . . . . . . . . . . . . . . . . . . . . . . . . . . . . 23

AUTHORS' CONCLUSIONS . . . . . . . . . . . . . . . . . . . . . . . . . . . . . . . . . . . . . . . . .

ACKNOWLEDGEMENTS . . . . . . . . . . . . . . . . . . . . . . . . . . . . . . . . . . . . . . . .

REFERENCES . . . . . . . . . . . . . . . . . . . . . . . . . . . . . . . . . . . . . . . . . . . . . .

CHARACTERISTICS OF STUDIES . . . . . . . . . . . . . . . . . . . . . . . . . . . . . . . . . . . . . . . . . . . .

DATA AND ANALYSES . . . . . . . . . . . . . . . . . . . . . . . . . . . . . . . . . . . . . . . . . . . . . . . . . 45

Analysis 1.1. Comparison 1 Primary outcomes, Outcome 1 Febrile neutropenia rates (total). . . . . . . . . . . . 46

Analysis 1.2. Comparison 1 Primary outcomes, Outcome 2 Febrile neutropenia rates (all cycles). . . . . . . . . . . 47

Analysis 1.3. Comparison 1 Primary outcomes, Outcome 3 Febrile neutropenia rates (first cycles). . . . . . . . . . 48

Analysis 1.4. Comparison 1 Primary outcomes, Outcome 4 Early mortality. . . . . . . . . . . . . . . . . . . 49

Analysis 1.5. Comparison 1 Primary outcomes, Outcome 5 Infection-related mortality. . . . . . . . . . . . . 50

Analysis 2.1. Comparison 2 Secondary Outcomes, Outcome 1 Neutropenia grade IV (total). . . . . . . . . . . . 51

Analysis 2.2. Comparison 2 Secondary Outcomes, Outcome 2 Neutropenia grade IV (all cycle). . . . . . . . . $\quad . \quad 52$

Analysis 2.3. Comparison 2 Secondary Outcomes, Outcome 3 Neutropenia grade IV (first cycle). . . . . . . . . . 53

Analysis 2.4. Comparison 2 Secondary Outcomes, Outcome 4 Infections (total). . . . . . . . . . . . . . . . . 54

Analysis 2.5. Comparison 2 Secondary Outcomes, Outcome 5 Hospitalization (total). . . . . . . . . . . . . . . 55

Analysis 2.6. Comparison 2 Secondary Outcomes, Outcome 6 Hospitalization (all cycles). . . . . . . . . . . . . 56

Analysis 2.7. Comparison 2 Secondary Outcomes, Outcome 7 Hospitalization (first cycle). . . . . . . . . . . . 57

Analysis 2.8. Comparison 2 Secondary Outcomes, Outcome 8 Antibiotics (total). . . . . . . . . . . . . . . . $\quad 58$

Analysis 2.9. Comparison 2 Secondary Outcomes, Outcome 9 Antibiotics (all cycles). . . . . . . . . . . . . . . . 59

Analysis 2.10. Comparison 2 Secondary Outcomes, Outcome 10 Antibiotics (first cycle). . . . . . . . . . . . . 60

Analysis 2.11. Comparison 2 Secondary Outcomes, Outcome 11 Chemotherapy, planned dose in time. . . . . . . 61

Analysis 2.12. Comparison 2 Secondary Outcomes, Outcome 12 Bone pain. . . . . . . . . . . . . . . . . . . 62

Analysis 2.13. Comparison 2 Secondary Outcomes, Outcome 13 Injection-site reaction. . . . . . . . . . . . 63

ADDITIONAL TABLES . . . . . . . . . . . . . . . . . . . . . . . . . . . . . . . . . . . . . . . . 63

APPENDICES . . . . . . . . . . . . . . . . . . . . . . . . . . . . . . . . . . . . . . . 71

HISTORY . . . . . . . . . . . . . . . . . . . . . . . . . . . . . . . . . . . . . . . . 75

CONTRIBUTIONS OF AUTHORS . . . . . . . . . . . . . . . . . . . . . . . . . . . . . . . . . . . . . . 75

DECLARATIONS OF INTEREST . . . . . . . . . . . . . . . . . . . . . . . . . . . . . . . . . . . . . . 75

SOURCES OF SUPPORT . . . . . . . . . . . . . . . . . . . . . . . . . . . . . . . . . . . . . . . 75

DIFFERENCES BETWEEN PROTOCOL AND REVIEW . . . . . . . . . . . . . . . . . . . . . . . . 76

Primary prophylactic colony-stimulating factors for the prevention of chemotherapy-induced febrile neutropenia in breast cancer patients (Review)

Copyright () 2012 The Cochrane Collaboration. Published by John Wiley \& Sons, Ltd. 


\title{
[Intervention Review] \\ Primary prophylactic colony-stimulating factors for the prevention of chemotherapy-induced febrile neutropenia in breast cancer patients
}

\author{
Peter Renner ${ }^{1}$, Stefania Milazzo ${ }^{1}$, Jian Ping Liu $^{2}$, Marcel Zwahlen ${ }^{3}$, Josef Birkmann ${ }^{1}$, Markus Horneber ${ }^{1}$ \\ ${ }^{1}$ Medizinische Klinik 5-Schwerpunkt Onkologie/Haematologie, Klinikum Nord, Nuernberg, Germany. ${ }^{2}$ Centre for Evidence-Based \\ Chinese Medicine, Beijing University of Chinese Medicine, Beijing, China. ${ }^{3}$ Institute of Social and Preventive Medicine, University \\ of Bern, Bern, Switzerland
}

Contact address: Markus Horneber, Medizinische Klinik 5-Schwerpunkt Onkologie/Haematologie, Klinikum Nord, Prof.-ErnstNathan-Str. 1, Nuernberg, D-90419, Germany. horneber@klinikum-nuernberg.de.

Editorial group: Cochrane Breast Cancer Group.

Publication status and date: New, published in Issue 10, 2012.

Review content assessed as up-to-date: 8 August 2011.

Citation: Renner P, Milazzo S, Liu JP, Zwahlen M, Birkmann J, Horneber M. Primary prophylactic colony-stimulating factors for the prevention of chemotherapy-induced febrile neutropenia in breast cancer patients. Cochrane Database of Systematic Reviews 2012, Issue 10. Art. No.: CD007913. DOI: 10.1002/14651858.CD007913.pub2.

Copyright (C) 2012 The Cochrane Collaboration. Published by John Wiley \& Sons, Ltd.

\begin{abstract}
A B S T R A C T
Background

High-dose or dose-intensive cytotoxic chemotherapy often causes myelosuppression and severe neutropenia among cancer patients. Severe neutropenia accompanied by fever, named febrile neutropenia (FN), is the most serious manifestation of neutropenia usually requiring hospitalization and intravenous antibiotics. FN and neutropenia can lead to chemotherapy treatment delays or dose reductions, which potentially compromises the effectiveness of cancer treatment and prospects for a cure. Granulocyte-macrophage (GM) and granulocyte colony-stimulating factors (G-CSFs) are administered during chemotherapy in order to prevent or reduce the incidence or the duration of FN and neutropenia.
\end{abstract}

\section{Objectives}

To assess the effect of prophylactic colony-stimulating factors (CSFs) in reducing the incidence and duration of FN, and all-cause and infection-related mortality during chemotherapy in patients with breast cancer.

\section{Search methods}

We searched the Cochrane Central Register of Controlled Trials (CENTRAL), MEDLINE, EMBASE, HEALTHSTAR, International Health Technology Assessment, SOMED, AMED and BIOSIS up to 8 August 2011. We also searched three Chinese databases (VIP, CNKI, CBM), the metaRegister of Controlled Trials, ClinicalTrials.gov, the World Health Organization's International Clinical Trials Registry Platform (WHO ICTRP) and OpenGrey.eu up to August 2011.

\section{Selection criteria}

Randomized controlled trials (RCTs) comparing CSFs (any dose) with placebo or no treatment in patients with breast cancer at any stage, at risk of developing FN while undergoing any type of chemotherapy.

Primary prophylactic colony-stimulating factors for the prevention of chemotherapy-induced febrile neutropenia in breast cancer patients (Review)

Copyright $\odot 2012$ The Cochrane Collaboration. Published by John Wiley \& Sons, Ltd. 


\section{Data collection and analysis}

We used pooled risk ratios (RR) with 95\% confidence intervals (CIs) for binary outcomes. At least two review authors independently extracted data and assessed the risk of bias of the included studies. Trial authors were contacted for further details when information was unclear.

\section{Main results}

We included eight RCTs involving 2156 participants with different stages of breast cancer and chemotherapy regimens. The trials were carried out between 1995 and 2008 and judged as being at least at moderate risk of bias. The strength of the evidence was weak for the majority of outcomes, which was mostly because of the small numbers of evaluable patients, varying definitions, as well as unclear measurements of the trials' outcomes and uncertain influences of supportive treatments on them. In most trials, the chemotherapy regimens had a risk of FN that was below the threshold at which current guidelines recommend routine primary prophylaxis with CSFs. Using CSFs significantly reduced the proportion of patients with FN (RR 0.27; 95\% CI 0.11 to 0.70 ; number needed to treat for an additional beneficial outcome (NNTB) 12) but there was substantial heterogeneity which can be explained by possible differential effects of G-CSFs and GM-CSFs and different definitions of FN. A significant reduction in early mortality was observed in CSF-treated patients compared to placebo or no treatment (RR 0.32; 95\% CI 0.13 to 0.77 ; NNTB 79). This finding was based on 23 fatal events in 2143 patients; wherein 19 of these 23 events occurred in one study and 17 events were attributed to progression of the disease by the study authors. For infection-related mortality, there were no significant differences between CSF and control groups (RR 0.14; $95 \%$ CI 0.02 to 1.29 ). In CSF-treated patients, the risk for hospitalization was significantly reduced (RR 0.14; $95 \%$ CI 0.06 to 0.30 ; NNTB 13), as well as the use of intravenous antibiotics (RR 0.35; 95\% CI 0.22 to 0.55 ; NNTB 18). The risks of severe neutropenia, infection or not maintaining the scheduled dose of chemotherapy did not differ between CSF-treated and control groups. CSFs frequently led to bone pain (RR 5.88; 95\% CI 2.54 to 13.60; number needed to treat for an additional harmful outcome (NNTH) 3) and injectionsite reactions (RR 3.59; 95\% CI 2.33 to 5.53; NNTH 3).

\section{Authors' conclusions}

In patients with breast cancer receiving chemotherapy, CSFs have shown evidence of benefi $t$ in the prevention of FN. There is evidence, though less reliable, of a decrease of all-cause mortality during chemotherapy and a reduced need for hospital care. No reliable evidence was found for a reduction of infection-related mortality, a higher dose intensity of chemotherapy with CSFs or diminished rates of severe neutropenia and infections. The majority of adverse events reported from CSF use were bone pain and injection-site reactions but no conclusions could be drawn regarding late-term side effects.

\section{PLAIN LANGUAGE SUMMARY}

Prophylactic colony-stimulating factors to prevent infectious complications in patients with breast cancer undergoing chemotherapy

Patients with breast cancer receiving chemotherapy have an increased risk of infection mediated through a low number of protective white blood cells (neutropenia). Neutropenia is a common toxicity of many chemotherapy agents and is caused by the suppression of the bone marrow. The first sign of infection is usually a fever, which indicates a potentially life-threatening condition if it occurs during severe neutropenia (febrile neutropenia $(\mathrm{FN})$ ). FN requires hospital care including the administration of intravenous antibiotics and possible delays in the continuation of chemotherapy. Colony-stimulating factors (CSFs) are drugs administered during chemotherapy in order to prevent or reduce the incidence or duration of FN and neutropenia. This review included eight trials in which 2156 patients with breast cancer had randomly received CSFs or placebo or no treatment during chemotherapy. These trials were carried out between 1995 and 2008. Prophylactic treatment with CSFs significantly reduced the risk of developing FN by 73\%. The estimated number of patients needed to be treated with CSFs in order to prevent one event of FN was 12. Although a significant decrease in mortality of all causes during chemotherapy and CSF therapy was noted, there was no reduction in infection-related mortality. There was no significant effect observed that planned chemotherapy schedules could be better maintained if CSFs were administered or that the number of patients with neutropenia decreased with CSFs. Notably, CSFs significantly reduced the need for hospital care yet frequently caused short-term adverse effects like bone pain and injection-site reactions. There were several limitations in this analysis: only a few trials could be included, the number of patients was low in many of these trials, and disease stages and chemotherapy treatments varied considerably. Moreover, the trial authors defined their outcomes differently, making comparisons across studies difficult. Information on the primary and secondary outcomes could not be obtained from all trials and the overall reporting quality was low. Many studies were dated and hence the administration of CSFs did not comply with current recommendations. Overall, CSFs have shown moderate evidence of bene

Primary prophylactic colony-stimulating factors for the prevention of chemotherapy-induced febrile neutropenia in breast cancer 
fi $t$ in the prevention of FN in patients with breast cancer receiving chemotherapy. The evidence that the administration of CSFs could reduce early mortality of all causes was weak and substantiates the need of further studies. There was no reduction in risk of infectionrelated mortality with CSF treatment. 


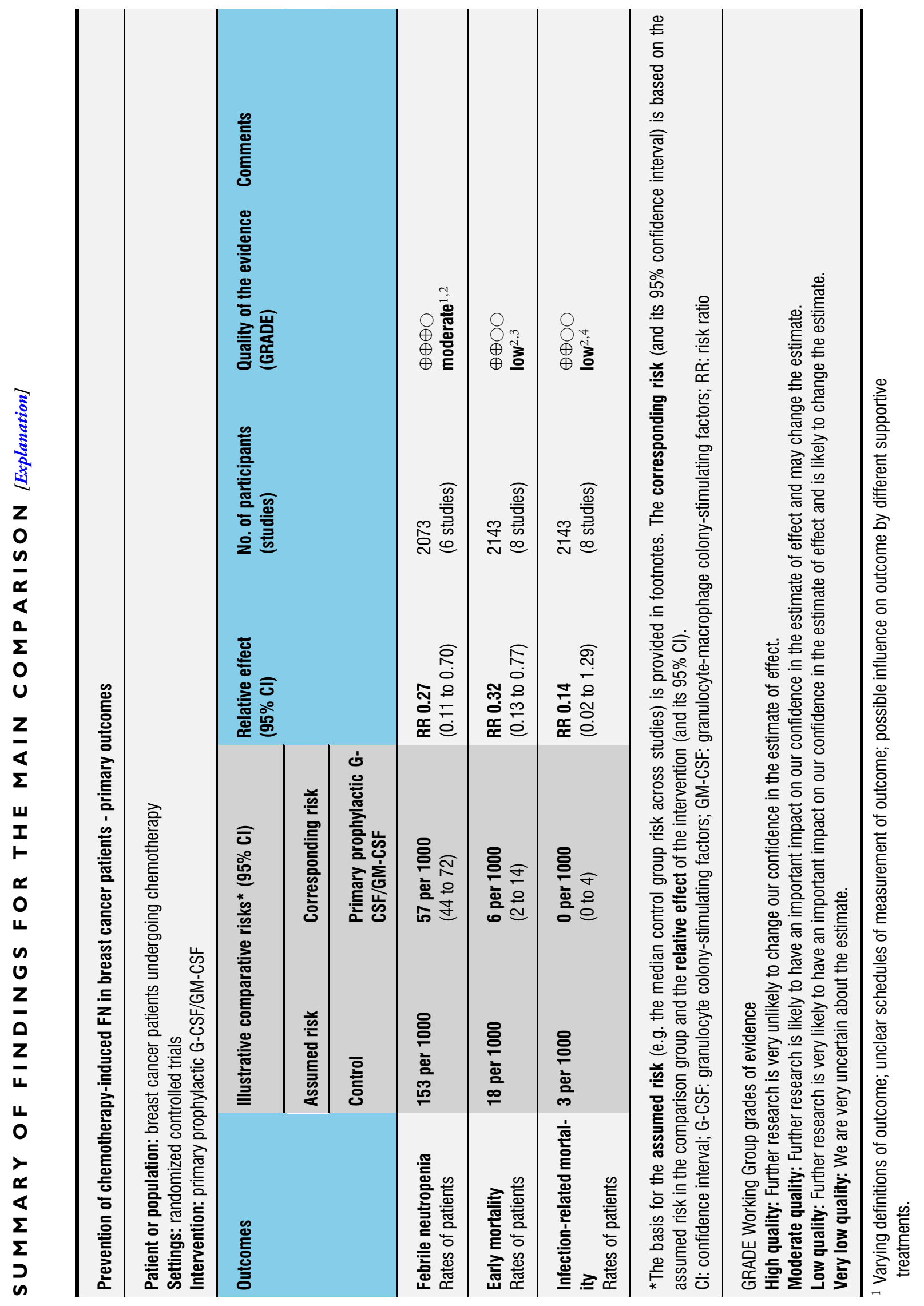

Primary prophylactic colony-stimulating factors for the prevention of chemotherapy-induced febrile neutropenia in breast cancer patients (Review)

Copyright (? 2012 The Cochrane Collaboration. Published by John Wiley \& Sons, Ltd. 


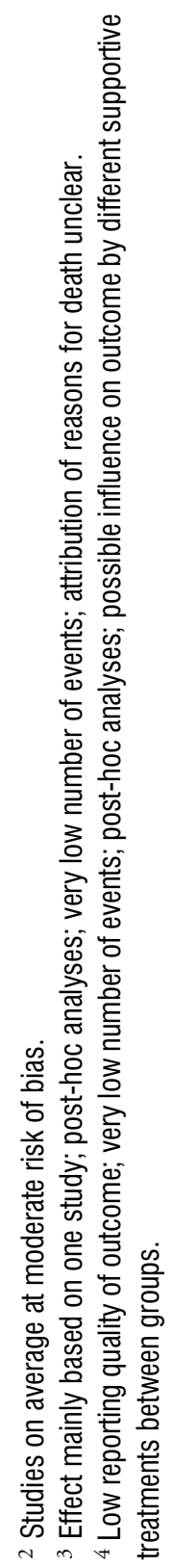

Primary prophylactic colony-stimulating factors for the prevention of chemotherapy-induced febrile neutropenia in breast cancer

patients (Review)

Copyright $\odot 2012$ The Cochrane Collaboration. Published by John Wiley \& Sons, Ltd. 


\section{B A C K G ROU N D}

\section{Description of the condition}

Chemotherapy still plays a major role in the treatment of patients with breast cancer. It is widely used as an adjuvant treatment in patients following primary removal of tumors to attain cure and to prevent recurrence, and as a palliative treatment in patients with metastatic disease. Palliative chemotherapy aims to induce tumor remission, to prolong survival, to control symptoms, and to maintain or improve quality of life. As with any other treatment, the potential benefits of either adjuvant or palliative chemotherapy for breast cancer must be balanced against the potential risks of treatment-related morbidity and mortality. Chemotherapy causes a wide range of adverse effects and can result in symptoms that are debilitating and that seriously impact on patients' quality of life. Nausea and vomiting, loss of hair and changes in blood cell counts constitute the most frequent, acute adverse effects. The changes in blood cell counts comprise a decrease in the number of red cells (anemia), platelets (thrombocytopenia) and white blood cells (leukopenia). While leukopenia means a decrease of all types of white blood cells, the term neutropenia describes a diminished number of neutrophil granulocytes. Neutrophils act as the first line of cellular defense against infectious agents. An episode of fever during the period of neutropenia is called febrile neutropenia $(\mathrm{FN}) . \mathrm{FN}$ is defined as a rise in axillary temperature to $>38.5$ ${ }^{\circ} \mathrm{C}$ for a duration of more than one hour while having an absolute neutrophil count (ANC) of less than $0.5 \times 10^{9} / \mathrm{L}$ (Crawford 2010). The risk of FN is directly related to the severity and duration of neutropenia (Bodey 1966). Although FN does not necessarily imply a documentable infection, it is most likely an indicator of some infectious condition. Once it occurs there is little chance to clarify the reasons (bacteria, virus, fungi, tumor-related) within a short period of time. Therefore FN is always managed like a severe infection. Infectious complications during neutropenia are potentially life threatening and mortality rates associated with FN range from 2\% to $21 \%$ (Smith 2006). Episodes of FN not only increase the costs of treatment through the required hospitalization (Crawford 2004) but could also lead to delays of chemotherapy or necessitate dose-reduction of chemotherapy. However, this creates a difficult clinical situation since the timing and dosage of cytotoxic substances are crucial elements that determine the success of a chemotherapeutic treatment (Samson 1984). Hence, reducing dose intensity or dose density of chemotherapy is clinically undesirable as it might jeopardize its effectiveness.

\section{Description of the intervention}

During the 1960s, the concept of the formation of mature blood cells from hematopoietic stem cells was established on an experimental basis using mainly murine assays. Immature cells from bone marrow, when given to culture plates, give rise to different colonies or colony-forming units (CFU), as bacteria do when plated on agar (Bradley 1966; Pike 1970). For the myeloid lineage, these aggregates were termed colony-forming unit granulocyte macrophage (CFU-GM) and colony-forming unit granulocyte (CFU-G). Two distinct cytokines called colony-stimulating factors (CSFs) were found to induce each type of the observed colonies: GM-CSF and G-CSF. Both CSFs became available for clinical use during the late 1980s and different types of GM-CSF and G-CSF are available on the market. Filgrastim and lenograstim are the most commonly used G-CSFs and sargramostim and molgramostim are the most commonly used GM-CSFs. Since 2002, a long-acting form of filgrastim linked to polyethylene glycol, pegfilgrastim, and several officially approved subsequent versions of filgrastim, so-called biosimilars, have been available (Jelkmann 2010; Petros 2003).

G-CSFs and, to a much lesser extent, GM-CSFs are being used during chemotherapy in patients with breast cancer for two main purposes: (1) as concomitant treatment to antibiotics in febrile neutropenic patients or (2) as prophylactic treatment either starting with the fi rst cycle of chemotherapy if neutropenia is likely to occur, or in cases where severe neutropenia is already documented (primary prophylaxis), or in patients who have already experienced infectious complications during neutropenia in earlier cycles of chemotherapy (secondary prophylaxis).

\section{How the intervention might work}

GM-CSFs expand the compartment of granulocyte and monocyte precursor cells in the bone marrow, thereby increasing the number of mature granulocytes and monocytes in the blood stream. The action of G-CSFs is not restricted but concentrated to the granulocyte lineage, leading not only to a dramatic increase of neutrophils in the peripheral blood (Lyman 2010), but also a reduction in the maturation time from stem cell to the neutrophil granulocyte (Lyman 2010). In addition to their growth promoting actions, CSFs exert effects on phagocytosis, motility, bactericidal activity, and surface molecule expression of neutrophils and monocytes (Carulli 1997; Fazzi 2007). Hence, the effi cacy of CSFs is believed to not only function via a shortening of the neutropenic episode but also by increasing the anti-infectious capacity of myeloid blood cells.

\section{Why it is important to do this review}

An effective prophylaxis of FN during chemotherapy would ideally decrease infection-related morbidity and mortality without the need for dose reductions or delays of chemotherapy. There is evidence that CSFs might be effective agents to prevent $\mathrm{FN}$ in cancer patients receiving chemotherapy, but the debate on the best prevention strategy remains controversial (Herbst 2009; Kuderer 2006). Current guidelines recommend the prophylactic use of CSF in cancer chemotherapies with an estimated risk of $\mathrm{FN}$ of about 
$20 \%$ and in patients who have already experienced a febrile neutropenic episode (Aapro 2011; Crawford 2007; Crawford 2010; Smith 2006). However, observational data suggest that the utilization of CSFs does not comply with current guidelines (Ramsey 2010). Considering the prevalence of breast cancer, the high costs of infectious complications after chemotherapy and of CSF themselves, and the fact that there is no systematically synthesized evidence from randomized controlled trials (RCTs) concerning the efficacy and safety of G-CSFs and GM-CSFs in breast cancer, a systematic review and meta-analysis on this topic are justified.

\section{O B J E C T I V E S}

To identify, assess, meta-analyze and summarize the evidence concerning the efficacy and safety of primary prophylactic CSFs (GCSFs or GM-CSFs) compared to placebo or no treatment for the prevention of FN, early mortality and infection-related mortality in patients with breast cancer undergoing chemotherapy.

\section{METHODS}

\section{Criteria for considering studies for this review}

\section{Types of studies}

RCTs that compared the use of any kind of either G-CSFs or GMCSFs versus no treatment or placebo for the prevention of neutropenia and neutropenia-related complications in patients with breast cancer undergoing chemotherapy.

\section{Types of participants}

Patients with breast cancer at any stage of disease undergoing treatment with any type and dosage of chemotherapy who were at risk of experiencing FN or neutropenia.

\section{Types of interventions}

The intervention group received any kind of either G-CSF or GMCSF at any administered dosage as primary prophylaxis during each cycle of a standard non-myeloablative chemotherapy prior to the onset of neutropenia in the treatment of breast cancer. The control group had to receive the identical chemotherapy regimen as the intervention group and a placebo or no treatment was given instead of G-CSF or GM-CSF.

If studies assessed primary CSF prophylaxis in the intervention arms and allowed secondary CSF prophylaxis in control arms in subsequent cycles, studies were included but we used only outcome data of cycle one (except for hard outcomes: mortality data) in our meta-analysis.

We excluded trials investigating the sequential administration of G-CSF or GM-CSF or their administration as secondary prophylaxis. We also excluded trials in which CSFs were administered before chemotherapy in order to induce a state of hematopoietic stem-cell arrest (i.e. priming).

\section{Types of outcome measures}

\section{Primary outcomes}

- Proportion of patients with FN.

- Duration of FN (definition of FN is described for each study).

- Early mortality (mortality during the study).

- Infection-related mortality (during the study).

\section{Secondary outcomes}

- Proportion of patients with neutropenia.

- Duration of neutropenia (definition of neutropenia is described for each study).

- Proportion of patients being hospitalized or treated, or both, with antibiotics because of FN.

- Duration of hospitalization and antibiotic treatment.

- Administration of chemotherapy (e.g. number of dose delays or dose reductions, relative dose intensity).

- Incidence of CSF-related adverse effects (e.g. bone pain and injection-site reaction).

\section{Search methods for identification of studies}

See: Breast Cancer Group methods used in reviews.

\section{Electronic searches}

\section{Deutsches Institut für Medizinische Dokumentation und Information (DIMDI)}

We searched the following databases in DIMDI (8 August 2011): Deutsche Ärzteblatt, Global Health, BIOSIS, AMED, CCMED, the Cochrane Central Register of Controlled Trials (CENTRAL), Database of Reviews of Abstracts of Effects, Cochrane Database of Systematic Reviews, EMBASE, EMBASE Alert, Hogrefe Verlagsdatenbank und Volltexte, SciSearch, Krause \& Pachernegg Verlagsdatenbank, Karger Verlagsdatenbank, MEDLINE, MEDIKAT, NHS Economic Evaluation database, Thieme Verlagsdatenbank and Thieme Verlagsdatenbank PrePrint. The corresponding search strategy can be seen in Appendix 1. We placed no language restrictions. 


\section{Gray literature}

For ongoing trials, we searched the ClinicalTrials.gov ( clinicaltrials.gov) and the World Health Organization's International Clinical Trials Registry Platform (WHO ICTRP) for technical or research reports, doctoral dissertations and conference papers. We accessed OpenGrey.eu (August 2011). The search strategies used on these databases are in Appendix 2.

\section{Chinese databases}

One review author (JPL) conducted searches on three Chinese medical databases (VIP, CNKI and CBM; accessed September 2011). Translations of the trials of interest published in Chinese were conducted by the same review author. The corresponding search strategy can be seen in Appendix 3.

\section{Searching other resources}

\section{References from published studies}

We screened the reference lists of all located studies for eligible trials by titles first and thereafter screened abstracts of studies of possible interest. Where possible, we obtained a copy of the full article for each reference reporting a potentially eligible trial. Where this was not possible, we attempted to contact the authors to provide additional information. We did not impose language restrictions. Studies that could be excluded after reading the full article were labeled as excluded trials and reasons for exclusion were stated in the Characteristics of excluded studies section.

\section{Unpublished literature}

We tried to identify unpublished or ongoing trials through correspondence with experts in the field. We did not impose language restrictions.

\section{Data collection and analysis}

\section{Selection of studies}

All titles, study information and abstracts retrieved from the electronic searches were downloaded to a reference management database. After the removal of duplicates, screening of the title, abstract and full-text was performed independently by at least two review authors (PR, SM, MH, JL). Assessment for eligibility of the full texts of all potentially relevant references was carried out using an eligibility form that contained the following questions:

- Was the study described as randomized?

- Were the participants being treated with chemotherapy for breast cancer?
- Did patients in the study arms of interest receive the same chemotherapy?

- Were patients of at least one arm given CSFs (the factors include G-CSF or GM-CSF)?

- Did patients of at least one arm receive placebo or no treatment instead of CSF?

- Did the study report at least one of the outcome measures defined in the protocol (see "Types of outcome measures")?

All studies that fulfilled all of the aforementioned criteria were included. In case of disagreement between two review authors, a third review author was consulted.

\section{Data extraction and management}

\section{Data extraction}

Two review authors (PR, SM) independently extracted data on the characteristics of patients and interventions, study quality components and outcomes onto a data extraction form especially developed for the review. We resolved differences by discussion or by appeal to a third review author (MH), if necessary. We accounted for both clinical and methodological differences of the individual trials. Data for meta-analysis were either extracted from the original publications of the included trials or from other published versions of the trials or were used from additional information that trial authors provided.

\section{Assessment of risk of bias in included studies}

We applied the guidelines delineated in the Cochrane Handbook for Systematic Reviews of Interventions (Higgins 2011) for the judgment of risk of bias. They were applied according to the following six domains:

- sequence generation;

- allocation concealment;

- blinding of participants, personnel and outcome assessors;

- incomplete outcome data;

- selective outcome reporting; and

- other sources of bias.

When the retrieved information was not available, we contacted the authors of the trial publications to provide the information.

Furthermore, we assessed the quality of evidence using the Grading of Recommendations Assessment, Development and Evaluation (GRADE) approach (Higgins 2011).

\section{Measures of treatment effect}

The decision on whether or not to combine the results of the included studies in a meta-analysis depended on the similarity of trial characteristics and the number of trials reporting on each outcome. For dichotomous variables, we calculated individual and 
pooled statistics as risk ratios (RR) with $95 \%$ confidence intervals (CI). In the case where we obtained significant results in our metaanalysis, we calculated the number needed to treat for an additional beneficial outcome (NNTB) and absolute risk reduction (ARR) using a $2 \times 2$ table (www.ebem.org/nntcalculator.html).

\section{Assessment of heterogeneity}

We assessed the heterogeneity of treatment effect between trials by visual inspection of the forest plots, and by using the standard Chi 2 test with a significance level of 0.1 . We also examined heterogeneity using the $\mathrm{I}^{2}$ statistic and used thresholds for the interpretation according to the Cochrane Handbook for Systematic Reviews of Interventions (Higgins 2011). When we detected heterogeneity, we sought reasons for it by examining clinical and methodological characteristics of the individual study and considered the appropriateness of reporting a pooled estimate. Heterogeneity was categorized into four groups depending on the $\mathrm{I}^{2}$ (Higgins 2011):

- $0 \%$ to $30 \%$ : low;

- $30 \%$ to $50 \%$ : moderate;

- $50 \%$ to $75 \%$ : substantial; and

- $75 \%$ to $100 \%$ : considerable heterogeneity.

\section{Data synthesis}

The study data were pooled using a fixed-effect model. A priori, we assumed only one true estimate and low levels of heterogeneity for all outcomes. In cases where we detected substantial or considerable heterogeneity that could not be declared by specific instances, we used a random-effects model for the respective outcome.

\section{Subgroup analysis and investigation of heterogeneity}

We performed subgroup analyses only if one of the outcome parameters demonstrated statistically significant differences between treatment groups and we regarded all subgroup analyses as hypothesis-generating. Where possible, we explored the impact of the type of CSF and the duration of CSF administration (either only in cycle one or across all delivered cycles) on outcomes in a subgroup analysis.

\section{Sensitivity analysis}

In general we abandoned sensitivity or post-hoc analysis but where necessary we performed sensitivity analysis owing to moderate to considerable heterogeneity among studies in the meta-analysis.

\section{R E S U L T S}

\section{Description of studies}

See: Characteristics of included studies; Characteristics of excluded studies; Characteristics of ongoing studies.

\section{Results of the search}

The search strategy identified a total of 1023 citations from which we removed 232 duplicates. In total, screening of the titles and abstracts identified 46 potentially eligible citations. The full-text screening of the 46 publications identified 16 articles that pertained to eight eligible RCTs (Figure 1).

The agreement between review authors for study eligibility was excellent (kappa > 0.9). Reasons for the exclusion of studies are described in the Characteristics of excluded studies table. 
Figure I. Study flow diagram.

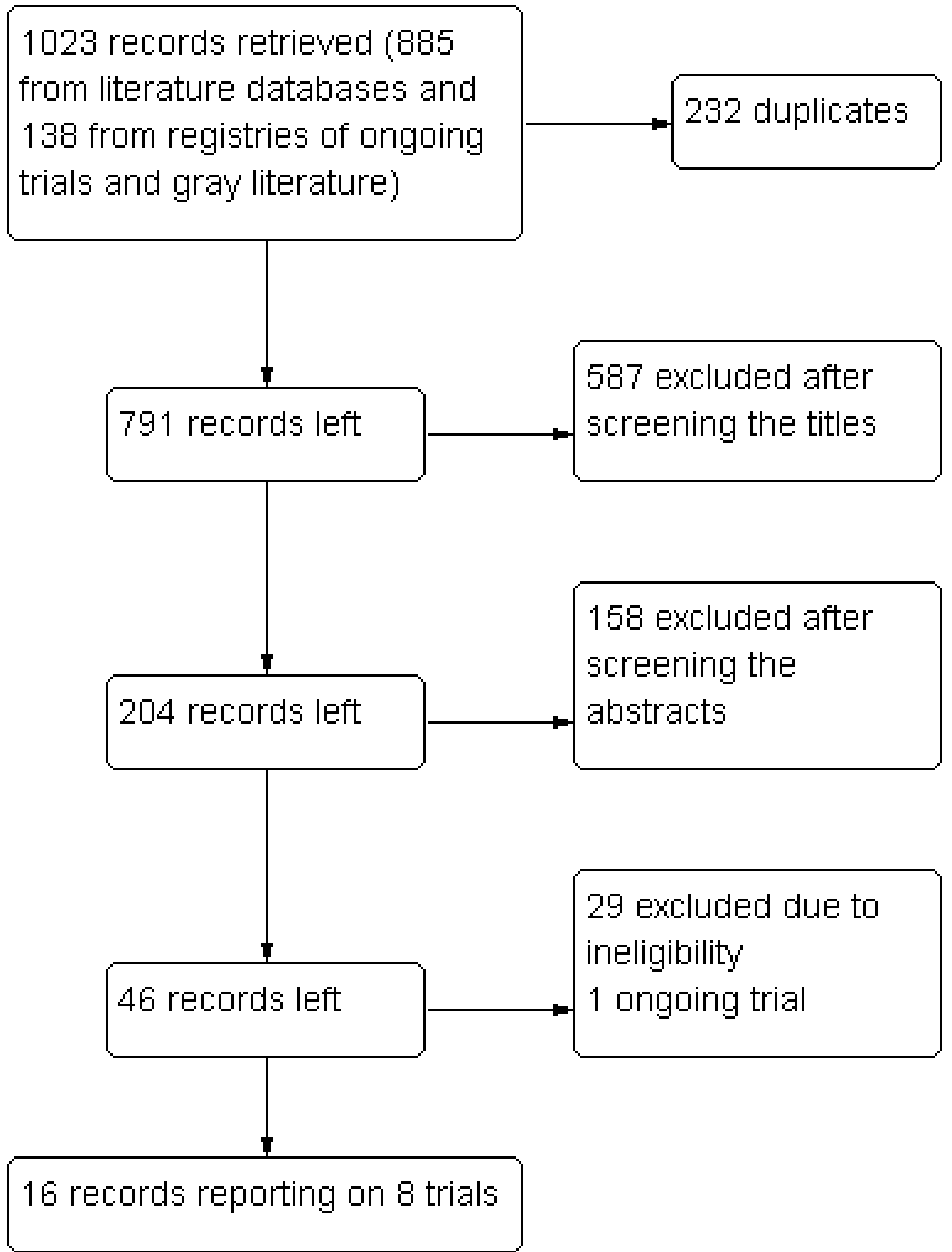




\section{Included studies}

Eight trials were included in the review (Chevallier 1995; Del Giglio 2008; Hansen 1995; Jones 1996; Muhonen 1996; Papaldo 2003; Romieu 2007; Vogel 2005) and study details are shown in the Characteristics of included studies table. Two trials were conducted in France (Chevallier 1995; Romieu 2007) and one of each in the US (Jones 1996), Denmark (Hansen 1995), Italy (Papaldo 2003), Brazil (Del Giglio 2008) and Finland (Muhonen 1996). Six trials were multicenter studies (Chevallier 1995; Del Giglio 2008; Muhonen 1996; Papaldo 2003; Romieu 2007; Vogel 2005) and Vogel 2005 and Del Giglio 2008 were multinational studies. In addition to the original publication (Papaldo 2003), four papers reported further on this study (Di Cosimo 2005; Papaldo 2004; Papaldo 2005; Papaldo 2006). Data concerning economic outcomes and a 10-year follow-up of Chevallier 1995 was published by Mapelli 1994 and Veyret 2006. Brugger 2009 presented further data of Romieu 2007. Sharma 2004 is a summary of the main findings of Vogel 2005. All study authors were contacted for additional information; however, only two authors kindly provided additional data (Hansen 1995; Papaldo 2003).

\section{Participants}

A total of 2156 adult patients (2148 women; eight men) were included in the eight studies (range: 20 to 928 ; mean: 270; median: 131). The age of the patients ranged from 18 to 78 years and the mean age was approximately 50 years. Romieu 2007 only included patients older than 65 years.

\section{Treatment situations}

Three studies treated patients with localized stages and adjuvant chemotherapies after surgery (Jones 1996; Papaldo 2003; Romieu 2007), one with inflammatory breast cancers and neoadjuvant chemotherapy before surgery (Chevallier 1995) and four with metastatic diseases and palliative chemotherapies (Del Giglio 2008; Hansen 1995, Muhonen 1996, Vogel 2005; for details of used chemotherapy regimens see Table 1).

\section{Intervention and control treatments}

Six trials used G-CSF: one trial compared lenograstim with placebo (Chevallier 1995), two trials compared pegfilgrastim with placebo (Romieu 2007; Vogel 2005), two trials used filgrastim compared with no treatment (Muhonen 1996; Papaldo 2003) and one trial used a biosimilar filgrastim (non-glycosylated r-metHuGCSF) compared with filgrastim and with no treatment (Del Giglio 2008).
Two trials used GM-CSF: one trial compared sargramostim with placebo (Jones 1996) and one trial compared GM-CSF with no treatment (Hansen 1995). For details of applied type of CSF refer to Table 2.

\section{Study designs}

In all eight studies, patients were treated in parallel designs. Six studies were made up of two study groups, one study was made up of three groups, one study was made up of four groups. All studies included at least four chemotherapy cycles up to a maximum of six cycles. Three studies used true double-blind designs (Chevallier 1995; Jones 1996; Vogel 2005) and in four studies, patients of the control groups were treated with placebo (Chevallier 1995; Del Giglio 2008; Jones 1996; Vogel 2005).

In Jones 1996, Romieu 2007 and Vogel 2005, all patients developing an event of FN at any time during the study were treated with CSFs in all subsequent cycles. Del Giglio 2008 dismantled the control group after cycle one and all patients of this group received the study drug in subsequent cycles. Romieu 2007 compared primary and secondary prophylaxis of pegfilgrastim, and patients who developed FN in the control group in cycle one received pegfilgrastim in all following cycles.

\section{Outcomes}

Two trials (Jones 1996; Vogel 2005) described the number of patients with $\mathrm{FN}$ as the primary outcome. The six remaining trials reported different primary outcomes: duration of grade IV neutropenia (Chevallier 1995; Del Giglio 2008; Jones 1996), number of neutropenic events (Romieu 2007), disease-free survival (DFS; Papaldo 2003) and duration of severe neutropenia (Hansen 1995). Trial authors' definitions and measurements of outcomes varied considerably (see Table 3).

\section{Febrile neutropenia}

All but one study (Muhonen 1996) provided data concerning FN. Six studies reported on the rates of patients developing FN (Chevallier 1995; Del Giglio 2008; Jones 1996; Papaldo 2003; Romieu 2007; Vogel 2005), one study reported on the number of febrile episodes (Papaldo 2003) and one study (Hansen 1995) reported the duration of $\mathrm{FN}$ events in days.

\section{Early mortality and infection-related mortality}

Four studies reported data on all-cause mortality (Del Giglio 2008; Jones 1996; Romieu 2007; Vogel 2005) and five studies reported on infection-related mortality during the study (Chevallier 1995;

Primary prophylactic colony-stimulating factors for the prevention of chemotherapy-induced febrile neutropenia in breast cancer 
Del Giglio 2008; Jones 1996; Romieu 2007; Vogel 2005). In those studies where the authors did not report on mortality, we assumed that no deaths had occurred.

\section{Severe neutropenia}

Four trials reported on the rates of patients with severe (WHO grade IV) neutropenia (Jones 1996; Muhonen 1996; Papaldo 2003; Romieu 2007).

\section{Infections}

Three studies reported on the incidence of infections (Chevallier 1995; Muhonen 1996; Romieu 2007). Chevallier 1995 distinguished between fever of unknown origin and clinically or microbiologically documented infections. Romieu 2007 and Muhonen 1996 stated only the number of patients with infections.

\section{Hospitalization}

Two trials reported on the rate of patients being hospitalized because of FN (Jones 1996; Vogel 2005), while three trials reported on the duration of hospitalization for any reason (Chevallier 1995; Hansen 1995; Muhonen 1996).

\section{Use of antibiotics}

Four trials reported on the rates of patients treated with intravenous (i.v.) antibiotics because of FN (Hansen 1995; Jones 1996; Papaldo 2003; Vogel 2005) and two trials on the duration of treatment with i.v. antibiotics (Chevallier 1995; Hansen 1995).

\section{Administration of chemotherapy}

Four studies reported the percentage or the number of patients who received the planned chemotherapy doses at scheduled times and doses (Chevallier 1995; Papaldo 2003; Romieu 2007; Vogel 2005). Three studies (Chevallier 1995; Hansen 1995; Papaldo 2003) reported the number of patients who received all planned cycles. Two further studies reported dose reductions of single chemotherapy agents (Muhonen 1996; Jones 1996); however, the reporting quality was so low that the data could not be used.

\section{Adverse events}

All studies reported short-term adverse events related to CSF use. The most common were injection-site reactions and bone pain. We extracted data concerning injection-site reactions from two studies (Chevallier 1995; Jones 1996) and bone pain from three studies (Chevallier 1995; Muhonen 1996; Papaldo 2003), which reported rates for both study arms. Late-term adverse events were not reported in any of the included trials.
}

\section{Conflicts of interests}

Three trials explicitly declared possible conflicts of interest (Del Giglio 2008; Romieu 2007; Vogel 2005) and five trials acknowledged assistance from the pharmaceutical industry and supply of study medication (Chevallier 1995; Del Giglio 2008; Muhonen 1996; Romieu 2007; Vogel 2005). In the Vogel 2005 trial, six out of the eight authors were affiliated with the manufacturer of the interventional drug. No details about the source of the study medication were provided in Hansen 1995, Jones 1996 and Papaldo 2003.

\section{Excluded studies}

Trials that were first considered to be of possible relevance but were subsequently excluded can be viewed at the Characteristics of excluded studies table. The main reasons for excluding trials were different chemotherapy regimens between study groups and missing control groups. No ongoing studies or studies awaiting classification were suitable for inclusion at the time point when we conducted the review.

\section{Risk of bias in included studies}

The quality of the included studies and their risk of bias were assessed separately for the different outcomes of primary interest (FN and early/infection-related mortality). The studies are grouped below by the grades of risk of bias.

The included studies were judged as having the following risk of bias concerning $\mathrm{FN}$ :

- low: Chevallier 1995; Jones 1996;

- moderate: Del Giglio 2008; Vogel 2005;

- moderate to high: Papaldo 2003; Romieu 2007;

- high: Hansen 1995.

Muhonen 1996 did not report on this outcome. The funnel plot of the six studies reporting the numbers of patients developing at least one event of FN suggested potential publication bias owing to missing studies reporting results to the right-hand side of the drawn effect-size. Assessing funnel plots of outcomes other than FN was impossible owing to the small number of studies.

The included studies were further judged as having the following risk of bias concerning early mortality and infection-related mortality:

- low: Chevallier 1995; Jones 1996;

- low to moderate: Del Giglio 2008; Romieu 2007;

- moderate: Hansen 1995;Muhonen 1996; Papaldo 2003; Vogel 2005.

Overall, the reasons for higher grades of risk of bias were because of inadequate reporting of the methods used for random allocation, unblinded study designs, unbalanced risk factors for the outcome of interest, inadequate definitions and measurements of outcomes (Table 3), different supportive treatment between groups and small sample sizes. To allow for comparisons, we assessed the quality of 
each study using the Jadad scale, which resulted in an average score of 2.3 of a maximum of 5 (range: 1 to 4 ) and the Delphi scale with an average score of 4.6 of a maximum of 7 (range: 4 to 7 ).

For the risk of bias of the included studies in detail refer to the Characteristics of included studies, Figure 2 and Figure 3.

Figure 2. 'Risk of bias' graph: review authors' judgments about each 'Risk of bias' item presented as percentages across all included studies.

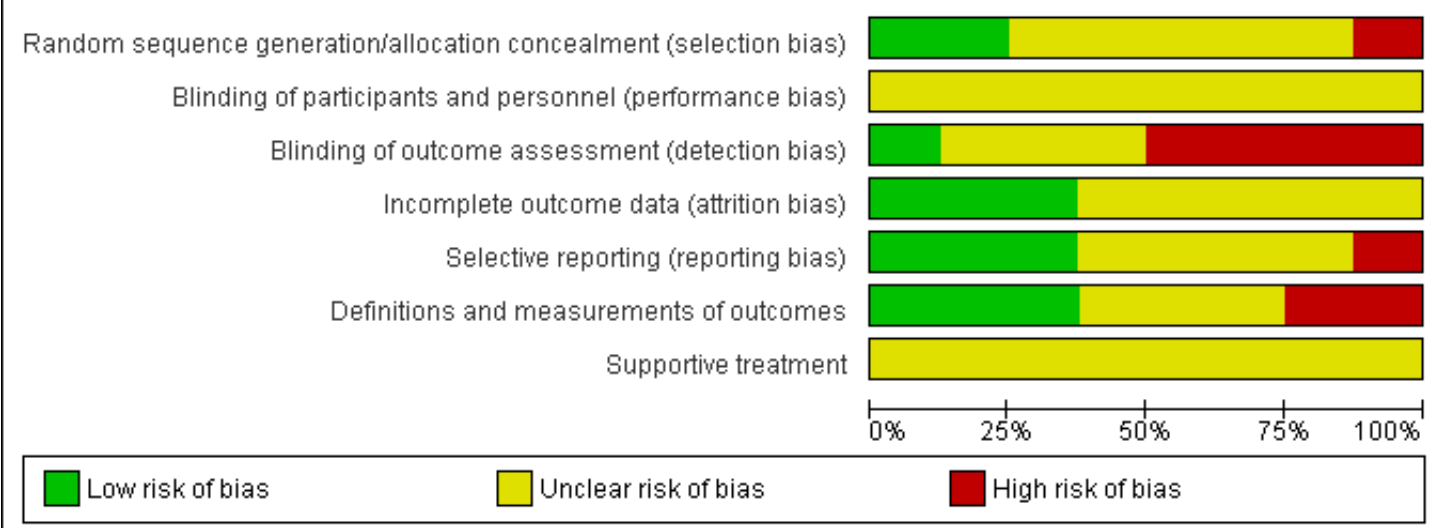


Figure 3. 'Risk of bias' summary: review authors' judgments about each 'Risk of bias' item for each included study.

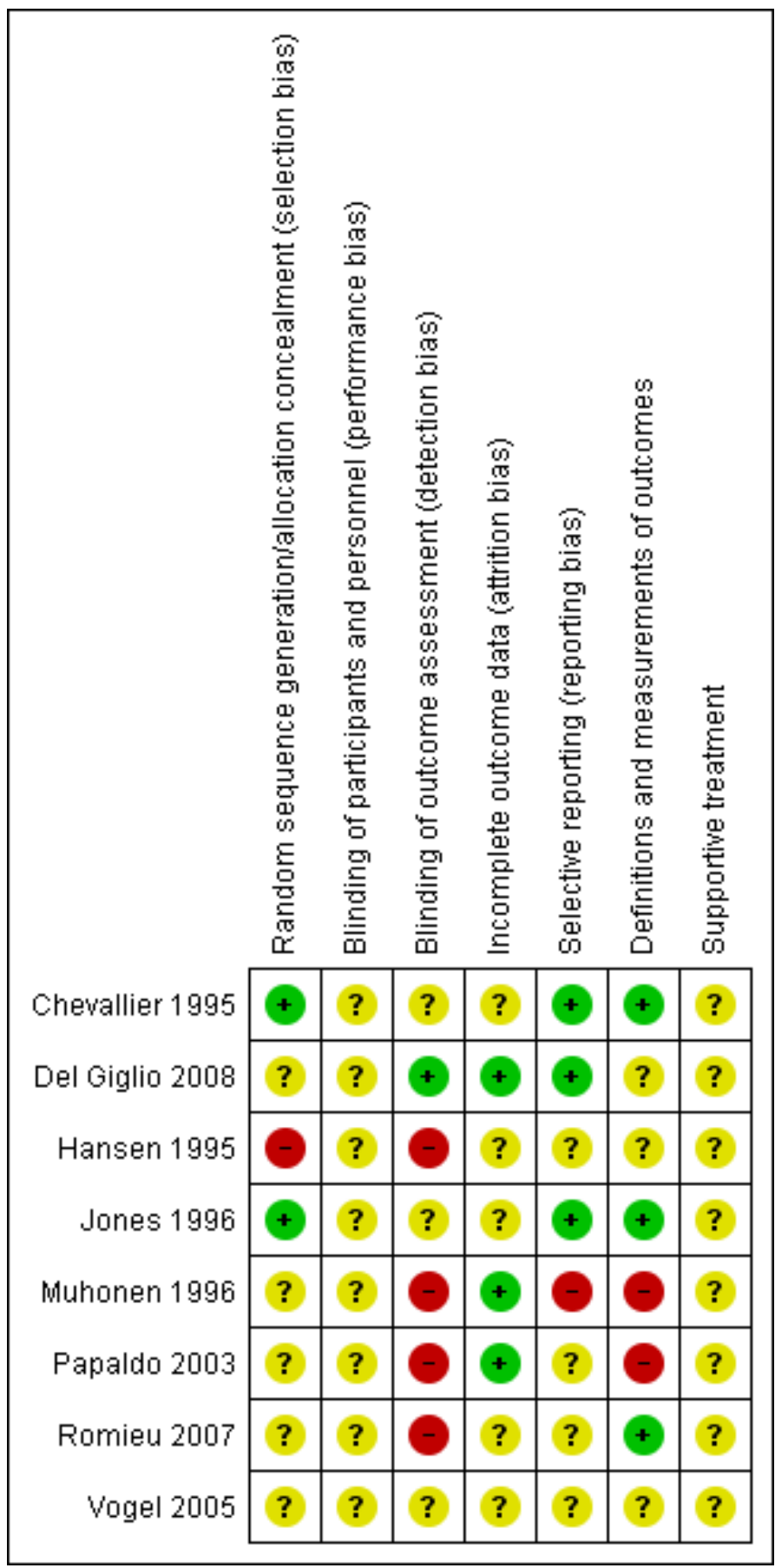

Primary prophylactic colony-stimulating factors for the prevention of chemotherapy-induced febrile neutropenia in breast cancer 


\section{Effects of interventions}

See: Summary of findings for the main comparison Prevention of chemotherapy-induced FN in breast cancer patients - primary outcomes; Summary of findings 2 Prevention of chemotherapyinduced FN in breast cancer patients - secondary outcomes For the analyses, we used first-cycle data from Jones 1996, Romieu 2007 and Vogel 2005. In these three studies, CSFs were applied as secondary prophylaxis in case of developing a febrile neutropenic event in patients of the control groups from cycle two and did not met the inclusion criteria in these cycles. Data of cycles two to four of Del Giglio 2008 could not be used for analysis because the control group was dissolved after the first cycle in this study. We used cumulated data across all cycles of the four remaining trials (Chevallier 1995; Hansen 1995; Muhonen 1996; Papaldo 2003).

\section{Febrile neutropenia}

\section{Number of patients}

In six studies, a total of 79 of 1137 patients in the intervention groups and 141 of 936 patients in the control groups developed at least one episode of FN (Chevallier 1995; Del Giglio 2008; Jones 1996; Papaldo 2003; Romieu 2007; Vogel 2005; Table 4). The pooled risk of FN was significantly reduced in CSF-treated patients (RR 0.27; 95\% CI 0.11 to 0.70; Analysis 1.1; Figure 4). The percentage of the variability in the effect estimates owing to heterogeneity rather than by chance was substantial $\left(\mathrm{I}^{2}=89 \%\right.$; NNTB 12; ARR 0.08). When we analyzed the data without Chevallier 1995, who defined FN in a broader way, heterogeneity was reduced $\left(\mathrm{I}^{2}=50 \%\right)$. There was no heterogeneity $\left(\mathrm{I}^{2}=0 \%\right)$ when we excluded Vogel 2005 and Romieu 2007 (two studies that used pegfilgrastim). The treatment benefit of the filgrastim-treated patients in the three remaining studies remained significant (RR 0.32 ; $95 \%$ CI 0.21 to 0.48$)$.

Figure 4. Forest plot of comparison: I Primary outcomes, outcome: I.I number of patients with at least one event of FN during the study period.

\begin{tabular}{|c|c|c|c|c|c|c|c|c|}
\hline \multirow{2}{*}{$\frac{\text { Study or Subgroup }}{\text { 1.1.1 G-CSF }}$} & \multicolumn{2}{|c|}{$\mathrm{CSF}$} & \multicolumn{2}{|c|}{ Control } & Weight & Risk Ratio & \multicolumn{2}{|c|}{$\begin{array}{c}\text { Risk Ratio } \\
\text { M-H, Random, } 95 \% \mathrm{Cl}\end{array}$} \\
\hline & & & & & & & & \\
\hline Romieu 2007 & 0 & 30 & 3 & 29 & $7.2 \%$ & $0.14[0.01,2.56]$ & $\longleftarrow$ & \\
\hline Papaldo 2003 & 3 & 237 & 16 & 241 & $17.0 \%$ & $0.19[0.06,0.65]$ & & \\
\hline Vogel 2005 & 5 & 463 & 51 & 465 & $19.4 \%$ & $0.10[0.04,0.24]$ & & \\
\hline Del Giglio 2008 & 34 & 276 & 25 & 70 & $22.6 \%$ & $0.34[0.22,0.54]$ & & \\
\hline Chevallier 1995 & 36 & 61 & 42 & 59 & $23.4 \%$ & $0.83[0.64,1.08]$ & & \\
\hline $\begin{array}{l}\text { Subtotal }(95 \% \mathrm{Cl}) \\
\text { Total events }\end{array}$ & 78 & 1067 & 137 & 864 & $\mathbf{8 9 . 5} \%$ & $0.27[0.10,0.75]$ & & \\
\hline \multicolumn{9}{|c|}{$\begin{array}{l}\text { Heterogeneity: } \text { Tau }^{2}=1.00 ; \mathrm{Chi}^{2}=44.17, \mathrm{df}=4(\mathrm{P}=0.00001) ; \mathrm{I}^{2}=91 \% \\
\text { Test for overall effect: } Z=2.53(\mathrm{P}=0.01)\end{array}$} \\
\hline \multicolumn{9}{|l|}{ 1.1.2 GM-CSF } \\
\hline $\begin{array}{l}\text { Jones } 1996 \\
\text { Subtotal (95\% Cl) }\end{array}$ & 1 & $\begin{array}{l}70 \\
70\end{array}$ & 4 & $\begin{array}{l}72 \\
72\end{array}$ & $\begin{array}{l}10.5 \% \\
10.5 \%\end{array}$ & $\begin{array}{l}0.26[0.03,2.24] \\
\mathbf{0 . 2 6}[0.03,2.24]\end{array}$ & & \\
\hline $\begin{array}{l}\text { Total events } \\
\text { Heterogeneity: Not a } \\
\text { Test for overall effect }\end{array}$ & $\begin{array}{l}1 \\
\text { plicable } \\
Z=1.23(\end{array}$ & $P=0.2$ & 22) & & & & & \\
\hline Total (95\% Cl) & & 1137 & & 936 & $100.0 \%$ & $0.27[0.11,0.70]$ & & \\
\hline Total events & 79 & & 141 & & & & & \\
\hline $\begin{array}{l}\text { Heterogeneity: Tau } \\
\text { Test for overall effect } \\
\text { Test for subqroup dif }\end{array}$ & $\begin{array}{l}0.96 ; \mathrm{Chi}^{2} \\
\mathrm{Z}=2.72( \\
\text { erences: }\end{array}$ & $\begin{array}{l}\mathrm{l}^{2}=44 . \\
\mathrm{P}=0.0 \\
\mathrm{Chi}^{2}=\end{array}$ & $\begin{array}{l}82, d f=5 \\
007) \\
0.00, d f=\end{array}$ & $\begin{array}{l}(P<0.0 \\
1(P=0\end{array}$ & $\begin{array}{l}00001) ; 1^{2} \\
0.96) \cdot l^{2}=\end{array}$ & $\begin{array}{l}=89 \% \\
0 \%\end{array}$ & $\begin{array}{c}0.010 .1 \\
\text { Favours CSF }\end{array}$ & $\begin{array}{c}10 \quad 100 \\
\text { Favours control }\end{array}$ \\
\hline
\end{tabular}

Subgroup analyses

First-cycle data and cumulated data across all chemotherapy cycles

Two studies reported on cumulated FN rates across all cycles.

Primary prophylactic colony-stimulating factors for the prevention of chemotherapy-induced febrile neutropenia in breast cancer 
Thirty-nine of 298 patients in the intervention groups and 58 of 300 patients in the control groups had at least one episode of FN (Chevallier 1995; Papaldo 2003). The pooled RR was 0.44 and not significant (95\% CI 0.09 to 2.24$)$ with substantial heterogeneity $\left(\mathrm{I}^{2}=86 \%\right.$; Analysis 1.2$)$. Four studies reported on FN rates during the first cycle of chemotherapy. Forty of 839 patients in the intervention groups and 83 of 636 patients in the control groups developed FN (Del Giglio 2008; Jones 1996; Romieu 2007; Vogel 2005). The risk of FN was significantly reduced in CSF-treated patients (RR $0.20 ; 95 \%$ CI 0.08 to 0.52 ) with substantial heterogeneity $\left(\mathrm{I}^{2}=61 \%\right.$; Analysis 1.3$)$. Heterogeneity disappeared when two pegfilgrastim studies were excluded (Romieu 2007; Vogel 2005; $\mathrm{I}^{2}=0 \%$ ), while the $\mathrm{RR}$ remained significant (RR 0.34; 95\% CI 0.22 to 0.53 ). Both pegfilgrastim studies also remained free from heterogeneity $\left(\mathrm{I}^{2}=0 \%\right)$ and showed significant treatment benefits (RR 0.10 ; $95 \%$ CI 0.04 to 0.24 ).

\section{G-CSF and GM-CSF}

In the five G-CSF studies, 78 of 1067 patients in the intervention groups and 137 of 864 patients in the control groups developed FN (RR 0.23; 95\% CI 0.11 to 0.46; Chevallier 1995; Del Giglio 2008; Papaldo 2003; Romieu 2007; Vogel 2005) and heterogeneity was substantial $\left(\mathrm{I}^{2}=62 \%\right)$. The GM-CSF study reported one of 70 patients in the interventional groups and four of 72 patients in the control groups with $\mathrm{FN}$ and this did not result in a significant treatment benefit for GM-CSF-treated patients (RR 0.25; 95\% CI 0.03 to 2.26; Jones 1996).

\section{Duration}

Only one study (Hansen 1995) reported on the duration of febrile neutropenic events and reported a non-significant difference of one day between the intervention group (median: four days) and the control group (median: five days) across all cycles.

\section{Early mortality}

In all eight studies, six of 1181 patients in the intervention groups and 17 of 962 patients in the control groups died during the study (Chevallier 1995; Del Giglio 2008; Hansen 1995; Jones 1996; Muhonen 1996; Papaldo 2003; Romieu 2007; Vogel 2005). Causes of death are listed in Table 5. The early mortality risk was significantly lower in CSF-treated patients (RR 0.32; 95\% CI 0.13 to 0.77$)$ without heterogeneity among the trials $\left(\mathrm{I}^{2}=\right.$ $0 \%$; NNTB 79; ARR 0.01; Analysis 1.4; Figure 5). The RR of early mortality was mainly affected by the large study of Vogel 2005, which reported five versus 14 deaths in the control and intervention group, respectively. The significance of the difference disappeared when Vogel 2005 was excluded from analysis (RR $0.19 ; 95 \%$ CI 0.03 to 1.24$)$. 
Figure 5. Forest plot of comparison: I Primary outcomes, outcome: I.4 Early mortality during the study period.

\begin{tabular}{|c|c|c|c|c|c|c|c|c|c|c|}
\hline \multirow{2}{*}{$\begin{array}{l}\text { Study or Subgroup } \\
1.4 .1 \mathrm{G}-\mathrm{CSF}\end{array}$} & \multicolumn{2}{|l|}{ CSF } & $\begin{array}{l}\text { Contr } \\
\text { Events }\end{array}$ & $\begin{array}{l}\text { ol } \\
\text { Total }\end{array}$ & \multirow[t]{2}{*}{ Weight } & $\begin{array}{c}\text { Risk Ratio } \\
\text { M-H, Fixed, } 95 \% \mathrm{Cl} \\
\end{array}$ & \multicolumn{3}{|c|}{$\begin{array}{c}\text { Risk Ratio } \\
\text { M-H, Fixed, } 95 \% \mathrm{Cl}\end{array}$} & \\
\hline & & & & & & & & & & \\
\hline Chevallier 1995 & 0 & 61 & 0 & 59 & & Not estimable & & & & \\
\hline Papaldo 2003 & 0 & 254 & 0 & 243 & & Not estimable & & & & \\
\hline Muhonen 1996 & 0 & 16 & 0 & 15 & & Not estimable & & & & \\
\hline Romieu 2007 & 0 & 30 & 1 & 29 & $8.2 \%$ & $0.32[0.01,7.61]$ & & & & \\
\hline Del Giglio 2008 & 1 & 276 & 2 & 70 & $17.1 \%$ & $0.13[0.01,1.38]$ & & & & \\
\hline Vogel 2005 & 5 & 463 & 14 & 465 & $74.8 \%$ & $0.36[0.13,0.99]$ & & & & \\
\hline Subtotal $(95 \% \mathrm{Cl})$ & & 1100 & & 881 & $100.0 \%$ & $0.32[0.13,0.77]$ & & & & \\
\hline Total events & 6 & & 17 & & & & & & & \\
\hline \multicolumn{11}{|c|}{$\begin{array}{l}\text { Heterogeneity: } \mathrm{Chi}^{2}=0.62, \mathrm{df}=2(\mathrm{P}=0.73) ; \mathrm{I}^{2}=0 \% \\
\text { Test for overall effect: } Z=2.55(P=0.01)\end{array}$} \\
\hline \multicolumn{11}{|l|}{ 1.4.2 GM-CSF } \\
\hline Jones 1996 & 0 & 70 & 0 & 72 & & Not estimable & & & & \\
\hline $\begin{array}{l}\text { Hansen } 1995 \\
\text { Subtotal }(\mathbf{9 5 \%} \mathbf{C l})\end{array}$ & 0 & $\begin{array}{l}11 \\
\mathbf{8 1}\end{array}$ & 0 & $\begin{array}{r}9 \\
81\end{array}$ & & $\begin{array}{l}\text { Not estimable } \\
\text { Not estimable }\end{array}$ & & & & \\
\hline \multicolumn{11}{|c|}{$\begin{array}{l}\text { Heterogeneity: Not applicable } \\
\text { Test for overall effect: Not applicable }\end{array}$} \\
\hline Total $(95 \% \mathrm{Cl})$ & & 1181 & & 962 & $100.0 \%$ & $0.32[0.13,0.77]$ & & & & \\
\hline Total events & 6 & & 17 & & & & & & & \\
\hline $\begin{array}{l}\text { Heterogeneity: Chi } \\
\text { Test for overall effec } \\
\text { Test for subgroun di }\end{array}$ & $\begin{array}{l}0.62, \mathrm{df}= \\
Z=2.55 \\
\text { erences: }\end{array}$ & $\begin{array}{l}2(\mathrm{P}= \\
\mathrm{P}=0.0 \\
\text { Not ap }\end{array}$ & $\begin{array}{l}0.73) ; 1^{2}= \\
\text { 1) } \\
\text { plicable }\end{array}$ & & & & $\begin{array}{r}0.001 \\
\mathrm{~F}\end{array}$ & $\begin{array}{c}0.1 \\
\text { vours } \mathrm{CSF}\end{array}$ & Favours & $\begin{array}{c}1000 \\
\text { antrol }\end{array}$ \\
\hline
\end{tabular}

\section{Infection-related mortality}

In all eight studies, none of the 1181 patients in the intervention groups and three of 962 patients in the control groups died of infections. Two of the three deaths occurred in Vogel 2005 and one in Del Giglio 2008. Causes of deaths are listed in Table 6. The differences in the risk of dying from infection were not significant (RR 0.14; 95\% CI 0.02 to 1.29; Analysis 1.5; Figure 6). The results were homogeneous $\left(\mathrm{I}^{2}=0 \%\right.$; Analysis 1.5$)$. 
Figure 6. Forest plot of comparison: I Primary outcomes, outcome: I.5 Infection-related mortality.

\begin{tabular}{|c|c|c|c|c|c|c|c|c|}
\hline Study or Subgroup & \multicolumn{2}{|l|}{ CSF } & \multicolumn{2}{|c|}{ Control } & \multirow{2}{*}{ Weight } & $\begin{array}{c}\text { Risk Ratio } \\
\text { M-H, Fixed, } 95 \% \mathrm{Cl}\end{array}$ & \multicolumn{2}{|c|}{$\begin{array}{c}\text { Risk Ratio } \\
\text { M-H, Fixed, 95\% Cl }\end{array}$} \\
\hline \multicolumn{8}{|l|}{ 1.5.1 G-CSF } & \\
\hline Chevallier 1995 & 0 & 61 & 0 & 59 & & Not estimable & & \\
\hline Muhonen 1996 & 0 & 16 & 0 & 15 & & Not estimable & & \\
\hline Papaldo 2003 & 0 & 254 & 0 & 243 & & Not estimable & & \\
\hline Romieu 2007 & 0 & 30 & 0 & 29 & & Not estimable & & \\
\hline Del Giglio 2008 & 0 & 276 & 1 & 70 & $48.9 \%$ & $0.09[0.00,2.08]$ & 4 & \\
\hline $\begin{array}{l}\text { Vogel } 2005 \\
\text { Subtotal }(95 \% \mathrm{Cl})\end{array}$ & 0 & $\begin{array}{r}463 \\
1100\end{array}$ & 2 & $\begin{array}{l}465 \\
881\end{array}$ & $\begin{array}{r}51.1 \% \\
\mathbf{1 0 0 . 0 \%}\end{array}$ & $\begin{array}{l}0.20[0.01,4.17] \\
\mathbf{0 . 1 4}[\mathbf{0 . 0 2}, \mathbf{1 . 2 9}]\end{array}$ & & \\
\hline \multicolumn{9}{|c|}{ Heterogeneity: $\mathrm{Chi}^{2}=0.15, \mathrm{df}=1(\mathrm{P}=0.70) ; \mathrm{I}^{2}=0 \%$} \\
\hline \multicolumn{9}{|l|}{ 1.5.2 GM-CSF } \\
\hline Hansen 1995 & 0 & 11 & 0 & 9 & & Not estimable & & \\
\hline $\begin{array}{l}\text { Jones } 1996 \\
\text { Subtotal }(95 \% \mathrm{Cl})\end{array}$ & 0 & $\begin{array}{l}70 \\
81\end{array}$ & 0 & $\begin{array}{l}72 \\
81\end{array}$ & & $\begin{array}{l}\text { Not estimable } \\
\text { Not estimable }\end{array}$ & & \\
\hline $\begin{array}{l}\text { Total events } \\
\text { Heterogeneity: Not a } \\
\text { Test for overall effec }\end{array}$ & $\begin{array}{l}\quad 0 \\
\text { Olicable } \\
\text { Not appli }\end{array}$ & cable & 0 & & & & & \\
\hline Total $(95 \% \mathrm{Cl})$ & & 1181 & & 962 & $100.0 \%$ & $0.14[0.02,1.29]$ & & \\
\hline Total events & 0 & & 3 & & & & & \\
\hline $\begin{array}{l}\text { Heterogeneity: } \mathrm{Chi}^{2} \\
\text { Test for overall effec } \\
\text { Test for subgroup di }\end{array}$ & $\begin{array}{l}0.15, \mathrm{df}= \\
\mathrm{Z}=1.73 \\
\text { rences: }\end{array}$ & $\begin{array}{l}1(P= \\
P=0.0 \\
\text { Not }\end{array}$ & $\begin{array}{l}0.70) ; 1^{2}= \\
\text { p) } \\
\text { plicable }\end{array}$ & $=0 \%$ & & & 0.010 .1 & $\begin{array}{c}10100 \\
\text { Favours control }\end{array}$ \\
\hline
\end{tabular}

\section{Neutropenia}

\section{Number of patients}

In four studies, a total of 83 of 353 patients in the intervention groups and 191 of 359 patients in the control groups developed at least one episode of severe (WHO grade IV) neutropenia (N4) (Jones 1996; Muhonen 1996; Papaldo 2003; Romieu 2007 Table 4). The risk of N4 was not significantly reduced in CSF-treated patients (RR 0.44 ; $95 \%$ CI 0.17 to 1.18 ) with considerable heterogeneity among the studies $\left(\mathrm{I}^{2}=96 \%\right.$; Analysis 2.1$)$. Heterogeneity could not be further reduced.

\section{Subgroup analyses}

\section{First-cycle data and cumulated data across all chemotherapy cycles}

We used data from Muhonen 1996 and Papaldo 2003 who reported rates of patients with neutropenia across all cycles of chemotherapy. Seventeen of the 253 patients in the intervention group and 113 of 258 patients in the control group developed at least one neutropenic event that was significant (RR 0.19; 95\% CI 0.08 to 0.45; Analysis 2.2). In two studies (Jones 1996; Romieu 2007) that reported the rates of patients who developed at least one neutropenic event during cycle one, 66 of 100 patients in the intervention group and 78 of 101 patients in the control group developed at least one neutropenic event. The meta-analysis showed no significant benefits for CSF-treated patients (RR 0.89; 95\% CI 0.66 to 0.21 ; Analysis 2.3). Both subgroup analyses were of substantial heterogeneity $\left(\mathrm{I}^{2}=0.64\right.$ and $\mathrm{I}^{2}=0.63$, respectively).

\section{G-CSF and GM-CSF}

In the three studies (Muhonen 1996; Papaldo 2003; Romieu 2007) applying G-CSFs, 40 out of 283 patients in the intervention group and 134 of 287 patients in the control group developed at least one neutropenic event. The result was not significant (RR 0.36; 95\% CI 0.05 to 2.44 ) and had considerable heterogeneity ( $\mathrm{I}^{2}$ = 97\%; Analysis 2.1). Jones 1996 who applied GM-CSFs showed a significant benefit for patients in the intervention group (RR 0.78 ; $95 \%$ CI 0.62 to 0.97 ).

\section{Duration}


A pooled analysis of the duration of $\mathrm{N} 4$ could not be carried out because trial authors did not report the required details (e.g. standard deviations). However, all studies that investigated the duration of N4 reported that, on average, N4 lasted two days longer in the control groups compared to the CSF groups (Chevallier 1995; Del Giglio 2008; Hansen 1995; Jones 1996; Romieu 2007 Table 7).

\section{Infections}

In three studies, 55 of 107 patients in the intervention groups and 62 of 103 patients in the control groups experienced at least one infectious complication (Chevallier 1995; Muhonen 1996; Romieu 2007; Table 8). The RR was 0.86 (95\% CI 0.72 to 1.02 ) without heterogeneity among the trials $\left(\mathrm{I}^{2}=0 \%\right.$; Analysis 2.4$)$.

\section{Hospitalization}

In four studies, a total of six of 574 patients in the intervention groups and 50 of 575 patients in the control groups were admitted to hospital on at least one occasion (Hansen 1995; Jones 1996; Romieu 2007; Vogel 2005; Table 9). The risk for hospitalization was significantly reduced in CSF-treated patients (RR 0.14; 95\% CI 0.06 to 0.30$)$ without heterogeneity among the trials $\left(\mathrm{I}^{2}=0 \%\right.$; NNTB 13; ARR 0.08; Analysis 2.5).

\section{Subgroup analyses}

\section{First-cycle data and cumulated data across all chemotherapy cycles}

We only used data from Hansen 1995 who reported rates of patients hospitalized across all cycles of chemotherapy. None of the 11 patients in the intervention groups and one of nine patients in the control groups were admitted to hospital on at least one occasion, which was not significant (RR 0.28 ; 95\% CI 0.01 to 6.10; Analysis 2.6). In three studies that reported the rates of patients hospitalized during cycle one, six of 563 patients in the intervention groups and 49 of 566 patients in the control groups were admitted to hospital. The meta-analysis showed significant benefits for CSF-treated patients (RR 0.13; 95\% CI 0.06 to 0.30 ) and the results were homogeneous $\left(\mathrm{I}^{2}=0 \%\right.$; Jones 1996; Romieu 2007 Vogel 2005).

\section{$G-C S F$ and $G M-C S F$}

In the two studies applying G-CSF, five of the 493 patients in the intervention groups and 45 of 494 patients in the control groups were hospitalized (mainly for FN, severe neutropenia or infections). The risk for being hospitalized was significantly lower in the CSF groups (RR 0.12; 95\% CI 0.05 to 0.29 ) and the results were homogeneous $\left(\mathrm{I}^{2}=0 \%\right.$; Romieu 2007; Vogel 2005; Analysis 2.5). In the two studies applying GM-CSF, one out of 81 patients in the intervention groups and five of 81 patients in the control groups were admitted to hospitals. The difference was not significant (RR 0.26; 95\% CI 0.04 to 1.56; Hansen 1995; Jones $1996)$ and there was no heterogeneity $\left(\mathrm{I}^{2}=0 \%\right)$.

\section{Use of intravenous antibiotics}

In four studies, 22 of 781 patients in the intervention groups and 65 of 787 patients in the control groups were treated at least once with i.v. antibiotics (Hansen 1995; Jones 1996; Papaldo 2003; Vogel 2005; Table 9). The risk for being treated with i.v. antibiotics was significantly lower in CSF-treated patients (RR 0.35; 95\% CI 0.22 to 0.55$)$ with low heterogeneity among the trials $\left(\mathrm{I}^{2}=19 \%\right.$; NNTB 18; ARR 0.05; Analysis 2.8).

\section{Subgroup analyses}

First-cycle data and cumulated data across all chemotherapy cycles

In two studies, 16 of 248 patients in the intervention groups and 33 of 250 patients received i.v. antibiotics during all cycles of chemotherapy (Hansen 1995; Papaldo 2003). The pooled risk for antibiotic treatment was also significantly reduced (RR 0.50; $95 \%$ CI 0.28 to 0.87$)$ without heterogeneity $\left(\mathrm{I}^{2}=0 \%\right.$; Analysis 2.9$)$. In two studies, six of 533 patients in the intervention groups and 32 of 537 patients in the control groups received i.v. antibiotics in the first cycle of chemotherapy (Jones 1996; Vogel 2005). The pooled risk for being treated was lower in the CSF group albeit not significant (RR 0.40; 95\% CI 0.03 to 4.77) with considerable heterogeneity between the trials $\left(\mathrm{I}^{2}=96 \%\right.$; Analysis 2.10$)$.

The pooled risk for being treated with i.v. antibiotics was significantly lower in the two studies applying G-CSF (RR 0.35; 95\% CI 0.22 to 0.57; Papaldo 2003; Vogel 2005) with substantial heterogeneity between the two trials $\left(\mathrm{I}^{2}=72 \%\right)$. In the two studies applying GM-CSF, there was no significant difference in the risks (RR 0.26 ; $95 \%$ CI 0.04 to 1.56 ) with no heterogeneity $\left(\mathrm{I}^{2}=0 \%\right.$; Hansen 1995; Jones 1996).

\section{Administration of chemotherapy}

In four studies, 674 out of 794 patients in the intervention groups and 647 out of 794 patients in the control groups received the planned chemotherapy cycles at scheduled times and doses (Chevallier 1995; Papaldo 2003; Romieu 2007 Vogel 2005; Table 10). The RR was 1.05 (95\% CI 0.97 to 1.13 ) with substantial heterogeneity $\left(\mathrm{I}^{2}=61 \%\right.$; Analysis 2.11$)$. There were no GM-CSF studies in the analysis. 


\section{Adverse events}

\section{Bone pain}

Two studies with a total of 151 patients reported the number of patients with bone pain in both study arms (Chevallier 1995; Muhonen 1996). Papaldo 2003 did not report the number of patients with bone pain in the control group and therefore could not be considered for analysis. The pooled risk (RR) for bone pain was 5.88 for CSF-treated patients (95\% CI 2.54 to 13.60 ) with no heterogeneity $\left(\mathrm{I}^{2}=0 \%\right.$; NNH 3; Table 11 Analysis 2.12).

\section{Injection-site reaction}

Two studies with a total of 262 patients reported the number of patients with injection-site reactions (Chevallier 1995; Jones 1996). The pooled risk (RR) for injection-site reaction was 3.59 for CSF-treated patients (95\% CI 2.33 to 5.53 ) with no heterogeneity $\left(\mathrm{I}^{2}=0 \%\right.$, NNTH 3; Table 11 Analysis 2.13). 


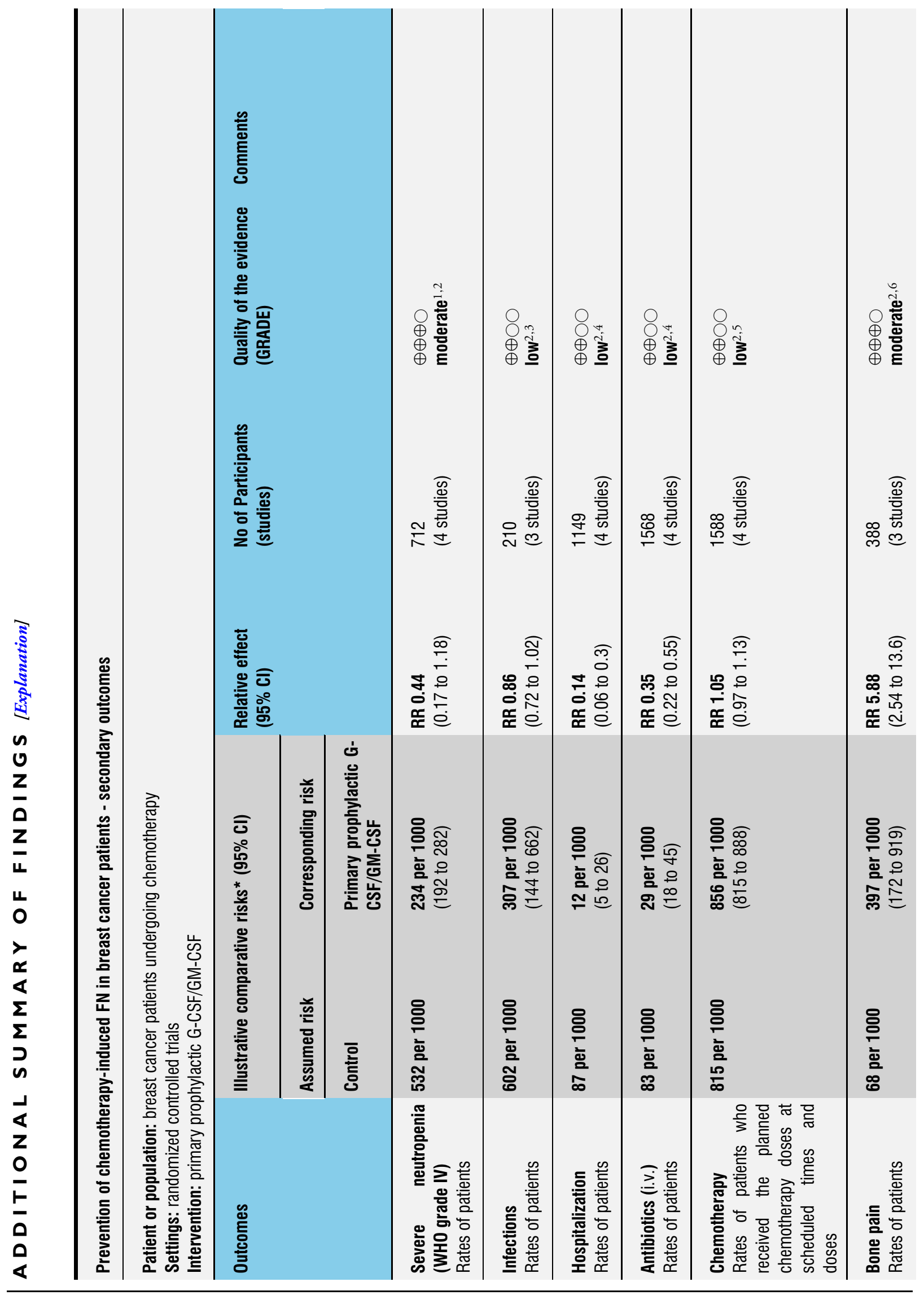

Primary prophylactic colony-stimulating factors for the prevention of chemotherapy-induced febrile neutropenia in breast cancer 21 patients (Review)

Copyright $\odot 2012$ The Cochrane Collaboration. Published by John Wiley \& Sons, Ltd. 


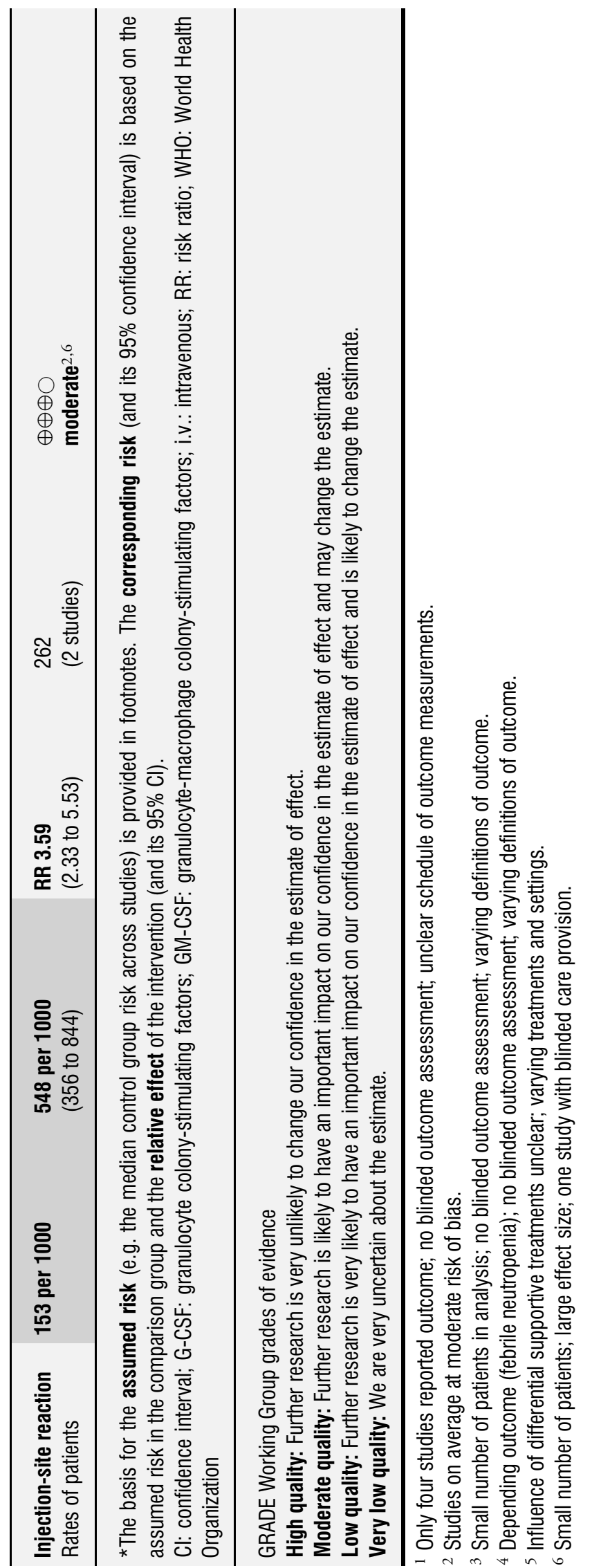

Primary prophylactic colony-stimulating factors for the prevention of chemotherapy-induced febrile neutropenia in breast cancer 


\section{ISCUSSIO N}

\section{Summary of main results}

This is the first systematic review and meta-analysis that has addressed the evidence for the use of CSFs on the prevention of FN and its complications in patients with breast cancer undergoing chemotherapy. We identified eight RCTs with a total of 2156 patients. The patients were treated with neoadjuvant (one study), adjuvant (three studies) or palliative chemotherapy regimens (four studies). Six studies used G-CSF (three filgrastim, two pegfilgrastim, one lenograstim) and two studies used GM-CSF (one molgramostim and one sargramostim). The majority of studies were judged as being at least at moderate risk of bias.

In our meta-analysis, CSFs significantly reduced the number of patients with FN (RR 0.27; NNTB 12), early mortality (RR 0.32; NNTB 79), the need for hospital care (RR 0.14; NNTB 13) and the application of i.v. antibiotics (RR 0.35; NNTB 18). The duration of $\mathrm{FN}$ or severe neutropenic events could not be assessed because of the limited number of studies reporting this outcome or the poor quality of reporting. CSFs frequently caused specific short-term adverse effects like bone pain (RR 5.88; NNTH 3) and injection-site reactions (RR 3.59; NNTH 3) and did not significantly reduce the risk of severe neutropenia, infections and infection-related mortality. The administration of CSFs did not confer better maintenance of chemotherapy regimens at scheduled times and doses.

\section{Overall completeness and applicability of evidence}

This review summarized the evidence regarding primary prophylaxis of neutropenia-related complications with CSFs in a variety of settings. The included trials comprised different breast cancer samples (i.e. metastatic disease, adjuvant treatment situations, inflammatory cancers), investigated six different types of CSFs and took place in different countries with different health care systems, thus increasing the generalizability of these results. However, the overall completeness of the review findings is limited and the applicability of evidence restricted owing to the following aspects.

First, more than $40 \%$ of the patients included in our analyses came from one study with a moderate risk of bias and the overall number of included studies was small.

Second, most outcomes were investigated insufficiently. For example, fewer than half of the studies applied standard definitions of FN and only one study differentiated the etiology of infections or febrile episodes according to the definitions of the International Immunocompromised Host Society (ICHS). Furthermore, most studies measured body temperature orally in order to detect FN. There is not only clear evidence that the accuracy and reliability of the measurement of body temperature depends on the site and method of measurement but also that oral mucositis can lead to inaccurate estimates when fever is measured orally. Ciuraru et al (Ciuraru 2008) found evidence that chemotherapy-associated mucositis in breast cancer patients increased the oral but not systemic body temperature. They concluded that "mucositis may provide an 'inflammation bias' that could lead to the overuse of antibiotics and growth factors in $20 \%$ to $40 \%$ of patients with cancer" (Ciuraru 2008). In addition, although there was evidence that the exact timing of blood counts during chemotherapy might optimize G-CSF prophylaxis (Ammann 2002), only three trials reported daily measurement schedules of body temperature and ANCs. Hence, evidence of treatment effects on these outcomes or on depending outcomes (e.g. hospitalization) needs to be interpreted carefully including the non-significant effects on the prevention of severe neutropenia. Moreover, most trials were underpowered to detect effects of CSF treatments on outcomes, which rarely occur during treatment with chemotherapies with low to moderate risk of FN such as infection-related and early mortality. Third, five of the eight studies reported no deaths and in the remaining three studies, a very small number of events occurred. Nineteen of 23 events were reported in one study and were attributed to disease progression by the authors (Vogel 2005). The reduction of all-cause mortality therefore might be attributed to different risk factors rather than to treatment effects of CSFs.

Fourth, the trials' study populations differed considerably regarding baseline risks of FN and infections. Sensitivity analyses were considered to examine the differential effects of CSFs on different risk populations; however, the analyses were not feasible in the present review, owing to the small number of trials per disease stage or treatment situation. No studies were identified in which the effectiveness of CSFs in breast cancer patients with different risks were compared. Thus, conclusions cannot be drawn regarding differential treatment effects depending on different risks.

Fifth, current guidelines on the use of CSFs during cancer chemotherapy recommend prophylactic CSFs in chemotherapy regimens with a risk of FN of more than $20 \%$. However, only two out of six studies that reported on this outcome had an incidence of FN of more than $20 \%$ in the control group (Chevallier 1995; Del Giglio 2008). All other studies had risks in the control groups between $10 \%$ and 20\% (Jones 1996; Romieu 2007; Vogel 2005) or even below 10\% (Papaldo 2003). Therefore, the results of our analyses were based on trials in which CSFs were given to patients of whom many, according to current guidelines, did not qualify for prophylactic administration of CSFs.

Sixth, the application schedules of filgrastim examined in the included trials varied considerably. Del Giglio 2008 scheduled filgrastim treatment 24 hours after chemotherapy, Muhonen 1996 on day four and Papaldo 2003 on day eight. The timing of filgrastim administration post-chemotherapy has profound effects on hematologic recovery. There is evidence that the effectiveness of filgrastim depends on its dose schedule (Crawford 1997) and that beginning on day four to six yielded better hematologic recoveries compared with administration of filgrastim on day eight.

Primary prophylactic colony-stimulating factors for the prevention of chemotherapy-induced febrile neutropenia in breast cancer 
The results of Papaldo 2003 furthermore suggested that not only the beginning of CSF treatment but also a less intense schedule with only two applications of filgrastim (day eight and 12 after chemotherapy) could be as effective as the usually applied constant dosing schedules. Hendler 2011 found possible benefit even for shorter treatment schedules with filgrastim in patients with breast cancer. Therefore, included trials with delayed and longer schedules might have led to an underestimation of the treatment effect. Seventh, several of the chemotherapy regimens in the included studies were either uncommon drug combinations or rarely used in the given schedule for the respective treatment situations (Chevallier 1995; Del Giglio 2008; Hansen 1995; Muhonen 1996; Papaldo 2003).

Finally, current guidelines no longer recommend supportive treatment with GM-CSFs (e.g. Aapro 2011; Crawford 2010), although there is evidence that sargramostim could be a cost-effective alternative to filgrastim or pegfilgrastim in the prevention of FN and related complications (Heaney 2009).

\section{Quality of the evidence}

The eight included RCTs differed with regards to their risk of bias and quality of reporting. Only two trials were judged as having only minor deficiencies in methodological quality. The results of all other studies were deemed to be influenced by a certain degree of selection, performance or detection bias owing to unconcealed treatment allocation, lack of blinding of patients and care providers, or unblinded outcome assessments. In addition, the supportive treatments applied for the outcomes of interest (infections, etc.) were not adequately reported and might have individual variations, which would mask or bias the results.

Three trials declared possible conflicts of interest and five trials acknowledged assistance from the pharmaceutical industry and supply of study medication. In the largest trial, six out of the eight trial authors were affiliated with the manufacturer of the interventional drug. It has been shown that studies sponsored by pharmaceutical companies were more likely to have outcomes favoring the sponsor than were studies with other sponsors (Higgins 2011).

Despite our comprehensive search strategy, there might be unpublished trials with non-significant results. We were not able to obtain published protocols for most included trials in this review and thus were not able to judge the risk of selective reporting for these studies reliably.

\section{Potential biases in the review process}

This review considered the currently available information on this topic. A comprehensive search of the literature was carried out without any language restrictions and included Chinese databases. It is of note that searches of the gray literature identified a large Italian study that was planned as a four-arm study with two arms investigating a research question related to CSF efficacy and was probably eligible for inclusion in our review. However, those two arms had not been carried out, according to the trial author, and the other two arms had been published in 2005 (Venturini 2005). It is also of note that one large ongoing study awaits assessment (Amgen 2015) and may be included in an update of this review. We contacted all relevant pharmaceutical companies but did not receive any RCT data from them. There is the potential for publication bias, which might be an issue in this review given the virtual non-existence of negative fi ndings that have been published, as demonstrated in the funnel plot of the primary outcome FN.

When pooled analyses were performed for some outcomes, high levels of heterogeneity were found. Heterogeneity appeared to result from differences in outcome definitions and the type of CSF used. We carried out a subgroup analysis for the primary outcome, FN, according to the cycle of chemotherapy in which the FN was recorded (first cycle, all cycles) and the type of CSF (G-CSF, GMCSF), which suggested a higher preventive effectiveness of CSFs during the first cycle and an advantage for G-CSF. Nevertheless, these analyses included only six trials. Furthermore, we could not perform any further subgroup analyses owing to the lack of data. A meta-analysis of secondary outcomes, such as the duration of neutropenia and hospitalization, could not be carried out since these variables were not given as mean numbers or the trial authors did not report standard deviations.

The findings of all outcomes should be regarded as uncertain because only results from up to six studies were available for the analyses and the results on early mortality and infection-related mortality were mainly based on the Vogel 2005 study, which was judged to have a moderate risk of bias and contributed more than $40 \%$ of all patients to the meta-analyses.

\section{Agreements and disagreements with other studies or reviews}

There are no published systematic reviews on the effectiveness of CSFs on FN and its complications in patients with breast cancer receiving chemotherapy. Two reviews in the area prior to this review included two of our eight included trials in aggregated analyses with other solid tumors (Kuderer 2007; Sung 2007). Kuderer 2007 was an update of Lyman 2002 with more included studies and was republished in 2011 (Kuderer 2011).

Our findings were that the administration of CSFs helped to prevent events of FN and reduced the need for hospital care, which was in line with the findings from both reviews (Kuderer 2007; Sung 2007). Kuderer 2007 furthermore found a reduction for allcause mortality during chemotherapy and infection-related mortality across a broad range of different cancers, chemotherapy regimens and baseline risks. We also detected a reduction of early mortality; however, 19 of the 23 fatal events had occurred in only one study and five out of eight studies in this analysis did not report deaths during the study period. In accordance with the find- 
ings of Sung 2007 in their subgroup of solid tumors (in which also lymphoma were included), we could not find a reduction in infections or infection-related mortality.

In their analyses of trials with patients with solid tumors, Kuderer 2007 found a higher relative dose intensity of chemotherapy in groups with CSFs. We also found a slightly higher rate of patients in the CSF groups who had received the planned chemotherapy cycles at scheduled times and doses.

\section{AUTHORS, CONCLUSIONS}

\section{Implications for practice}

In patients with breast cancer receiving chemotherapy, CSFs have shown evidence of benefi $t$ in the prevention of FN. There is evidence, though less reliable, of a decrease of all-cause mortality during chemotherapy and a reduced need for hospital care. No reliable evidence was found for a reduction of infection-related mortality, a higher dose intensity of chemotherapy with CSFs or diminished rates of severe neutropenia and infections. The majority of adverse events reported from CSF use were bone pain and injection-site reactions but no conclusions could be drawn regarding late-term side effects. Most studies included in this review used chemotherapy regimens with FN risks below the threshold of $20 \%$ for which the administration of CSF is recommended by current best practice guidelines. No meaningful conclusions could be drawn concerning differential effects between the applied CSF in these clinical settings owing to the small number of trials.

\section{Implications for research}

The evidence of benefit found in this review notwithstanding, most of the studies included were of uncertain methodological quality and some of them old and carried out before best practice guidelines were implemented. However, observational data suggest that, based on current guidelines, CSFs are underutilized for chemotherapy regimens with high risk of FN and overutilized for those with low risk (Ramsey 2010). In addition, there are doubts that the current management of $\mathrm{FN}$ in patients with breast cancer is cost-effective, even if it follows current best practice guidelines (Trueman 2009). Furthermore, there is evidence that not only CSFs but also antibiotics are successful in reducing infectious complications in cancer patients receiving chemotherapy (Gafter-Gvili 2009; Herbst 2009).

Thus, arguments could be made for clinical trials comparing the efficiency of different supportive treatment strategies in preventing $\mathrm{FN}$ and its associated morbidity and mortality after chemotherapy with low and moderate FN risk for breast cancer. Future studies should adhere to adequate concealment of randomization and blinding of the interventions and assessment of outcomes (or both), should report data on all-cause mortality, and provide concise definitions as well as properly timed measurements of the outcomes under study.

\section{ACK NOW LEDGEMENTS}

The authors thank Xun Li and He Yu for their help in conducting the search in Chinese databases and extraction and translation of data of possibly relevant publications. Many thanks are also extended to Michael Baum and Martin Wilhelm for their helpful comments on the manuscript and to the Dr. Ernst and Anita Bauer Foundation for funding a training workshop within the framework of the doctoral thesis of PR.

\section{R E F E R E N C E S}

\section{References to studies included in this review}

Chevallier 1995 \{published data only\}

* Chevallier B, Chollet P, Merrouche Y, Roche H, Fumoleau

P, Kerbrat P, et al.Lenograstim prevents morbidity from intensive induction chemotherapy in the treatment of inflammatory breast cancer. Journal of Clinical Oncology 1995;13(7):1564-71. [MEDLINE: 96]

Mapelli V, Graf vond der Schulenburg JM, Laaser U, Allhoff PG, Rossi F. Economic evaluation of lenograstim (glycosylated rHuG-CSF) in the treatment of inflammatory breast cancer for Germany and Italy. Pharmacoeconomics 1994;6 Suppl 2:27-35. [MEDLINE: 99]

Veyret C, Levy C, Chollet P, Merrouche Y, Roche H, Kerbrat $\mathrm{P}$, et al.Inflammatory breast cancer outcome with epirubicinbased induction and maintenance chemotherapy: ten-year results from the French Adjuvant Study Group GETIS 02 Trial. Cancer 2006;107(11):2535-44. [MEDLINE: 1]

Del Giglio 2008 \{published data only\}

* del Giglio A, Eniu A, Ganea-Motan D, Topuzov E, Lubenau H. XM02 is superior to placebo and equivalent to Neupogen in reducing the duration of severe neutropenia and the incidence of febrile neutropenia in cycle 1 in breast cancer patients receiving docetaxel/doxorubicin chemotherapy. BMC Cancer 2008;8:332.

Hansen 1995 \{published data only\}

* Hansen F, Stenbygaard L, Skovsgaard T. Effect of granulocyte-macrophage colony-stimulating factor (GM$\mathrm{CSF}$ ) on hematologic toxicity induced by high-dose chemotherapy in patients with metastatic breast cancer. Acta Oncologica 1995;34(7):919-24. [MEDLINE: 225] 
Jones 1996 \{published data only\}

* Jones SE, Schottstaedt MW, Duncan LA, Kirby RL, Good RH, Mennel RG, et al.Randomized double-blind prospective trial to evaluate the effects of sargramostim versus placebo in a moderate-dose fluorouracil, doxorubicin, and cyclophosphamide adjuvant chemotherapy program for stage II and III breast cancer. Journal of Clinical Oncology 1996;14(11):2976-83. [MEDLINE: 210]

Muhonen 1996 \{published data only\}

* Muhonen T, Jantunen I, Pertovaara H, Voutilainen L, Maiche A, Blomqvist C, et al.Prophylactic filgrastim (G-CSF) during mitomycin-C, mitoxantrone, and methotrexate (MMM) treatment for metastatic breast cancer. A randomized study. American Journal of Clinical Oncology 1996;19(3):232-4. [MEDLINE: 91]

Papaldo 2003 \{published data only\}

Di CS, Ferretti G, Papaldo P, Carlini P, Fabi A, Ruggeri $\mathrm{EM}$, et al.Does the concurrent use of anthracycline and granulocyte colony-stimulating factor influence the risk of secondary leukaemia in breast cancer women?. Annals of Oncology 2005;16(7):1209-10. [MEDLINE: 15] Papaldo P, Di CS, Ferretti G, Vici P, Marolla P, Carlini P, et al.Effect of filgrastim on serum lactate dehydrogenase and alkaline phosphatase values in early breast cancer patients. Cancer Investigation 2004;22(4):650-3. [MEDLINE: 19] Papaldo P, Ferretti G, Di CS, Giannarelli D, Marolla P, Lopez $\mathrm{M}$, et al.Does granulocyte colony-stimulating factor worsen anemia in early breast cancer patients treated with epirubicin and cyclophosphamide?. Journal of Clinical Oncology 2006;24(19):3048-55. [MEDLINE: 3]

* Papaldo P, Lopez M, Cortesi E, Cammilluzzi E, Antimi M, Terzoli E, et al.Addition of either lonidamine or granulocyte colony-stimulating factor does not improve survival in early breast cancer patients treated with high-dose epirubicin and cyclophosphamide. Journal of Clinical Oncology 2003;21 (18):3462-8. [MEDLINE: 29]

Papaldo P, Lopez M, Marolla P, Cortesi E, Antimi M, Terzoli $\mathrm{E}$, et al.Impact of five prophylactic filgrastim schedules on hematologic toxicity in early breast cancer patients treated with epirubicin and cyclophosphamide. Journal of Clinical Oncology 2005;23(28):6908-18. [MEDLINE: 11]

Romieu 2007 \{published data only\}

Brugger W, Bacon P, Lawrinson S, Romieu G. Neutrophil recovery in elderly breast cancer patients receiving adjuvant anthracycline-containing chemotherapy with pegfilgrastim support. Critical Reviews in Oncology/Hematology 2009;72: 265-9.

* Romieu G, Clemens M, Mahlberg R, Fargeot P, Constenla M, Schutte M, et al.Pegfilgrastim supports delivery of FEC100 chemotherapy in elderly patients with high risk breast cancer: a randomized phase 2 trial. Critical Reviews in Oncology/Hematology 2007;64:64-72.

Vogel 2005 \{published data only\}

Sharma DC. Pegfilgrastim lowers side-effects of chemotherapy. Lancet Oncology 2004;5(8):461. [MEDLINE: 253]

* Vogel CL, Wojtukiewicz MZ, Carroll RR, Tjulandin SA,
Barajas-Figueroa LJ, Wiens BL, et al.First and subsequent cycle use of pegfilgrastim prevents febrile neutropenia in patients with breast cancer: a multicenter, double-blind, placebo-controlled phase III study. Journal of Clinical Oncology 2005;23(6):1178-84. [MEDLINE: 18]

\section{References to studies excluded from this review}

\section{Ardizzoni 1994 \{published data only\}}

Ardizzoni A, Venturini M, Sertoli MR, Giannessi PG, Brema F, Danova M, et al.Granulocyte-macrophage colonystimulating factor (GM-CSF) allows acceleration and dose intensity increase of CEF chemotherapy: a randomised study in patients with advanced breast cancer. British Journal of Cancer 1994;69(2):385-91.

\section{Athanassiou 1996 \{published data only\}}

Athanassiou A. Dose intensification by using human recombinant granulocyte- macrophage colony stimulating factor in advanced breast cancer patients. European Journal of Gynaecological Oncology 1996;17:411-3.

Bono 2009 \{published data only\}

Bono P, Kellokumpu-Lehtinen PL, Alanko T, Kokko R, Asola R, Turpeenniemi-Hujanen T, et al.Docetaxel 100 versus $80 \mathrm{mg} / \mathrm{m} 2$ as adjuvant treatments of early breast cancer: an exploratory analysis of a randomised trial. Annals of Oncology 2009;20(3):595-6.

Ellis 2011 \{published data only\} Ellis GK, Barlow WE, Gralow JR, Hortobagyi GN, Russell CA, Royce ME, et al.Phase III comparison of standard doxorubicin and cyclophosphamide versus weekly doxorubicin and daily oral cyclophosphamide plus granulocyte colony-stimulating factor as neoadjuvant therapy for inflammatory and locally advanced breast cancer: SWOG 0012. Journal of Clinical Oncology 2011;29 (8):1014-21.

\section{Gascon 2010 \{published data only\}} Gascon P, Fuhr U, Sorgel F, Kinzig-Schippers M, Makhson A, Balser S, et al.Development of a new G-CSF product based on biosimilarity assessment. Annals of Oncology 2010; 21(7):1419-29.

\section{Gebbia 1994 \{published data only\}} Gebbia V, Valenza R, Testa A, Cannata G, Borsellino N, Gebbia N. A prospective randomized trial of thymopentin versus granulocyte-colony stimulating factor with or without thymopentin in the prevention of febrile episodes in cancer patients undergoing highly cytotoxic chemotherapy. Anticancer Research 1994;14(2B):731-4.

\section{Green 2003 \{published data only\}}

Green MD, Koelbl H, Baselga J, Galid A, Guillem V, Gascon P, et al.A randomized double-blind multicenter phase III study of fixed-dose single-administration pegfilgrastim versus daily filgrastim in patients receiving myelosuppressive chemotherapy. Annals of Oncology 2003;14(1):29-35.

Hatam 2011 \{published data only\} Hatam N, Ahmadloo N, Ahmad Kia Daliri A, Bastani P, Askarian M. Quality of life and toxicity in breast cancer 
patients using adjuvant TAC (docetaxel, doxorubicin, cyclophosphamide), in comparison with FAC (doxorubicin, cyclophosphamide, 5-fluorouracil). Archives of Gynecology and Obstetrics 2011;284(1):215-20.

Holmes 2002 \{published data only\}

Holmes FA, Jones SE, O'Shaughnessy J, Vukelja S, George $\mathrm{T}$, Savin M, et al.Comparable efficacy and safety profiles of once-per-cycle pegfilgrastim and daily injection filgrastim in chemotherapy-induced neutropenia: a multicenter dosefinding study in women with breast cancer. Annals of Oncology 2002;13(6):903-9.

Holmes 2002b \{published data only\}

Holmes FA, O'Shaughnessy JA, Vukelja S, Jones SE, Shogan $\mathrm{J}$, Savin M, et al.Blinded, randomized, multicenter study to evaluate single administration pegfilgrastim once per cycle versus daily filgrastim as an adjunct to chemotherapy in patients with high-risk stage II or stage III/IV breast cancer. Journal of Clinical Oncology 2002;20(3):727-31.

Iiristo 2011 \{published data only\}

Iiristo M, Wiklund T, Wilking N, Bergh J, Brandberg Y. Tailored chemotherapy doses based on toxicity in breast cancer result in similar quality of life values, irrespective of given dose levels. Acta Oncologica 2011;50(3):338-43.

Ikonomidis 2008 \{published data only\}

Ikonomidis I, Papadimitriou C, Vamvakou G, Katsichti P, Venetsanou K, Stamatelopoulos K, et al.Treatment with granulocyte colony stimulating factor is associated with improvement in endothelial function. Growth Factors 2008; 26(3):117-24.

Joensuu 2010 \{published data only\} Joensuu H, Sailas L, Alanko T, Sunela K, Huuhtanen R, Utriainen $\mathrm{M}$, et al.Docetaxel versus docetaxel alternating with gemcitabine as treatments of advanced breast cancer: final analysis of a randomised trial. Annals of Oncology 2010;21(5):968-73.

Khrichkova 2008 \{published data only\} Khrichkova TY, Goldberg VE, Zhdanov VV, Matyash MG, Vysotckaya VV, Simolina EI, et al.Mechanisms of stimulation of granulocytopoiesis with neupogen in patients with breast cancer during chemotherapy. Bulletin of Experimental Biology and Medicine 2008;145(4):467-71.

Martin 2006 \{published data only\}

Martin M, Lluch A, Segui MA, Ruiz A, Ramos M, Adrover $\mathrm{E}$, et al.Toxicity and health-related quality of life in breast cancer patients receiving adjuvant docetaxel, doxorubicin, cyclophosphamide (TAC) or 5-fluorouracil, doxorubicin and cyclophosphamide (FAC): impact of adding primary prophylactic granulocyte-colony stimulating factor to the TAC regimen. Annals of Oncology 2006;17(8):1205-12.

Schröder 1999 \{published data only\} Schröder CP, de-Vries EG, Mulder NH, Willemse PH, Sleijfer DT, Hospers GA, et al.Prevention of febrile leucopenia after chemotherapy in high-risk breast cancer patients: no significant difference between granulocytecolony stimulating growth factor or ciprofloxacin plus amphotericin B. Journal of Antimicrobial Chemotherapy 1999;43:741-3.

Steger 1992 \{published data only\}

Steger GG, Locker G, Rainer H, Mader RM, Sieder $\mathrm{AE}, \mathrm{Gnant} \mathrm{MF}$, et al.Cutaneous reactions to GM-CSF in inflammatory breast cancer. New England Journal of Medicine 1992;327(4):286. [MEDLINE: 233]

\section{Stöger 1998 \{published data only\}}

Stöger H, Samonigg H, Krainer M, Ploszczynski M, Nirnberger G, Maca S, et al.Dose intensification of epidoxorubicin and cyclophosphamide in metastatic breast cancer: a randomised study with two schedules of granulocyte-macrophage colony stimulating factor. European Journal of Cancer 1998;34(4):482-8. [MEDLINE: 196]

\section{Tomova 2009 \{published data only\}}

Tomova A, Bartsch R, Brodowicz T, Tzekova V, Timcheva C, Wiltschke $\mathrm{C}$, et al.Concomitant docetaxel plus gemcitabine versus sequential docetaxel followed by gemcitabine in anthracycline-pretreated metastatic or locally recurrent inoperable breast cancer patients: a prospective multicentre trial of the Central European Cooperative O. Breast Cancer Research and Treatment 2009;119(1):169-76.

Venturini 2005 \{published data only\} Venturini M, Del Mastro L, Aitini E, Baldini E, Caroti $\mathrm{C}$, Contu A, et al.Dose-dense adjuvant chemotherapy in early breast cancer patients: results from a randomized trial. Journal of the National Cancer Institute 2005;97(23): 1724-33.

von Minckwitz 2008a \{published data only\} von Minckwitz G, Kummel S, du Bois A, Eiermann W, Eidtmann H, Gerber B, et al.Pegfilgrastim +/- ciprofloxacin for primary prophylaxis with TAC (docetaxel/doxorubicin/ cyclophosphamide) chemotherapy for breast cancer. Results from the GEPARTRIO study. Annals of Oncology 2008;19 (2):292-8.

von Minckwitz 2010 \{published data only\} von Minckwitz G, Rezai M, Loibl S, Fasching PA, Huober $\mathrm{J}$, Tesche H, et al.Capecitabine in addition to anthracyclineand taxane-based neoadjuvant treatment in patients with primary breast cancer: Phase III GeparQuattro study. Journal of Clinical Oncology 2010;28(12):2015-23.

von Minckwitz 2011 \{published data only\} von Minckwitz G, Eidtmann H, Loibl S, Blohmer JU, Costa SD, Fasching PA, et al.Integrating bevacizumab, everolimus, and lapatinib into current neoadjuvant chemotherapy regimen for primary breast cancer. Safety results of the GeparQuinto trial. Annals of Oncology 2011;22(2):301-6.

Waller 2010 \{published data only\}

Waller CF, Semiglazov VF, Tjulandin S, Bentsion D, Chan $S$, Challand R. A phase III randomized equivalence study of biosimilar filgrastim versus Amgen filgrastim in patients receiving myelosuppressive chemotherapy for breast cancer. Onkologie 2010;33(19):504-11. 
Wang 2004 \{published data only\}

Wang TJ, Liu LL, Cheng GH, Liu XL, Qu YQ, Wu ZF, et al.A brief report on effect of rhG-CSF in treating leukopenia after radio- and chemotherapy of patients with breast cancer [Chong zu ren G-CSF dui fang hua liao yin qi ru xian ai huan zhe bai xi bao jian shao zheng de liao xiao guan cha]. Journal of Experimental Hematology [Zhong Guo Shi Yan Xue Ye Xue Za Zhi] 2004;12(3):381-2.

Weaver 2001 \{published data only\}

Weaver CH, Schulman KA, Buckner CD. Mobilization of peripheral blood stem cells following myelosuppressive chemotherapy: a randomized comparison of filgrastim, sargramostim, or sequential sargramostim and filgrastim. Bone Marrow Transplantation 2001;27(2):23-9.

Yau 1996 \{published data only\}

Yau JC, Neidhart JA, Triozzi P, Verma S, Neumunaitis J, Verma $S$, et al.Randomized placebo-controlled trial of granulocyte-macrophage colony-stimulating-factor support for dose-intensive cyclophosphamide, etoposide, and cisplatin. American Journal of Hematology 1996;51(4): 289-95.

Zhang 1999 \{published data only\} Zhang W, Jiang Q, Zheng Y, Yang C. Clinical effects of low-dose rhG-CSF on prevention and treatment of chemotherapy induced leukopenia in breast cancer. The Practical Journal of Cancer 1999;14(2):152-5.

Zhou 2006 \{published data only\}

Zhou Q, Wang K, Li X, Huang L, Liao N, Zheng D, et al.Study on the strategies of domestic rhG-CSF in preventing neutropenia caused by breast cancer chemotherapy. Chinese Journal of Cancer Prevention and Treatment [Zhong Hua Zhong Liu Fang Zhi Za Zhi] 2006;13(16):1250-2.

\section{References to ongoing studies}

\section{Amgen 2015 \{unpublished data only\}}

A Prospective Observational Study of Neutropenia and Anemia Management in Subjects With Solid Tumors Receiving Myelotoxic Chemotherapy. Ongoing study December 2007.

\section{Additional references}

\section{Aapro 2011}

Aapro MS, Bohlius J, Cameron DA, Dal Lago L, Donnelly JP, Kearney N, et al.2010 update of EORTC guidelines for the use of granulocyte-colony stimulating factor to reduce the incidence of chemotherapy-induced febrile neutropenia in adult patients with lymphoproliferative disorders and solid tumours. European Journal of Cancer 2011;47(1): 8-32.

Ammann 2002

Ammann RA, Leibundgut K, Hirt A, Ridolfi Luthy A. Individual timing of blood counts in G-CSF prophylaxis after myelosuppressive chemotherapy reduces G-CSF injections, blood counts, and costs: a prospective randomized study in children and adolescents. Support Care Cancer 2002;10(8):613-8.

Bodey 1966

Bodey GP, Buckley M, Sathe YS, Freireich EJ. Quantitative relationships between circulating leukocytes and infection in patients with acute leukemia. Annals of Internal Medicine 1966;64:328-40.

\section{Bradley 1966}

Bradley TR, Metcalf $\mathrm{D}$. The growth of mouse bone marrow cells in vitro. Australian Journal of Experimental Biology and Medical Science 1966;44(3):287-99.

\section{Brugger 2009}

Brugger W, Bacon P, Lawrinson S, Romieu G. Neutrophil recovery in elderly breast cancer patients receiving adjuvant anthracycline-containing chemotherapy with pegfilgrastim support. Critical Reviews Oncology/Hematology 2009;72(3): 265-9.

\section{Carulli 1997}

Carulli G. Effects of recombinant human granulocyte colony-stimulating factor administration on neutrophil phenotype and functions. Haematologica 1997;82(5): 606-16.

\section{Ciuraru 2008}

Ciuraru NB, Braunstein R, Sulkes A, Stemmer SM. The influence of mucositis on oral thermometry: when fever may not reflect infection. Clinical Infectious Diseases 2008; 46(12):1859-63.

\section{Crawford 1997}

Crawford J, Kreisman H, Garewal H, Jones SE, Shoemaker D, Pupa MR, et al.The impact of filgrastim schedule variation on hematopoietic recovery post-chemotherapy. Annals of Oncology 1997;8(11):1117-24.

\section{Crawford 2004}

Crawford J, Dale DC, Lyman GH. Chemotherapy-induced neutropenia: risks, consequences, and new directions for its management. Cancer 2004;100(2):228-37.

Crawford 2007

Crawford J, Althaus B, Armitage J, Balducci L, Bennett C, Blayney DW, et al.NCCN clinical practice guidelines in oncology. Myeloid growth factors. Journal of the National Comprehensive Cancer Network 2007;5:188-202.

\section{Crawford 2010}

Crawford J, Caserta C, Roila F. Hematopoietic growth factors: ESMO clinical practice guidelines for the applications. Annals of Oncology 2010;21(Suppl 5): v248-51.

\section{Di Cosimo 2005}

Di Cosimo S, Ferretti G, Papaldo P, Carlini P, Fabi A, Ruggeri EM, et al.Does the concurrent use of anthracycline and granulocyte colony-stimulating factor influence the risk of secondary leukaemia in breast cancer women?. Annals of Oncology 2005;16(7):1209-10. [MEDLINE: 15] 
Fazzi 2007

Fazzi R, Orciuolo E, Trombi L, Mattii L, Battola B, Riccioni $\mathrm{R}$, et al.PEG-filgrastim activity on granulocyte functions. Leukemia Research 2007;31(10):1453-5.

\section{Gafter-Gvili 2009}

Gafter-Gvili A, Fraser A, Paul M, van de Wetering M, Kremer L, Leibovici L. Antibiotic prophylaxis for bacterial infections in afebrile neutropenic patients following chemotherapy. Cochrane Database of Systematic Reviews 2009, Issue 4. [DOI: 10.1002/ 14651858.CD004386.pub2]

\section{Heaney 2009}

Heaney ML, Toy EL, Vekeman F, Laliberte F, Dority BL, Perlman D, et al.Comparison of hospitalization risk and associated costs among patients receiving sargramostim, filgrastim, and pegfilgrastim for chemotherapy-induced neutropenia. Cancer 2009;115(20):4839-48.

\section{Hendler 2011}

Hendler D, Rizel S, Yerushalmi R, Neiman V, Bonilla $\mathrm{L}$, Braunstein R, et al.Different schedules of granulocyte growth factor support for patients with breast cancer receiving adjuvant dose-dense chemotherapy: a prospective nonrandomized study. American Journal of Clinical Oncology 2011;34(6):619-24.

\section{Herbst 2009}

Herbst C, Naumann F, Kruse EB, Monsef I, Bohlius J, Schulz H, et al.Prophylactic antibiotics or G-CSF for the prevention of infections and improvement of survival in cancer patients undergoing chemotherapy. Cochrane Database of Systematic Reviews 2009, Issue 1. [DOI: 10.1002/14651858.CD007107.pub2]

\section{Higgins 2011}

Higgins JPT, Green S (editors). Cochrane Handbook for Systematic Reviews of Interventions Version 5.0.1 [updated March 2011]. The Cochrane Collaboration. 2011. Available from www.cochrane-handbook.org.

Jelkmann 2010 Jelkmann W. Biosimilar epoetins and other "follow-on" biologics: update on the European experiences. American Journal of Hematology 2010;85(10):771-80.

Kuderer 2006

Kuderer NM, Dale DC, Crawford J, Cosler LE, Lyman GH. Mortality, morbidity, and cost associated with febrile neutropenia in adult cancer patients. Cancer 2006;106(10): 2258-66.

Kuderer 2007

Kuderer NM, Dale DC, Crawford J, Lyman GH. Impact of primary prophylaxis with granulocyte colony-stimulating factor on febrile neutropenia and mortality in adult cancer patients receiving chemotherapy: a systematic review. Journal of Clinical Oncology 2007;25:3158-67.

Kuderer 2011

Kuderer NM. Meta-analysis of randomized controlled trials of granulocyte colony-stimulating factor prophylaxis in adult cancer patients receiving chemotherapy. Cancer

Treatment and Research 2011;157:127-43.

\section{Lyman 2002}

Lyman GH, Kuderer NM, Djulbegovic B. Prophylactic granulocyte colony-stimulating factor in patients receiving dose-intensive cancer chemotherapy: a meta-analysis. American Journal of Medicine 2002;112:406-11.

\section{Lyman 2010}

Lyman GH, Kuderer NM. Hematopoietic growth factors. In: Chabner BA, Longo DL editor(s). Cancer Chemotherapy and Biotherapy - Principles and Practice. 5th Edition. Philadelphia: Lippincott Williams \& Wilkins, 2010: 708-21.

\section{Mapelli 1994}

Mapelli V, Graf vond der Schulenburg JM, Laaser U, Allhoff PG, Rossi F. Economic evaluation of lenograstim (glycosylated rHuG-CSF) in the treatment of inflammatory breast cancer for Germany and Italy. Pharmacoeconomics 1994;6(Suppl 2):27-35. [MEDLINE: 99]

Papaldo 2004

Papaldo P, Di CS, Ferretti G, Vici P, Marolla P, Carlini P, et al.Effect of filgrastim on serum lactate dehydrogenase and alkaline phosphatase values in early breast cancer patients. Cancer Investigation 2004;22(4):650-3. [MEDLINE: 19]

Papaldo 2005

Papaldo P, Lopez M, Marolla P, Cortesi E, Antimi M, Terzoli E, et al.Impact of five prophylactic filgrastim schedules on hematologic toxicity in early breast cancer patients treated with epirubicin and cyclophosphamide. Journal of Clinical Oncology 2005;23(28):6908-18. [MEDLINE: 11]

Papaldo 2006

Papaldo P, Ferretti G, Di CS, Giannarelli D, Marolla P, Lopez $\mathrm{M}$, et al.Does granulocyte colony-stimulating factor worsen anemia in early breast cancer patients treated with epirubicin and cyclophosphamide?. Journal of Clinical Oncology 2006;24(19):3048-55. [MEDLINE: 3]

\section{Petros 2003}

Petros WP. Introduction: pegfilgrastim, a new era in the management of chemotherapy-induced neutropenia. Pharmacotherapy 2003;23(8 Pt 2):1S-2S.

Pike 1970

Pike BL, Robinson WA. Human bone marrow colony growth in agar-gel. Journal of Cellular Physiology 1970;76 (1):77-84.

Ramsey 2010

Ramsey SD, McCune JS, Blough DK, McDermott CL, Clarke L, Malin JL, et al.Colony-stimulating factor prescribing patterns in patients receiving chemotherapy for cancer. American Journal of Managed Care 2010;16(9): 678-86.

Samson 1984 Samson MK, Rivkin SE, Jones SE, Costanzi JJ, LoBuglio AF, Stephens RL, et al.Dose-response and dose-survival advantage for high versus low-dose cisplatin combined with vinblastine and bleomycin in disseminated testicular cancer. 
A Southwest Oncology Group study. Cancer 1984;53(5): 1029-35.

Sharma 2004

Sharma DC. Pegfilgrastim lowers side-effects of chemotherapy. Lancet Oncology 2004;5(8):461. [MEDLINE: 253]

\section{Smith 2006}

Smith TJ, Khatcheressian J, Lyman GH, Ozer H, Armitage JO, Balducci L, et al.2006 Update of recommendations for the use of white blood cell growth factors: an evidencebased clinical practice guideline. Journal of Clinical Oncology 2006;24(19):3187-205.

Sung 2007

Sung L, Nathan PC, Alibhai SM, Tomlinson GA, Beyene J.
Meta-analysis: effect of prophylactic hematopoietic colonystimulating factors on mortality and outcomes of infection. Annals of Internal Medicine 2007;147(6):400-11.

Trueman 2009

Trueman P. Prophylactic G-CSF in patients with early-stage breast cancer: a health economic review. British Journal of Cancer 2009; 101 Supplementary 1:S15-7.

\section{Veyret 2006}

Veyret C, Levy C, Chollet P, Merrouche Y, Roche H, Kerbrat $\mathrm{P}$, et al.Inflammatory breast cancer outcome with epirubicinbased induction and maintenance chemotherapy: ten-year results from the French Adjuvant Study Group GETIS 02 Trial. Cancer 2006;107(11):2535-44. [MEDLINE: 1]

* Indicates the major publication for the study 


\section{CHARACTERISTICS OF STUDIES}

\section{Characteristics of included studies [ordered by study ID]}

\section{Chevallier 1995}

Methods

Design: 2-arm, double-blind, placebo-controlled, Phase III trial

Follow up: after the induction period, patients were evaluated every 4 months for the first 2 years, biannually for the next 3 years, and once per year thereafter

Ethical approval: yes

\begin{tabular}{ll} 
Participants & $\begin{array}{l}\text { No. of patients randomized: } 120 \\
\text { No. of patients evaluated: } 101 \text { (for tumor response) } \\
\text { Stage of cancer: invasive and inflammatory breast cancer (T4d) } \\
\text { Demographics: women, age range } 23 \text { to } 65 \text { years (mean age: } 48 \text { years) } \\
\text { Setting: multicenter study; France } \\
\text { Informed consent: yes (written) }\end{array}$ \\
\hline CSF intervention: G-CSF: lenograstim, $5 \mu \mathrm{gg} / \mathrm{kg} / \mathrm{d}$; $\mathrm{d} 6-15 \mathrm{sc} ;$ \\
$\begin{array}{l}\text { Control: identical placebo } \\
\text { Basic treatment: FEC-HD: } 5 \text {-fluorouracil } 750 \mathrm{mg} / \mathrm{m}^{2} \mathrm{~d} 1-4 \text {, epirubicin } 35 \mathrm{mg} / \mathrm{m}^{2} \mathrm{~d} 2- \\
\left.\text { 4, cyclophosphamide } 400 \mathrm{mg} / \mathrm{m}^{2} \mathrm{~d} 2-4\right) ; \text { every } 21 \mathrm{~d} \text {; } 4 \mathrm{cycles} ; \\
\text { Supportive treatment: antibiotics (i.v. or oral, or both) for treatment of FN (primary } \\
\text { or secondary prophylaxis was unclear); antibiotics were given in different schedules and } \\
\text { dosages according to } 3 \text { predefined categories of infections }\end{array}$ \\
\hline
\end{tabular}

Outcomes

Primary outcome measures: duration of neutropenia

Secondary outcome measures: incidence of FN; events of FN; ANC profiles; incidence of infections; hospitalization and antibiotic treatment; dose delays; OS and DFS; tumor response; toxicity

Notes

Risk of bias

\begin{tabular}{lll}
\hline Bias & Authors' judgement & Support for judgement \\
\hline $\begin{array}{l}\text { Random sequence generation/allocation } \\
\text { concealment (selection bias) }\end{array}$ & Low risk & $\begin{array}{l}\text { Quote: ”[...] patients were randomized } \\
{[\ldots] \text { “ }} \\
\text { Comment: sequence generation was n.r. } \\
\text { Allocation concealment was n.r. Patient } \\
\text { characteristics at baseline were similarly dis- } \\
\text { tributed. Sample size }>100 \text { patients }\end{array}$ \\
\hline
\end{tabular}

Blinding of participants and personnel Unclear risk (performance bias)

All outcomes
Quote: "[...] a double-blind administration of lenograstim versus vehicle was chosen." Comment: n.s. ${ }^{*}$ whether placebo was identically looking but owing to use of vehicle, adequate process of blinding was assumed; possible risk of unblinding owing to CSF- 
Chevallier 1995 (Continued)

specific adverse drug reactions

\begin{tabular}{|c|c|c|}
\hline $\begin{array}{l}\text { Blinding of outcome assessment (detection } \\
\text { bias) } \\
\text { All outcomes }\end{array}$ & Unclear risk & $\begin{array}{l}\text { Comment: blinding of outcome assess- } \\
\text { ment n.r. }\end{array}$ \\
\hline $\begin{array}{l}\text { Incomplete outcome data (attrition bias) } \\
\text { All outcomes }\end{array}$ & Unclear risk & $\begin{array}{l}\text { Quote: “[...] } 16 \text { withdrew from the study } \\
\text { (13 placebo and three lenograstim) for the } \\
\text { following reasons }[\ldots] \text { ". } \\
\text { Comment: attrition rate } 13 \% \text {; reasons for } \\
\text { withdrawal were n.r. separately for each } \\
\text { group; attrition rate was not equally dis- } \\
\text { tributed between groups }\end{array}$ \\
\hline Selective reporting (reporting bias) & Low risk & $\begin{array}{l}\text { Comment: no indication for selective re- } \\
\text { porting }\end{array}$ \\
\hline $\begin{array}{l}\text { Definitions and measurements of out- } \\
\text { comes }\end{array}$ & Low risk & $\begin{array}{l}\text { Comment: FN clearly defined; body tem- } \\
\text { perature was measured twice daily, blood } \\
\text { cell counts daily }\end{array}$ \\
\hline Supportive treatment & Unclear risk & $\begin{array}{l}\text { Comment: systemic antibiotic treatment in } \\
\text { case of FN; precisely described clinical pro- } \\
\text { cedural method; patients in CGs were as- } \\
\text { sumed to have received antibiotics more } \\
\text { frequent }\end{array}$ \\
\hline
\end{tabular}

Del Giglio 2008

Methods

Design: 3-arm, open-label Phase III trial

Follow-up: 10 months

Ethical approval: yes

\begin{tabular}{ll} 
Participants & $\begin{array}{l}\text { No. of patients randomized: } 348 \\
\text { No. of patients evaluated: } 348 \\
\text { Stage of cancer: high-risk breast cancer stage II-IV } \\
\text { Demographics: women, age range } 25 \text { to } 74 \text { years } \\
\text { Setting: multicenter study; Belarus, Slovenia, South Africa, Brazil, Chile, Russia, Hun- } \\
\text { gary, Lithuania, Romania, Poland } \\
\text { Informed consent: yes (written) }\end{array}$ \\
\hline CSF intervention: G-CSF: filgrastim $(X M 02$ or Neupogen), $5 \mu \mathrm{g} / \mathrm{kg} / \mathrm{d} ; \mathrm{d} 2 \mathrm{until}$ ANC \\
$\geq 10 \times 10^{9} / \mathrm{L}$ after nadir (minimum until d6, maximum until $\left.\mathrm{d} 15\right) \mathrm{sc}$ \\
Control: identical placebo \\
Basic treatment: doxorubicin $60 \mathrm{mg} / \mathrm{m}^{2}, \mathrm{DCT} 75 \mathrm{mg} / \mathrm{m}^{2} ; \mathrm{d} 1$ i.v.; every $21 \mathrm{~d} ;$ maximum \\
4 cycles \\
Supportive treatment: no information about administration of antibiotics
\end{tabular}

Primary prophylactic colony-stimulating factors for the prevention of chemotherapy-induced febrile neutropenia in breast cancer 


\section{Del Giglio 2008 (Continued)}

\begin{tabular}{ll} 
Outcomes & $\begin{array}{l}\text { Primary outcome measures: duration of neutropenia in cycle } 1 \\
\text { Secondary outcome measures: incidence of FN; ANC profile }\end{array}$ \\
\hline Notes & Drug approval study for a filgrastim biosimilar (XM02) \\
\hline
\end{tabular}

\section{Risk of bias}

\begin{tabular}{|c|c|c|}
\hline Bias & Authors' judgement & Support for judgement \\
\hline $\begin{array}{l}\text { Random sequence generation/allocation } \\
\text { concealment (selection bias) }\end{array}$ & Unclear risk & $\begin{array}{l}\text { Quote: "[...] patients were randomized in a } \\
\text { 2:2:1 ratio [...]" } \\
\text { Comment: sequence generation was n.r.; } \\
\text { allocation concealment was n.r. Slight dif- } \\
\text { ferences in the distribution of prior radia- } \\
\text { tion therapy between treatment arms: IG1 } \\
\text { (XM02): } 10.7 \% \text {, IG2(Neupogen): } 6.6 \% \text {; } \\
\text { CG: } 12.5 \% \text {. Sample size }>100 \text { patients }\end{array}$ \\
\hline $\begin{array}{l}\text { Blinding of participants and personnel } \\
\text { (performance bias) } \\
\text { All outcomes }\end{array}$ & Unclear risk & $\begin{array}{l}\text { Quote: "A true double-blind design was } \\
\text { not feasible because XM02 and Neupogen } \\
\text { were formulated in different volumes. [... } \\
\text { ]" } \\
\text { Comment: unblinded study personnel; } \\
\text { blinding of patients was unclear; no details } \\
\text { about the placebo were reported }\end{array}$ \\
\hline
\end{tabular}

Blinding of outcome assessment (detection Low risk bias)

All outcomes

Incomplete outcome data (attrition bias) Low risk All outcomes
Quote: “investigator was kept blinded and performed all assessments [...]"

Comment: probably done

Quote: "Nine patients (2.6\%) discontinued the study due to an $\mathrm{AE}$ [adverse event], i.e., $2(1.4 \%)$ patients in the XM02 group $[\ldots]$ ”

Comment: attrition rate 2.6\%; reasons for withdrawal were n.r. separately for each group

Antibiotic treatment was n.r.

Selective reporting (reporting bias)

Low risk

Definitions and measurements of out- Unclear risk comes

Supportive treatment

Unclear risk
2 different definitions of FN; it was not stated which was applied

Daily measurement of body temperature and blood cell counts

Quote: "Secondary endpoints included [... ] and of protocol defined FN (administration of systemic antibiotics) [...]" 
Del Giglio 2008 (Continued)

Comment: patients in CGs were assumed to have received antibiotics more frequently

Hansen 1995

\begin{tabular}{|c|c|}
\hline Methods & $\begin{array}{l}\text { Design: 2-arm, open-label, Phase III trial } \\
\text { Follow-up: unclear } \\
\text { Ethical approval: yes }\end{array}$ \\
\hline Participants & $\begin{array}{l}\text { No. of patients randomized: } 20 \\
\text { No. of patients evaluated: } 18 \text { (for tumor response) } \\
\text { Stage of cancer: metastatic breast cancer, stage IV } \\
\text { Demographics: women, age range } 37-61 \text { years (median age: CSF IG: } 56 \text { years; CG: } 50 \\
\text { years) } \\
\text { Setting: single-center study; Denmark } \\
\text { Informed consent: yes (n.s.) }\end{array}$ \\
\hline Interventions & $\begin{array}{l}\text { CSF intervention: GM-CSF: molgramostim, } 5 \mu \mathrm{g} / \mathrm{kg} / \mathrm{d} \text {; d2-11 sc } \\
\text { Control: no treatment } \\
\text { Basic treatment: HD-cyclophosphamide } 2.5 \mathrm{~g} / \mathrm{m}^{2} ; \mathrm{d} 1 \text { i.v.; or HD-epirubicin } 130 \mathrm{mg} / \\
\mathrm{m}^{2} \text {; } \mathrm{d} 1 \text { i.v.; every } 21 \mathrm{~d} ; 4 \text { cycles } \\
\text { Supportive treatment: antibiotics (i.v.) for treatment of } \mathrm{FN} \text { (if applied as primary or } \\
\text { secondary prophylaxis was unclear) }\end{array}$ \\
\hline
\end{tabular}

Primary outcome measures: neutropenia duration

Secondary outcome measures: FN duration; ANC profiles; antibiotic usage owing to FN; hospitalization; FN events; tumor response

\begin{tabular}{ll} 
Outcomes & $\begin{array}{l}\text { Primary outcome measures: neutropenia duration } \\
\text { Secondary outcome measures: FN duration; ANC profiles; antibiotic usage owing to } \\
\text { FN; hospitalization; FN events; tumor response }\end{array}$ \\
\hline Notes & -
\end{tabular}

\section{Risk of bias}

\section{Bias}

Random sequence generation/allocation High risk concealment (selection bias)

\section{Support for judgement}

Quote: “[...] patients were randomly assigned to [...]"

Comment: sequence generation was n.r. Allocation concealment was n.r. Differences existed in pretreatment and in sites of metastases. Sample size $<100$ patients

Comment: no statements about blinding or any use of placebo, thus we judged the study as an open-label study

Comment: unblinded outcome assessment

Blinding of outcome assessment (detection High risk bias)

All outcomes

Primary prophylactic colony-stimulating factors for the prevention of chemotherapy-induced febrile neutropenia in breast cancer 
Hansen 1995 (Continued)

\begin{tabular}{|c|c|c|}
\hline $\begin{array}{l}\text { Incomplete outcome data (attrition bias) } \\
\text { All outcomes }\end{array}$ & Unclear risk & $\begin{array}{l}\text { Quote: "In the treatment arm two patient's } \\
\text { did not receive all }[\ldots] \text { courses }[. . .] \text { In the } \\
\text { control arm, one patient ceased treatment } \\
{[\ldots] \text { " }} \\
\text { Comment: attrition rate } 15 \% \text {; reasons } \\
\text { stated for each group }\end{array}$ \\
\hline Selective reporting (reporting bias) & Unclear risk & $\begin{array}{l}\text { Reporting the incidence of events instead } \\
\text { and no rates of patients with neutropenia }\end{array}$ \\
\hline $\begin{array}{l}\text { Definitions and measurements of out- } \\
\text { comes }\end{array}$ & Unclear risk & $\begin{array}{l}\text { FN not defined; daily measuring of body } \\
\text { temperature and blood cell counts }\end{array}$ \\
\hline Supportive treatment & Unclear risk & $\begin{array}{l}\text { Comment: incidence and duration of an- } \\
\text { tibiotic treatment was a secondary outcome } \\
\text { measure, criteria of administration was not } \\
\text { stated }\end{array}$ \\
\hline
\end{tabular}

Jones 1996

Methods

Design: 2 arm, double-blind, placebo-controlled, Phase III trial

Follow-up: 5 years poststudy to monitor disease status and survival

Ethical approval: yes

No. of patients randomized: 142
No. of patients evaluated: 131
Stage of cancer: T1N1 - T2N1- others (stage II-III)
Demographics: women, age range 25 to 69 years (mean age 47 years)
Setting: single-center study; USA
Informed consent: yes

Interventions
CSF intervention: GM-CSF: sargramostim, $250 \mu \mathrm{gg} / \mathrm{m}^{2} ; \mathrm{d} 3-15 \mathrm{sc}$
Control: identical placebo
Basic treatment: FAC-MD: fluorouracil $600 \mathrm{mg} / \mathrm{m}^{2}$, cyclophosphamide $750 \mathrm{mg} / \mathrm{m}^{2}$,
antimycin $60 \mathrm{mg} / \mathrm{m}^{2} ; \mathrm{d} 1$ i.v.; every $21 \mathrm{~d} ; 4 \mathrm{cycles}$
Supportive treatment: prophylactic antibiotics (i.v., oral, or both) at the onset of grade
III neutropenia (ANC $<1000 / \mu \mathrm{L})$

Outcomes

Primary outcome measures: neutropenia duration

Secondary outcome measures: neutropenia incidence; FN incidence; dose intensity; hospitalization; antibiotic use owing to $\mathrm{FN}$; toxicity

Notes

Risk of bias

Bias

Authors' judgement

Support for judgement

Primary prophylactic colony-stimulating factors for the prevention of chemotherapy-induced febrile neutropenia in breast cancer 
Random sequence generation/allocation Low risk concealment (selection bias)
Quote: “[...] patients were randomized to $[\ldots]^{\prime \prime}$

Comment: sequence generation was $\mathrm{n}$. r. Allocation concealment was n.r. There were no significant differences in sociodemographic and disease related parameters. Sample size $>100$ patients

Blinding of participants and personnel Unclear risk (performance bias)

All outcomes

Blinding of outcome assessment (detection Unclear risk bias)

All outcomes

Incomplete outcome data (attrition bias) Unclear risk

All outcomes

Selective reporting (reporting bias)

Low risk

Definitions and measurements of out- Low risk comes

Quote: "Patients [...] received the study drug $[. .$.$] in a double blind manner"; "[...]$ equivalent volume of placebo [...]"

Comment: method of blinding adequate; unblinding owing to specific adverse drug reactions could not be ruled out

Comment: blinding of outcome assessment n.r.

Quote: "there were three early withdrawals among patients randomized to placebo and eight among patients randomized to GMCSF”

Comment: attrition rate $8 \%$; reasons stated for each study group; attrition rate was not equally distributed between groups

Comment: no indication for selective reporting

FN clearly defined; body temperature was measured daily and blood cell counts 3 times weekly

Supportive treatment

Unclear risk

Quote: "[...] at the onset of grade 3 neutropenia $(\mathrm{ANC}<1000 / \mu \mathrm{l})$ patients received prophylactic antibiotics"

Comment: patients in CGs were assumed to have received antibiotics more frequently

Muhonen 1996

Methods
Design: 2-arm, open label, Phase III trial

Follow-up: unclear

Ethical approval: unclear 
Muhonen 1996 (Continued)

\begin{tabular}{|c|c|}
\hline Participants & $\begin{array}{l}\text { No. of patients randomized: } 32 \\
\text { No. of patients evaluated: } 31 \\
\text { Stage of cancer: metastatic or loco-regionally advanced breast cancer } \\
\text { Demographics: women, age range } 34 \text { to } 65 \text { years (median age: IG: } 51 \text { years; CG: } 52 \\
\text { years) } \\
\text { Setting: multicenter study; Finland } \\
\text { Informed consent: yes (verbal) }\end{array}$ \\
\hline Interventions & $\begin{array}{l}\text { CSF intervention: G-CSF: filgrastim, } 5 \mu \mathrm{g} / \mathrm{kg} \text {; } \mathrm{d} 4-17 \mathrm{sc} \\
\text { Control: no treatment } \\
\text { Basic treatment: MMM-StD: mitomycin } 8 \mathrm{mg} / \mathrm{m}^{2} \mathrm{~d} 1 \text {, mitoxantrone } 8 \mathrm{mg} / \mathrm{m}^{2} \mathrm{~d} 1 \text { and } \\
22 \text {, methotrexate } 35 \mathrm{mg} / \mathrm{m}^{2} \mathrm{~d} 1 \text { and } 22 \text {; i.v.; every } 42 \mathrm{~d} ; 6 \text { cycles } \\
\text { Supportive treatment: no information about the administration of antibiotics }\end{array}$ \\
\hline Outcomes & $\begin{array}{l}\text { Primary outcome measure: neutropenia incidence } \\
\text { Secondary outcome measures: infections; toxicity; dose delays; tumor response; survival }\end{array}$ \\
\hline Notes & - \\
\hline
\end{tabular}

Risk of bias

Bias

Random sequence generation/allocation Unclear risk concealment (selection bias)

\section{Support for judgement}

Quote: "Patients [...] were randomly assigned to [...]"

Comment: sequence generation was n.r. Allocation concealment was n.r. Slight differences in hormone pretreatment. Sample size $<100$ patients

Comment: no statements about blinding or any use of placebo, thus we judged the study as an open-label study

Comment: unblinded outcome assessment

Blinding of outcome assessment (detection High risk bias)

All outcomes

Incomplete outcome data (attrition bias) Low risk All outcomes

Selective reporting (reporting bias)

High risk

Quote: "one patient did not fulfil the entry criteria [...] and was removed from the study $[\ldots] ”$

Comment: attrition rate $1 \%$; no drop-outs during study period

Comment: no information on rates or events of FN provided 
Muhonen 1996 (Continued)

\begin{tabular}{|c|c|c|}
\hline $\begin{array}{l}\text { Definitions and measurements of out- } \\
\text { comes }\end{array}$ & High risk & $\begin{array}{l}\text { FN not defined; no statements about body } \\
\text { temperature measurements and blood cell } \\
\text { counts }\end{array}$ \\
\hline Supportive treatment & Unclear risk & $\begin{array}{l}\text { Comment: no information about adminis- } \\
\text { tration of antibiotics }\end{array}$ \\
\hline
\end{tabular}

\section{Papaldo 2003}

\begin{tabular}{|c|c|c|}
\hline Methods & \multicolumn{2}{|c|}{$\begin{array}{l}\text { Design: 4-arm, open-label, Phase III trial } \\
\text { Follow-up: median } 55 \text { months } \\
\text { Ethical approval: yes }\end{array}$} \\
\hline Participants & \multicolumn{2}{|c|}{$\begin{array}{l}\text { No. of patients randomized: } 506 \\
\text { No. of patients evaluated: } 497 \\
\text { Stage of cancer: stage I or II breast cancer } \\
\text { Demographics: women, age range } 25 \text { to } 65 \text { years (median age: IG1: } 47 \text { years; IG2: } 48 \\
\text { years; CG1: } 47 \text { years; CG2: } 47 \text { years) } \\
\text { Setting: multicenter study; Italy } \\
\text { Informed consent: yes }\end{array}$} \\
\hline Interventions & \multicolumn{2}{|c|}{$\begin{array}{l}\text { CSF intervention: G-CSF: filgrastim, } 5 \text { different schedules: } 480 \mu \mathrm{g} / \mathrm{d}, \mathrm{d} 8-14 ; 480 \mu \mathrm{g} / \\
\mathrm{d}, \mathrm{d} 8,10,12,14 ; 300 \mu \mathrm{g} /, \mathrm{d} 8-14 ; 300 \mu \mathrm{g} / \mathrm{d}, \mathrm{d} 8,10,12,14 ; 300 \mu \mathrm{g} / \mathrm{d}, \mathrm{d} 8,12 ; \\
\text { Control: no treatment } \\
\text { Basic treatment: epirubicin } 120 \mathrm{mg} / \mathrm{m}^{2} \text {, cyclophosphamide } 600 \mathrm{mg} / \mathrm{m}^{2} ; \mathrm{d} 1 \text { i.v.; every } \\
21 \mathrm{~d} ; 4 \text { cycles } \\
\text { Supportive treatment: antibiotics (i.v.) for treatment of a documented infection }\end{array}$} \\
\hline Outcomes & \multicolumn{2}{|c|}{$\begin{array}{l}\text { Primary outcome measures: DFS and OS } \\
\text { Secondary outcome measures: FN incidence; neutropenia incidence; toxicity }\end{array}$} \\
\hline Notes & \multicolumn{2}{|l|}{ - } \\
\hline \multicolumn{3}{|l|}{ Risk of bias } \\
\hline Bias & Authors' judgement & Support for judgement \\
\hline $\begin{array}{l}\text { Random sequence generation/allocation } \\
\text { concealment (selection bias) }\end{array}$ & Unclear risk & $\begin{array}{l}\text { Quote: "[...] were randomly assigned to [. } \\
\text {..] patients and tumor characteristics were } \\
\text { well balanced among the groups" } \\
\text { Comment: sequence generation was n.r. } \\
\text { Allocation concealment was n.r. Slight dif- } \\
\text { ferences in numbers of patients with in- } \\
\text { volved lymph nodes, tumor size and recep- } \\
\text { tor status between study arms. Sample size } \\
>100 \text { patients }\end{array}$ \\
\hline
\end{tabular}

Primary prophylactic colony-stimulating factors for the prevention of chemotherapy-induced febrile neutropenia in breast cancer 
Papaldo 2003 (Continued)

\begin{tabular}{|c|c|c|}
\hline $\begin{array}{l}\text { Blinding of participants and personnel } \\
\text { (performance bias) } \\
\text { All outcomes }\end{array}$ & Unclear risk & $\begin{array}{l}\text { Comment: no statements about blinding } \\
\text { or any use of placebo; thus we judged the } \\
\text { study as an open-label study }\end{array}$ \\
\hline $\begin{array}{l}\text { Blinding of outcome assessment (detection } \\
\text { bias) } \\
\text { All outcomes }\end{array}$ & High risk & Comment: unblinded outcome assessment \\
\hline $\begin{array}{l}\text { Incomplete outcome data (attrition bias) } \\
\text { All outcomes }\end{array}$ & Low risk & $\begin{array}{l}\text { Quote: "Nine patients were not assessable } \\
\text { for DFS and OS because [...]" } \\
\text { Comment: attrition rate } 2 \% \text {; reasons for } \\
\text { withdrawal were n.r. separately for each } \\
\text { group }\end{array}$ \\
\hline Selective reporting (reporting bias) & Unclear risk & Number of documented infections n.r. \\
\hline $\begin{array}{l}\text { Definitions and measurements of out- } \\
\text { comes }\end{array}$ & High risk & $\begin{array}{l}\text { FN clearly defined; no information about } \\
\text { measurements of body temperature, blood } \\
\text { cell counts once weekly }\end{array}$ \\
\hline Supportive treatment & Unclear risk & $\begin{array}{l}\text { Quote: “[...] antibiotics given for a docu- } \\
\text { mented infection" }\end{array}$ \\
\hline
\end{tabular}

Romieu 2007

Methods

Design: 2 arm, open-label, Phase II trial

Follow-up: 16 months

Ethical approval: yes

No. of patients randomized: 60
No. of patients evaluated: 59
Stage of cancer: node-positive breast cancer stage II-III
Demographics: women, age range 65 to 77 years
Setting: multicenter study; Germany, Spain, Italy, France
Informed consent: yes (written)

Interventions CSF intervention: G-CSF: pegfilgrastim, $6 \mathrm{mg} / \mathrm{d}$; $\mathrm{d} 2 \mathrm{sc}$

Control: no treatment in cycle 1

Basic treatment: FEC-100: 5-fluorouracil $500 \mathrm{mg} / \mathrm{m}^{2}$, epirubicin $100 \mathrm{mg} / \mathrm{m}^{2}$, cyclophosphamide $500 \mathrm{mg} / \mathrm{m}^{2}$; d1 i.v.; every $21 \mathrm{~d} ; 4$ to 6 cycles

Supportive treatment: secondary prophylaxis with antibiotics in case of FN

Outcomes

Primary outcome measure: neutropenic events in cycle 1

Secondary outcome measures: neutropenic events (all cycles); dose intensity; ANC profiles

Notes

Primary prophylactic colony-stimulating factors for the prevention of chemotherapy-induced febrile neutropenia in breast cancer 
Romieu 2007 (Continued)

Risk of bias

\begin{tabular}{|c|c|c|}
\hline Bias & Authors' judgement & Support for judgement \\
\hline $\begin{array}{l}\text { Random sequence generation/allocation } \\
\text { concealment (selection bias) }\end{array}$ & Unclear risk & $\begin{array}{l}\text { Quote: "[...] based on an open-label pre- } \\
\text { determined randomization schedule gener- } \\
\text { ated by a statistician }[\ldots] \text { treatment groups } \\
\text { were randomly assigned }(1: 1) \text { using an in- } \\
\text { teractive voice response system" } \\
\text { Comment: owing to the reported proce- } \\
\text { dure, we assumed an adequate sequence } \\
\text { generation and concealed allocation. Sam- } \\
\text { ple size }<100 \text { patients }\end{array}$ \\
\hline $\begin{array}{l}\text { Blinding of participants and personnel } \\
\text { (performance bias) } \\
\text { All outcomes }\end{array}$ & Unclear risk & $\begin{array}{l}\text { Quote: "this open-label, phase } 2 \text { study }[\ldots \\
\text { ]" } \\
\text { Comment: unblinded patients and person- } \\
\text { nel }\end{array}$ \\
\hline $\begin{array}{l}\text { Blinding of outcome assessment (detection } \\
\text { bias) } \\
\text { All outcomes }\end{array}$ & High risk & Comment: unblinded outcome assessment \\
\hline $\begin{array}{l}\text { Incomplete outcome data (attrition bias) } \\
\text { All outcomes }\end{array}$ & Unclear risk & $\begin{array}{l}\text { Quote: "three patients in the PP [primary } \\
\text { prophylaxis] group and four from the SP } \\
\text { [secondary prophylaxis] group were with- } \\
\text { drawn [...]" } \\
\text { Comment: attrition rate } 12 \% \text {; reasons } \\
\text { stated for each study group }\end{array}$ \\
\hline Selective reporting (reporting bias) & Unclear risk & $\begin{array}{l}\text { Comment: no outcome on hematologic } \\
\text { data (ANC, etc.) provided; antibiotic treat- } \\
\text { ment was n.r }\end{array}$ \\
\hline $\begin{array}{l}\text { Definitions and measurements of out- } \\
\text { comes }\end{array}$ & Low risk & $\begin{array}{l}\text { FN clearly defined; daily measuring of body } \\
\text { temperature; blood cell counts were taken } \\
3 \text { times weekly }\end{array}$ \\
\hline Supportive treatment & Unclear risk & $\begin{array}{l}\text { Quote: "secondary prophylaxis (antibiotic) } \\
\text { was allowed in patients who developed FN" } \\
\text { Comment: patients in CGs seemed to have } \\
\text { received antibiotics more frequently }\end{array}$ \\
\hline
\end{tabular}

Primary prophylactic colony-stimulating factors for the prevention of chemotherapy-induced febrile neutropenia in breast cancer 
Methods

Participants
Design: 2-arm, double blind, placebo-controlled, Phase III trial

Follow-up: not stated

Ethical approval: yes
No. of patients randomized: 928

No. of patients evaluated: 928

Stage of cancer: metastatic and non-metastatic breast cancer

Demographics: women (922), men (6), age range 21 to 88 years (mean 52 years)

Setting: multicenter study; 88 sites in Europe and the USA

Informed consent: yes
CSF intervention: G-CSF: pegfilgrastim, $6 \mathrm{mg}$; $\mathrm{d} 2 \mathrm{sc}$;

Control: identical placebo

Basic treatment: DCT-HD: DCT $100 \mathrm{mg} / \mathrm{m}^{2}$; d1 i.v.; every $21 \mathrm{~d}$; 4 cycles

Supportive treatment: antibiotics (i.v.) secondary prophylaxis for FN treatment; nonnarcotic analgesics and opioids for bone pain
Primary outcome measure: FN incidence

Secondary outcome measures: neutropenia incidence; hospitalization; antibiotic usage owing to FN; dose delays; toxicity

Large multinational drug approval study
Bias

Random sequence generation/allocation Unclear risk concealment (selection bias)
Quote: "Patients were randomly assigned to $[\ldots]$ the groups were well matched in characteristics [...]"

Comment: sequence generation was n.r.; allocation concealment was n.r. Slight differences in percentages of previous radiation therapy and chemotherapy and in first quartile of ANC. Sample size $>100$ patients

Quote: “[...] all patients received at least one dose of blinded study drug [...] and placebo were presented as identical prefilled syringes"

Comment: identical placebo; unblinding owing to specific adverse drug reactions could not be ruled out

Comment: blinding of outcome assessment n.r. bias)

Unclear risk

All outcomes 
Vogel 2005 (Continued)

\begin{tabular}{|c|c|c|}
\hline $\begin{array}{l}\text { Incomplete outcome data (attrition bias) } \\
\text { All outcomes }\end{array}$ & Unclear risk & $\begin{array}{l}\text { Quote: "thirty-five patients }(8 \%) \text { in the ini- } \\
\text { tial placebo group and } 27(6 \%) \text { in the peg- } \\
\text { filgrastim group withdrew from the study" } \\
\text { Comment: attrition rate } 7 \% \text {; reasons stated } \\
\text { for each study group }\end{array}$ \\
\hline Selective reporting (reporting bias) & Unclear risk & $\begin{array}{l}\text { Comment: number of dropped-out pa- } \\
\text { tients in cycle } 1 \text { not stated }\end{array}$ \\
\hline $\begin{array}{l}\text { Definitions and measurements of out- } \\
\text { comes }\end{array}$ & Unclear risk & $\begin{array}{l}\text { FN not clearly defined; body temperature } \\
\text { was measured twice daily, blood cell counts } \\
\text { once weekly in case of fever }\end{array}$ \\
\hline Supportive treatment & Unclear risk & $\begin{array}{l}\text { Quote: "[...] the incidence of need for IV } \\
\text { anti-infectives as a result of FN." } \\
\text { Comment: patients in CGs were assumed } \\
\text { to have received antibiotics more frequently }\end{array}$ \\
\hline
\end{tabular}

ANC: absolute neutrophil count; CG: control group; CSF: colony-stimulating factors; d: day; DCT: docetaxel; DFS: disease-free survival; FAC: fluorouracil, antimycin, cyclophosphamide; FEC: fluorouracil, epirubicin, cyclophosphamide; FEC-HD: fluorouracil, epirubicin, cyclophosphamide high-dose; FN: febrile neutropenia; G-CSF: granulocyte colony-stimulating factors; GM-CSF: granulocyte-macrophage colony-stimulating factors; HD: high-dose; IG: intervention group; ITT: intention-to-treat; i.v.: intravenous; MMM: mitomycin, mitoxantrone, methotrexate; No.: number; n.r.: not reported; n.s.: not significant; OS: overall survival; sc: subcutaneous.

\section{Characteristics of excluded studies [ordered by study ID]}

\begin{tabular}{l|l}
\hline Study & Reason for exclusion \\
\hline Ardizzoni 1994 & Different chemotherapy schedules between study arms \\
\hline Athanassiou 1996 & Different chemotherapy schedules between study arms \\
\hline Bono 2009 & Different basic treatments between study arms; no placebo or no-treatment control \\
\hline Ellis 2011 & Different basic treatments between study arms \\
\hline Gascon 2010 & No placebo or no-treatment control \\
\hline Gebbia 1994 & No data available for breast cancer patients; author was contacted several times but did not answer \\
\hline Green 2003 & No placebo or no-treatment control
\end{tabular}

Primary prophylactic colony-stimulating factors for the prevention of chemotherapy-induced febrile neutropenia in breast cancer 
(Continued)

\begin{tabular}{|c|c|}
\hline Hatam 2011 & Different basic treatments between study arms and no application of CSFs \\
\hline Holmes 2002 & No placebo or no-treatment control \\
\hline Holmes 2002b & No placebo or no-treatment control \\
\hline Iiristo 2011 & Different basic treatments between study arms \\
\hline Ikonomidis 2008 & $\begin{array}{l}\text { Study reported only biochemical parameters and no outcomes of interest of our systematic review. Study } \\
\text { author was contacted for additional data but did not answer }\end{array}$ \\
\hline Joensuu 2010 & Different basic treatments between study arms \\
\hline Khrichkova 2008 & $\begin{array}{l}\text { No information about randomization and recruitment of patients. Study did not report on outcomes of } \\
\text { interest for our systematic review }\end{array}$ \\
\hline Martin 2006 & Different basic treatments between study arms \\
\hline Schröder 1999 & No placebo or no-treatment control \\
\hline Steger 1992 & $\begin{array}{l}\text { Not clear how many patients were included in the trial. The publication reports only data for injection-site } \\
\text { reaction experienced by patients receiving GM-CSF. Author was contacted but could not provide data }\end{array}$ \\
\hline Stöger 1998 & Different chemotherapy schedules between study arms \\
\hline Tomova 2009 & Different basic treatments between study arms \\
\hline Venturini 2005 & $\begin{array}{l}\text { Patients in the G-CSF arm received chemotherapy every } 2 \text { weeks, while patients in the control arms received } \\
\text { chemotherapy every } 3 \text { weeks }\end{array}$ \\
\hline von Minckwitz 2008a & Treatment with CSFs was not randomly allocated \\
\hline von Minckwitz 2010 & Different basic treatments between study arms \\
\hline von Minckwitz 2011 & Different basic treatments between study arms and no control arm with placebo or no treatment \\
\hline Waller 2010 & No placebo or no-treatment control \\
\hline Wang 2004 & Unclear cross-over design; no placebo or no-treatment control \\
\hline Weaver 2001 & No placebo or no-treatment control \\
\hline Yau 1996 & $\begin{array}{l}\text { Outcomes of interests of our review only reported aggregated with data from patients with lymphoma. } \\
\text { Author was contacted but did not answer }\end{array}$ \\
\hline Zhang 1999 & Cross-over study; no placebo or no-treatment control \\
\hline
\end{tabular}

Primary prophylactic colony-stimulating factors for the prevention of chemotherapy-induced febrile neutropenia in breast cancer 
(Continued)

Zhou $2006 \quad$ No placebo or no-treatment control

CSF: colony-stimulating factors; G-CSF: granulocyte colony-stimulating factors; GM-CSF: granulocyte-macrophage colony-stimulating factors.

Characteristics of ongoing studies [ordered by study ID]

Amgen 2015

Trial name or title A Prospective Observational Study of Neutropenia and Anemia Management in Subjects With Solid Tumors Receiving Myelotoxic Chemotherapy

Methods Prospective observational study

Participants Breast cancer, non-small cell lung cancer, ovarian cancer and small cell lung cancer patients; the aim is to have approximately 800 breast cancer, 300 non-small cell lung cancer, 100 small-cell lung cancer and 100 ovarian cancer subjects

Interventions Chemotherapy and primary, secondary or no usage of G-CSF

Outcomes Primary outcome measure: incidence of febrile neutropenia; secondary outcome measure: G-CSF use, ESA use, anti-infective use, transfusions and hospitalizations

Starting date December 2007

Contact information Amgen Call Center

Notes

ESA: erythropoiesis-stimulating agents; G-CSF: granulocyte colony-stimulating factor. 
DATA AND ANALYSES

Comparison 1. Primary outcomes

\begin{tabular}{|c|c|c|c|c|}
\hline Outcome or subgroup title & $\begin{array}{l}\text { No. of } \\
\text { studies }\end{array}$ & $\begin{array}{c}\text { No. of } \\
\text { participants }\end{array}$ & Statistical method & Effect size \\
\hline 1 Febrile neutropenia rates (total) & 6 & 2073 & Risk Ratio (M-H, Random, 95\% CI) & $0.27[0.11,0.70]$ \\
\hline $1.1 \mathrm{G}-\mathrm{CSF}$ & 5 & 1931 & Risk Ratio (M-H, Random, 95\% CI) & $0.27[0.10,0.75]$ \\
\hline 1.2 GM-CSF & 1 & 142 & Risk Ratio (M-H, Random, 95\% CI) & $0.26[0.03,2.24]$ \\
\hline $\begin{array}{l}2 \text { Febrile neutropenia rates (all } \\
\text { cycles) }\end{array}$ & 2 & 598 & Risk Ratio (M-H, Random, 95\% CI) & $0.44[0.09,2.24]$ \\
\hline 2.1 G-CSF & 2 & 598 & Risk Ratio (M-H, Random, 95\% CI) & $0.44[0.09,2.24]$ \\
\hline $\begin{array}{l}3 \text { Febrile neutropenia rates (first } \\
\text { cycles) }\end{array}$ & 4 & 1475 & Risk Ratio (M-H, Random, 95\% CI) & $0.20[0.08,0.52]$ \\
\hline $3.1 \mathrm{G}-\mathrm{CSF}$ & 3 & 1333 & Risk Ratio (M-H, Random, 95\% CI) & $0.19[0.06,0.61]$ \\
\hline 3.2 GM-CSF & 1 & 142 & Risk Ratio (M-H, Random, 95\% CI) & $0.26[0.03,2.24]$ \\
\hline 4 Early mortality & 8 & 2143 & Risk Ratio (M-H, Fixed, 95\% CI) & $0.32[0.13,0.77]$ \\
\hline 4.1 G-CSF & 6 & 1981 & Risk Ratio (M-H, Fixed, 95\% CI) & $0.32[0.13,0.77]$ \\
\hline 4.2 GM-CSF & 2 & 162 & Risk Ratio (M-H, Fixed, 95\% CI) & $0.0[0.0,0.0]$ \\
\hline 5 Infection-related mortality & 8 & 2143 & Risk Ratio (M-H, Fixed, 95\% CI) & $0.14[0.02,1.29]$ \\
\hline $5.1 \mathrm{G}-\mathrm{CSF}$ & 6 & 1981 & Risk Ratio (M-H, Fixed, 95\% CI) & $0.14[0.02,1.29]$ \\
\hline 5.2 GM-CSF & 2 & 162 & Risk Ratio (M-H, Fixed, 95\% CI) & $0.0[0.0,0.0]$ \\
\hline
\end{tabular}

Comparison 2. Secondary Outcomes

\begin{tabular}{lccll} 
Outcome or subgroup title & $\begin{array}{c}\text { No. of } \\
\text { studies }\end{array}$ & $\begin{array}{c}\text { No. of } \\
\text { participants }\end{array}$ & \multicolumn{1}{c}{ Statistical method } & Effect size \\
\hline 1 Neutropenia grade IV (total) & 4 & 712 & Risk Ratio (M-H, Random, 95\% CI) & $0.44[0.17,1.18]$ \\
1.1 G-CSF & 3 & 570 & Risk Ratio (M-H, Random, 95\% CI) & $0.36[0.05,2.44]$ \\
1.2 GM-CSF & 1 & 142 & Risk Ratio (M-H, Random, 95\% CI) & $0.78[0.62,0.97]$ \\
2 Neutropenia grade IV (all cycle) & 2 & 511 & Risk Ratio (M-H, Random, 95\% CI) & $0.19[0.08,0.45]$ \\
$\quad$ 2.1 G-CSF & 2 & 511 & Risk Ratio (M-H, Random, 95\% CI) & $0.19[0.08,0.45]$ \\
2.2 GM-CSF & 0 & 0 & Risk Ratio (M-H, Random, 95\% CI) & $0.0[0.0,0.0]$ \\
3 Neutropenia grade IV (first & 2 & 201 & Risk Ratio (M-H, Random, 95\% CI) & $0.89[0.66,1.21]$ \\
$\quad$ cycle) & 1 & 59 & Risk Ratio (M-H, Random, 95\% CI) & $1.06[0.79,1.43]$ \\
3.1 G-CSF & 1 & 142 & Risk Ratio (M-H, Random, 95\% CI) & $0.78[0.62,0.97]$ \\
3.2 GM-CSF & 3 & 210 & Risk Ratio (M-H, Fixed, 95\% CI) & $0.86[0.72,1.02]$ \\
4 Infections (total) & 3 & 210 & Risk Ratio (M-H, Fixed, 95\% CI) & $0.86[0.72,1.02]$ \\
$\quad$ 4.1 G-CSF & 4 & 1149 & Risk Ratio (M-H, Fixed, 95\% CI) & $0.14[0.06,0.30]$ \\
5 Hospitalization (total) & 2 & 987 & Risk Ratio (M-H, Fixed, 95\% CI) & $0.12[0.05,0.29]$ \\
5.1 G-CSF & 2 & 162 & Risk Ratio (M-H, Fixed, 95\% CI) & $0.26[0.04,1.56]$ \\
5.2 GM-CSF & 1 & 20 & Risk Ratio (M-H, Fixed, 95\% CI) & $0.28[0.01,6.10]$ \\
6 Hospitalization (all cycles) & 1 & 20 & Risk Ratio (M-H, Fixed, 95\% CI) & $0.28[0.01,6.10]$ \\
$\quad$ 6.1 GM-CSF & 3 & 1129 & Risk Ratio (M-H, Fixed, 95\% CI) & $0.13[0.06,0.30]$ \\
7 Hospitalization (first cycle) & & &
\end{tabular}

Primary prophylactic colony-stimulating factors for the prevention of chemotherapy-induced febrile neutropenia in breast cancer 


$\begin{array}{lllll}\text { 7.1 G-CSF } & 2 & 987 & \text { Risk Ratio (M-H, Fixed, 95\% CI) } & 0.12[0.05,0.29] \\ \text { 7.2 GM-CSF } & 1 & 142 & \text { Risk Ratio (M-H, Fixed, 95\% CI) } & 0.26[0.03,2.24] \\ \text { 8 Antibiotics (total) } & 4 & 1568 & \text { Risk Ratio (M-H, Fixed, 95\% CI) } & 0.35[0.22,0.55] \\ \text { 8.1 G-CSF } & 2 & 1406 & \text { Risk Ratio (M-H, Fixed, 95\% CI) } & 0.35[0.22,0.57] \\ \text { 8.2 GM-CSF } & 2 & 162 & \text { Risk Ratio (M-H, Fixed, 95\% CI) } & 0.26[0.04,1.56] \\ 9 \text { Antibiotics (all cycles) } & 2 & 498 & \text { Risk Ratio (M-H, Fixed, 95\% CI) } & 0.50[0.28,0.87] \\ \text { 9.1 G-CSF } & 1 & 478 & \text { Risk Ratio (M-H, Fixed, 95\% CI) } & 0.51[0.29,0.90] \\ \text { 9.2 GM-CSF } & 1 & 20 & \text { Risk Ratio (M-H, Fixed, 95\% CI) } & 0.28[0.01,6.10] \\ 10 \text { Antibiotics (first cycle) } & 2 & 1070 & \text { Risk Ratio (M-H, Random, 95\% CI) } & 0.40[0.03,4.77] \\ \text { 10.1 G-CSF } & 1 & 928 & \text { Risk Ratio (M-H, Random, 95\% CI) } & 0.18[0.07,0.46] \\ \text { 10.2 GM-CSF } & 1 & 142 & \text { Risk Ratio (M-H, Random, 95\% CI) } & 0.85[0.76,0.95] \\ \text { 11 Chemotherapy, planned dose } & 4 & 1588 & \text { Risk Ratio (M-H, Random, 95\% CI) } & 1.05[0.97,1.13] \\ \text { in time } & & & & 1.05[0.97,1.13] \\ \text { 11.1 G-CSF } & 4 & 1588 & \text { Risk Ratio (M-H, Random, 95\% CI) } & 5.88[2.54,13.60] \\ \text { 12 Bone pain } & 2 & 151 & \text { Risk Ratio (M-H, Fixed, 95\% CI) } & 5.88[2.54,13.60] \\ \text { 12.1 G-CSF } & 2 & 151 & \text { Risk Ratio (M-H, Fixed, 95\% CI) } & 3.59[2.33,5.53] \\ 13 \text { Injection-site reaction } & 2 & 262 & \text { Risk Ratio (M-H, Fixed, 95\% CI) } & 3.39[1.85,6.20] \\ \text { 13.1 G-CSF } & 1 & 120 & \text { Risk Ratio (M-H, Fixed, 95\% CI) } & 3.81[2.05,7.05] \\ \text { 13.2 GM-CSF } & 1 & 142 & \text { Risk Ratio (M-H, Fixed, 95\% CI) } & \end{array}$

\section{Analysis I.I. Comparison I Primary outcomes, Outcome I Febrile neutropenia rates (total).}

Review: Primary prophylactic colony-stimulating factors for the prevention of chemotherapy-induced febrile neutropenia in breast cancer patients

Comparison: I Primary outcomes

Outcome: I Febrile neutropenia rates (total)

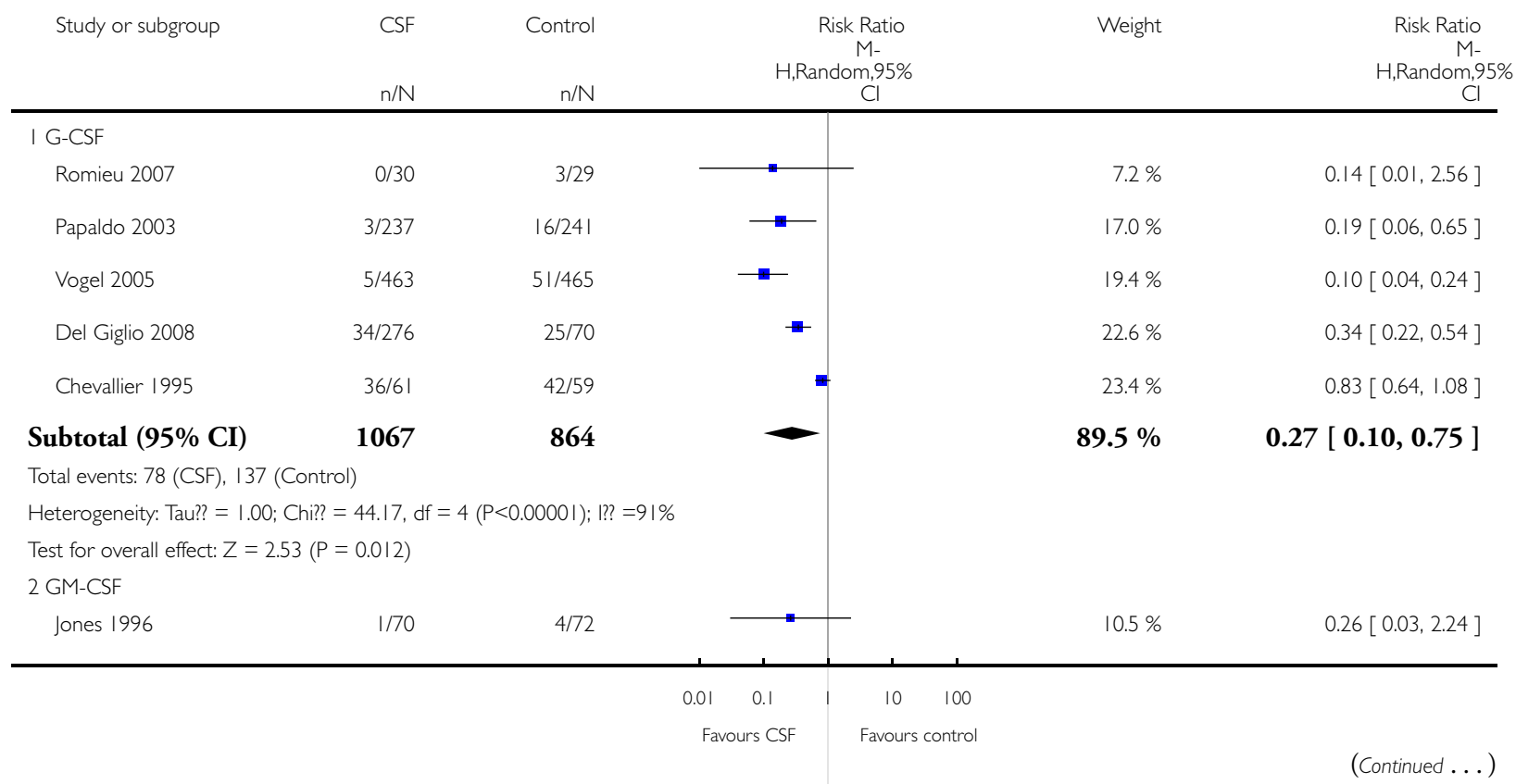

Primary prophylactic colony-stimulating factors for the prevention of chemotherapy-induced febrile neutropenia in breast cancer 


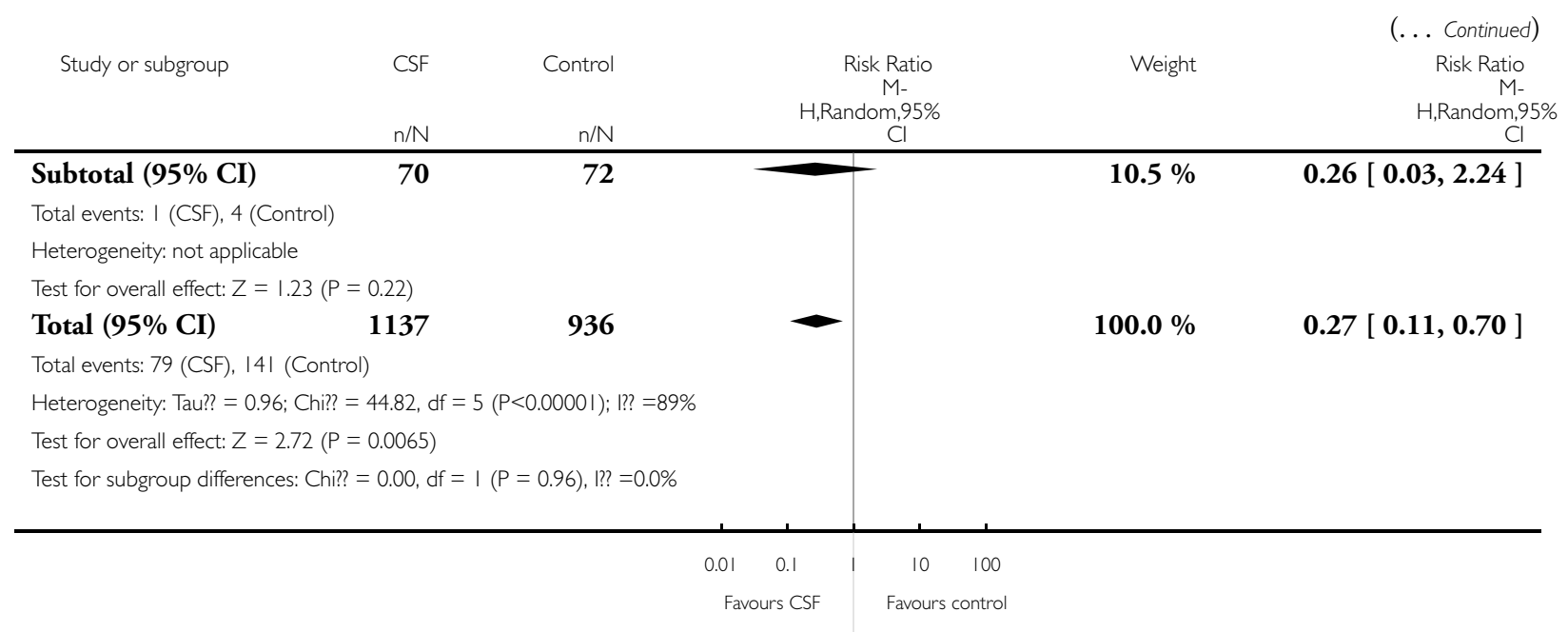

\section{Analysis I.2. Comparison I Primary outcomes, Outcome 2 Febrile neutropenia rates (all cycles).}

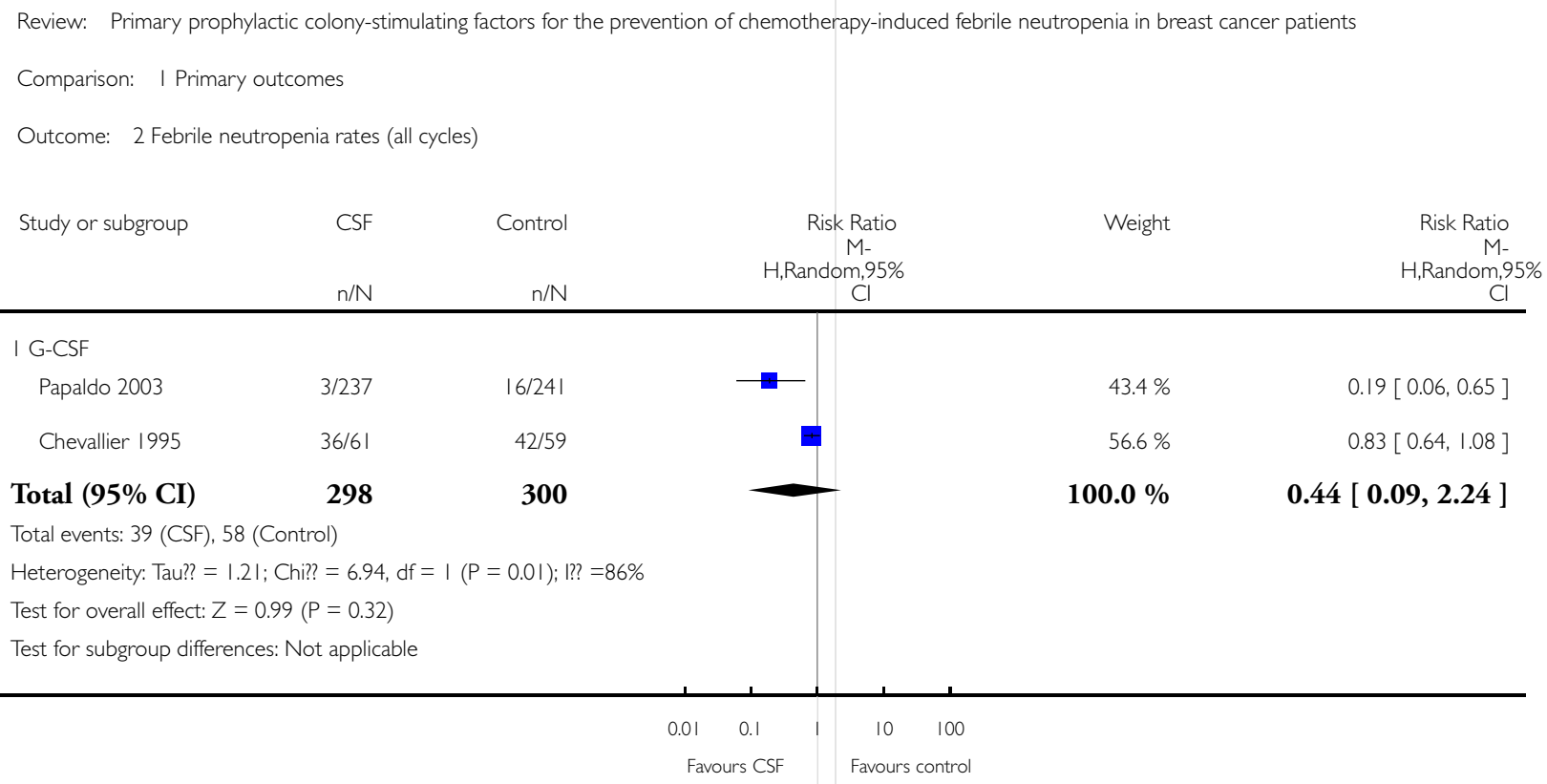




\section{Analysis I.3. Comparison I Primary outcomes, Outcome 3 Febrile neutropenia rates (first cycles).}

Review: Primary prophylactic colony-stimulating factors for the prevention of chemotherapy-induced febrile neutropenia in breast cancer patients

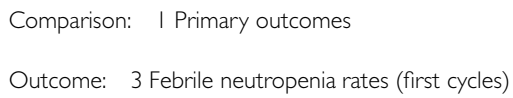

\begin{tabular}{|c|c|c|c|c|c|}
\hline Study or subgroup & $\begin{array}{l}\mathrm{CSF} \\
\mathrm{n} / \mathrm{N}\end{array}$ & $\begin{array}{r}\text { Control } \\
\text { n/N }\end{array}$ & $\begin{array}{c}\text { Risk Ratio } \\
\text { M- } \\
\text { H,Random,95\% } \\
\text { Cl }\end{array}$ & Weight & $\begin{array}{c}\text { Risk Ratio } \\
\text { M- } \\
\text { H,Random,95\% } \\
\text { Cl }\end{array}$ \\
\hline \multicolumn{6}{|l|}{ G-CSF } \\
\hline Romieu 2007 & $0 / 30$ & $3 / 29$ & - & $8.8 \%$ & $0.14[0.01,2.56]$ \\
\hline Vogel 2005 & $5 / 463$ & $51 / 465$ & $\rightarrow$ & $33.6 \%$ & $0.10[0.04,0.24]$ \\
\hline Del Giglio 2008 & $34 / 276$ & $25 / 70$ & 7 & $43.6 \%$ & $0.34[0.22,0.54]$ \\
\hline
\end{tabular}

Subtotal $(95 \% \mathrm{CI})$

769

564

$86.0 \%$

Total events: 39 (CSF), 79 (Control)

Heterogeneity: Tau?? = 0.7।; Chi?? = 7.88, $d f=2(P=0.02) ;$ I? $=75 \%$

Test for overall effect: $Z=2.76(P=0.0057)$

2 GM-CSF

Jones 1996

$1 / 70$

$4 / 72$

Subtotal (95\% CI)

70

72

Total events: I (CSF), 4 (Control)

Heterogeneity: not applicable

Test for overall effect: $Z=1.23(P=0.22)$

Total (95\% CI)

839

636

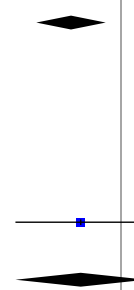

$0.19[0.06,0.61]$

Total events: 40 (CSF), 83 (Control)

Heterogeneity: Tau?? = 0.50; Chi?? = 7.78, $d f=3(P=0.05) ;$ I? $=61 \%$

Test for overall effect: $Z=3.28(P=0.0010)$

Test for subgroup differences: Chi?? $=0.06, \mathrm{df}=\mathrm{I}(\mathrm{P}=0.80), \mathrm{l} ? \mathrm{?}=0.0 \%$

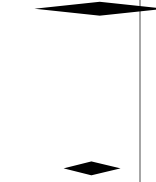

$14.0 \%$

$0.26[0.03,2.24]$

$14.0 \%$

$0.26[0.03,2.24]$ 


\section{Analysis I.4. Comparison I Primary outcomes, Outcome 4 Early mortality.}

Review: Primary prophylactic colony-stimulating factors for the prevention of chemotherapy-induced febrile neutropenia in breast cancer patients

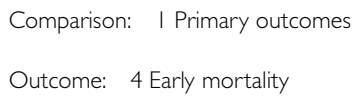

881

Total events: 6 (CSF), 17 (Control)

Heterogeneity: Chi? $=0.62, \mathrm{df}=2(P=0.73) ; 1 ? ?=0.0 \%$

Test for overall effect: $Z=2.55(P=0.011)$

2 GM-CSF

Jones 1996
Hansen 1995

Subtotal $(\mathbf{9 5 \%} \mathrm{CI})$

81

Total events: 0 (CSF), 0 (Control)

Heterogeneity: Chi?? = 0.0, df = $0(P<0.0000 I) ; 1 ? ?=0.0 \%$

Test for overall effect: $Z=0.0(P<0.0000$ I $)$

Total (95\% CI)

1181

Total events: 6 (CSF), 17 (Control)

Heterogeneity: Chi? $=0.62, \mathrm{df}=2(P=0.73) ; 1 ?$ ? $=0.0 \%$

Test for overall effect: $Z=2.55(P=0.01 \mathrm{I})$

Test for subgroup differences: Not applicable

81

962

$\begin{array}{rr} & 0.0[0.0,0.0] \\ & 0.0[0.0,0.0] \\ & 0.0[0.0,0.0] \\ r & 0.32[0.01,7.61] \\ & 0.13[0.01,1.38] \\ & 0.36[0.13,0.99]\end{array}$

$0.32[0.13,0.77$ ]

$0.0[0.0,0.0]$

$0.0[0.0,0.0]$

$0.0[0.0,0.0]$

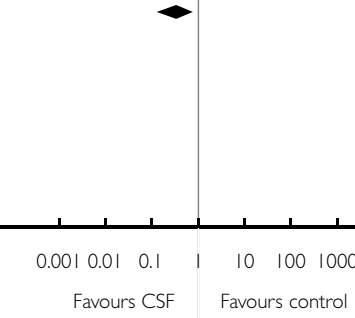




\section{Analysis I.5. Comparison I Primary outcomes, Outcome 5 Infection-related mortality.}

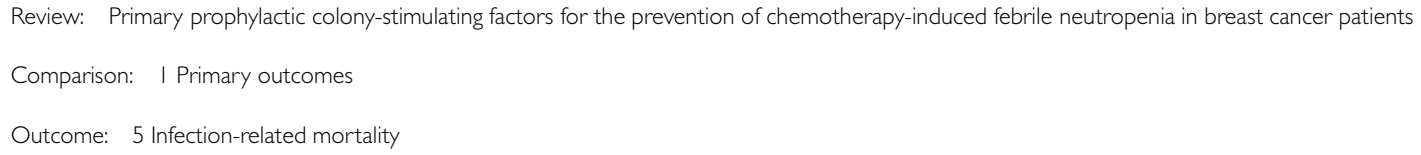

1100

881

Total events: 0 (CSF), 3 (Control)

Heterogeneity: Chi? $=0.15, \mathrm{df}=1(P=0.70) ; 1 ? ?=0.0 \%$

Test for overall effect: $Z=1.73(P=0.083)$

2 GM-CSF

Hansen 1995

Jones 1996

Subtotal $(\mathbf{9 5 \%} \mathrm{CI})$

81

81

Total events: 0 (CSF), 0 (Control)

Heterogeneity: Chi?? = 0.0, df =0 (P<0.0000 I); I? $=0.0 \%$

Test for overall effect: $Z=0.0(P<0.0000$ I $)$

Total (95\% CI)

1181

Total events: 0 (CSF), 3 (Control)

Heterogeneity: Chi? $=0.15, \mathrm{df}=\mathrm{I}(\mathrm{P}=0.70) ; 1 ?$ ? $=0.0 \%$

Test for overall effect: $Z=1.73(P=0.083)$

Test for subgroup differences: Not applicable

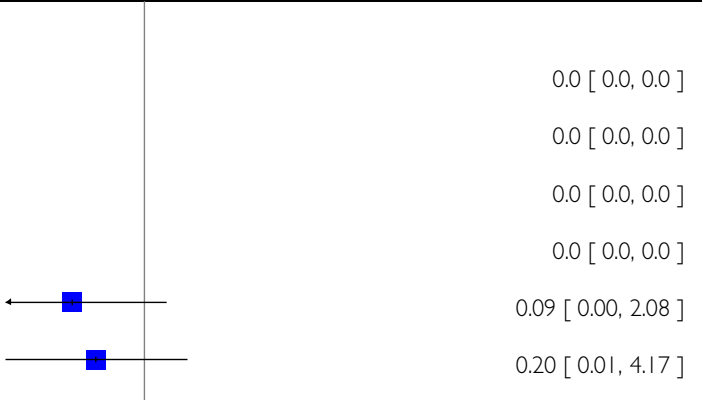

$0.0[0.0,0.0]$

$0.0[0.0,0.0]$

$0.0[0.0,0.0]$

$0.14[0.02,1.29]$ 


\section{Analysis 2.I. Comparison 2 Secondary Outcomes, Outcome I Neutropenia grade IV (total).}

Review: Primary prophylactic colony-stimulating factors for the prevention of chemotherapy-induced febrile neutropenia in breast cancer patients

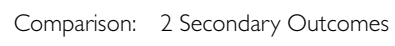

Papaldo 2003

Romieu 2007

283

$21 / 29$

Subtotal (95\% CI)

287

Total events: 40 (CSF), 134 (Control)

Heterogeneity: Tau?? = 2.80; Chi?? = 77.79, $\mathrm{df}=2$ (P<0.0000 I); I? =97\%

Test for overall effect: $Z=1.05(P=0.29)$

2 GM-CSF

Jones $1996 \quad 43 / 70 \quad 57 / 72$

Subtotal $(95 \% \mathrm{CI})$

70

72

Total events: 43 (CSF), 57 (Control)

Heterogeneity: not applicable

Test for overall effect: $Z=2.26(P=0.024)$

Total (95\% CI)

Total events: 83 (CSF), 191 (Control)

Heterogeneity: Tau?? = 0.93; Chi?? = 77.99, df = 3 (P<0.0000 I); I? =96\%

Test for overall effect: $Z=1.62(P=0.10)$

Test for subgroup differences: Chi?? $=0.62, d f=I(P=0.43), 1 ?$ ? $=0.0 \%$

\begin{tabular}{|c|c|c|}
\hline $\begin{array}{r}\text { Risk Ratio } \\
\text { M- } \\
\text { H,Random,95\% } \\
\text { Cl }\end{array}$ & Weight & $\begin{array}{r}\text { Risk Ratio } \\
\text { M- } \\
\text { H,Random, C59 } \\
\text { Cl } \\
\end{array}$ \\
\hline$\rightarrow$ & $22.1 \%$ & $0.31[0.13,0.76]$ \\
\hline$=$ & $24.9 \%$ & $0.13[0.08,0.23]$ \\
\hline 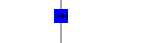 & $26.3 \%$ & $1.06[0.79,1.43]$ \\
\hline & $73.4 \%$ & $0.36[0.05,2.44]$ \\
\hline 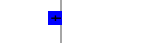 & $26.6 \%$ & $0.78[0.62,0.97]$ \\
\hline - & $26.6 \%$ & $0.78[0.62,0.97]$ \\
\hline & $100.0 \%$ & $0.44[0.17,1.18]$ \\
\hline
\end{tabular}

$0.0010 .01 \quad 0.1 \quad 1 \quad 10 \quad 100 \quad 1000$

Favours CSF Favours control 


\section{Analysis 2.2. Comparison 2 Secondary Outcomes, Outcome 2 Neutropenia grade IV (all cycle).}

Review: Primary prophylactic colony-stimulating factors for the prevention of chemotherapy-induced febrile neutropenia in breast cancer patients

Comparison: 2 Secondary Outcomes

Outcome: 2 Neutropenia grade IV (all cycle)

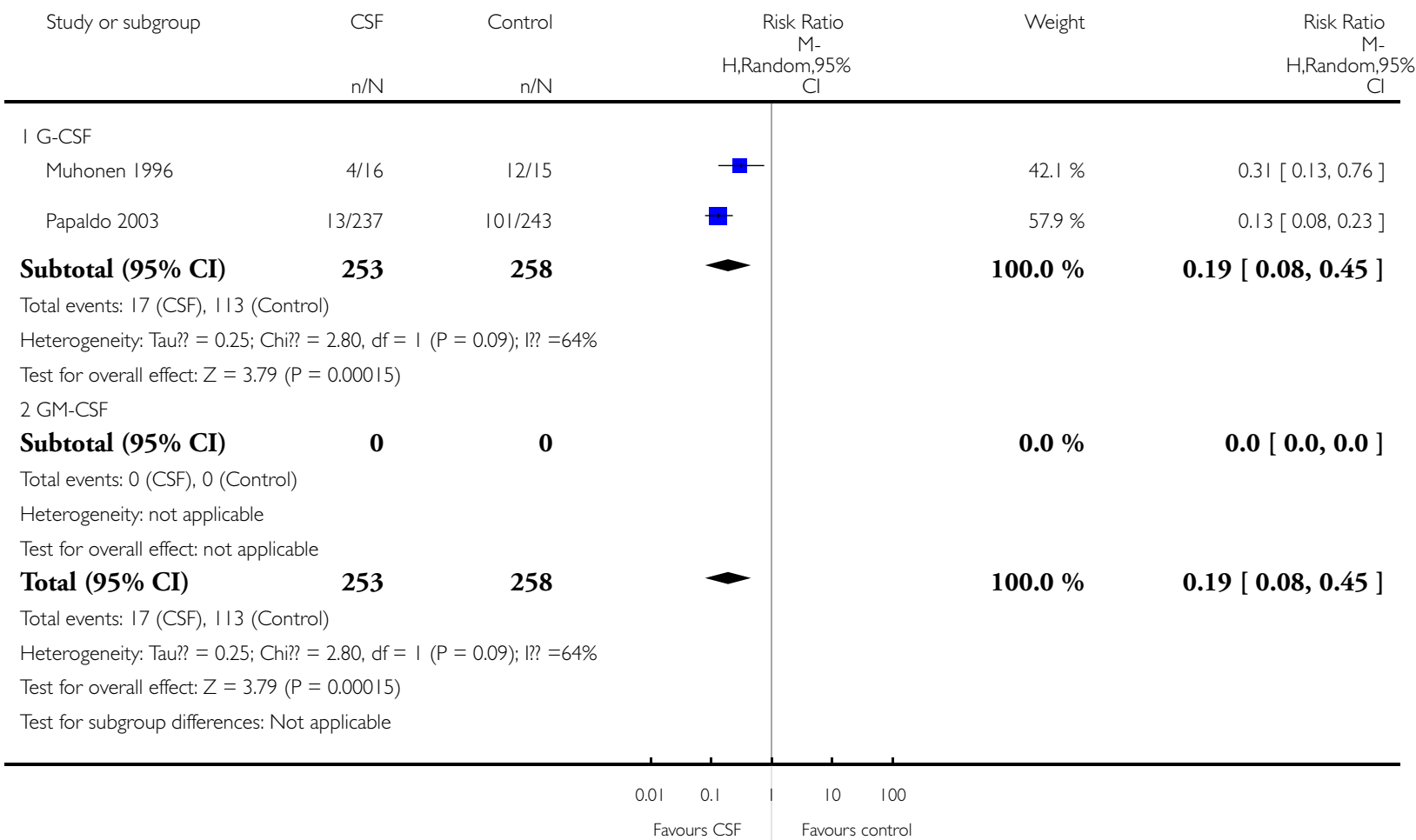




\section{Analysis 2.3. Comparison 2 Secondary Outcomes, Outcome 3 Neutropenia grade IV (first cycle).}

Review: Primary prophylactic colony-stimulating factors for the prevention of chemotherapy-induced febrile neutropenia in breast cancer patients

Comparison: 2 Secondary Outcomes

Outcome: 3 Neutropenia grade IV (first cycle)

\begin{tabular}{|c|c|c|c|c|c|}
\hline Study or subgroup & CSF & Control & $\begin{array}{c}\text { Risk Ratio } \\
\text { M- } \\
\mathrm{H}, \text { Random,95\% } \\
\mathrm{Cl}\end{array}$ & Weight & $\begin{array}{c}\text { Risk Ratio } \\
\text { M- } \\
\text { H,Random,95\% } \\
\text { Cl }\end{array}$ \\
\hline -CSF & & & & & \\
\hline Romieu 2007 & $23 / 30$ & $21 / 29$ & 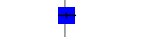 & $44.5 \%$ & $1.06[0.79,1.43]$ \\
\hline
\end{tabular}

Subtotal (95\% CI)

3029

Total events: 23 (CSF), 2 I (Control)

Heterogeneity: not applicable

Test for overall effect: $Z=0.37(P=0.7 \mathrm{I})$

2 GM-CSF

Jones 1996

$43 / 70 \quad 57 / 72$

Total events: 43 (CSF), 57 (Control)

Heterogeneity: not applicable

Test for overall effect: $Z=2.26(P=0.024)$

Total (95\% CI)

100

Total events: 66 (CSF), 78 (Control)

Heterogeneity: Tau?? = 0.03; Chi?? = 2.71, $d f=1(P=0.10) ;$ !? =63\%

Test for overall effect: $Z=0.74(P=0.46)$

Test for subgroup differences: Chi?? $=2.69, \mathrm{df}=1(P=0.10), 1 ? ?=63 \%$

101
$44.5 \%$

$1.06[0.79,1.43]$

$55.5 \%$

$0.78[0.62,0.97]$

$55.5 \%$

$0.78[0.62,0.97]$

$100.0 \%$

$0.89[0.66,1.21]$ 


\section{Analysis 2.4. Comparison 2 Secondary Outcomes, Outcome 4 Infections (total).}

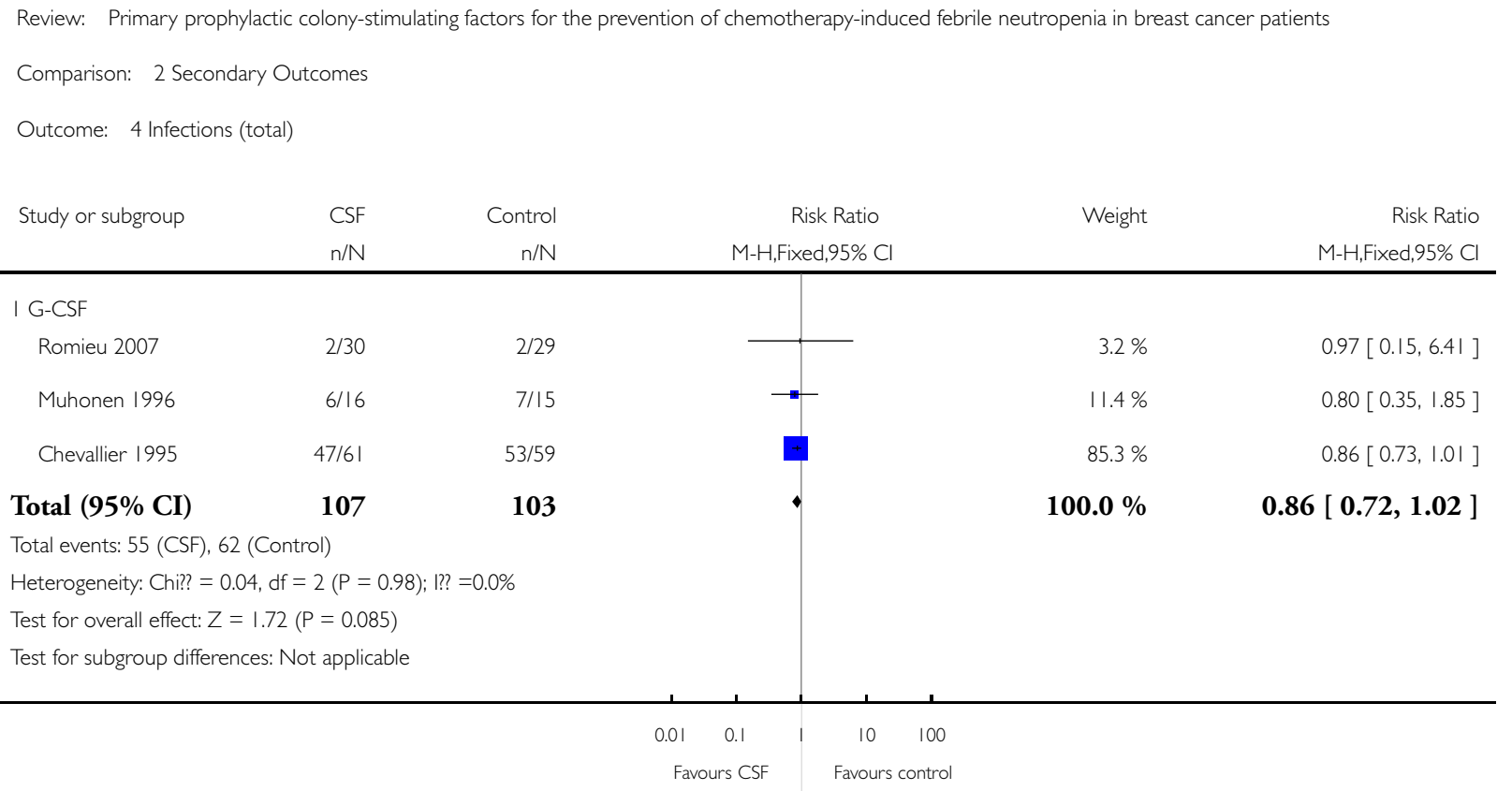




\section{Analysis 2.5. Comparison 2 Secondary Outcomes, Outcome 5 Hospitalization (total).}

Review: Primary prophylactic colony-stimulating factors for the prevention of chemotherapy-induced febrile neutropenia in breast cancer patients

Comparison: 2 Secondary Outcomes

Outcome: 5 Hospitalization (total)

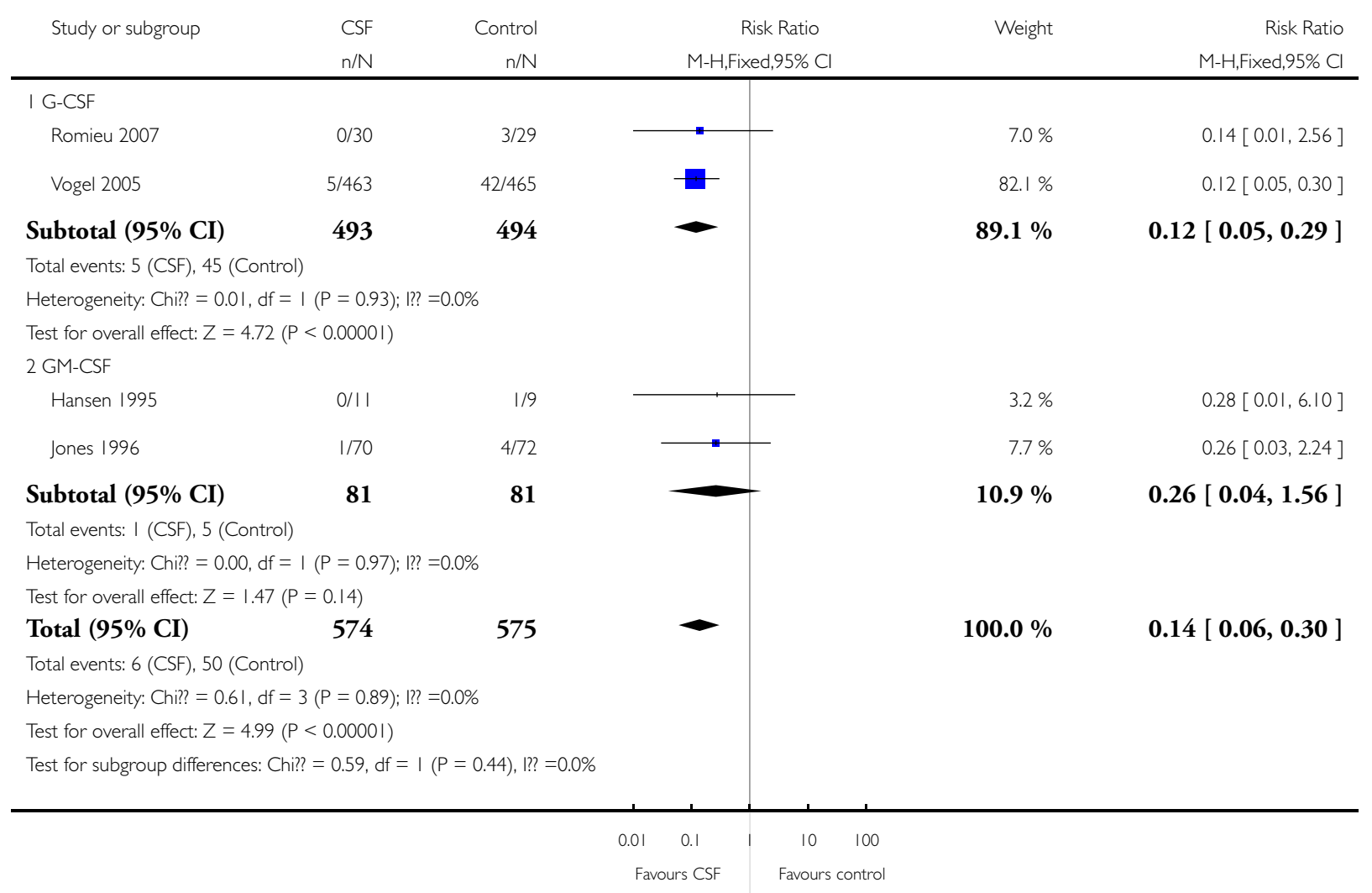

Primary prophylactic colony-stimulating factors for the prevention of chemotherapy-induced febrile neutropenia in breast cancer 


\section{Analysis 2.6. Comparison 2 Secondary Outcomes, Outcome 6 Hospitalization (all cycles).}

Review: Primary prophylactic colony-stimulating factors for the prevention of chemotherapy-induced febrile neutropenia in breast cancer patients

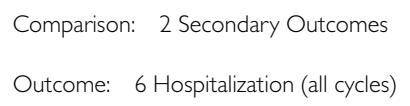

1

Total $(95 \% \mathrm{CI})$

)

Total events: 0 (CSF), I (Control)

Heterogeneity: not applicable

Test for overall effect: $Z=0.81(P=0.42)$

Test for subgroup differences: Not applicable

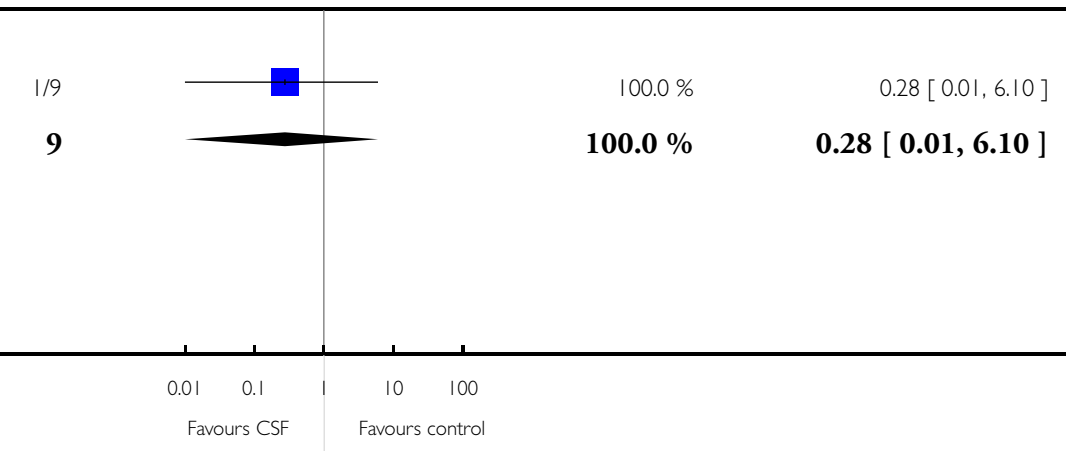




\section{Analysis 2.7. Comparison 2 Secondary Outcomes, Outcome 7 Hospitalization (first cycle).}

Review: Primary prophylactic colony-stimulating factors for the prevention of chemotherapy-induced febrile neutropenia in breast cancer patients

Comparison: 2 Secondary Outcomes

Outcome: 7 Hospitalization (first cycle)

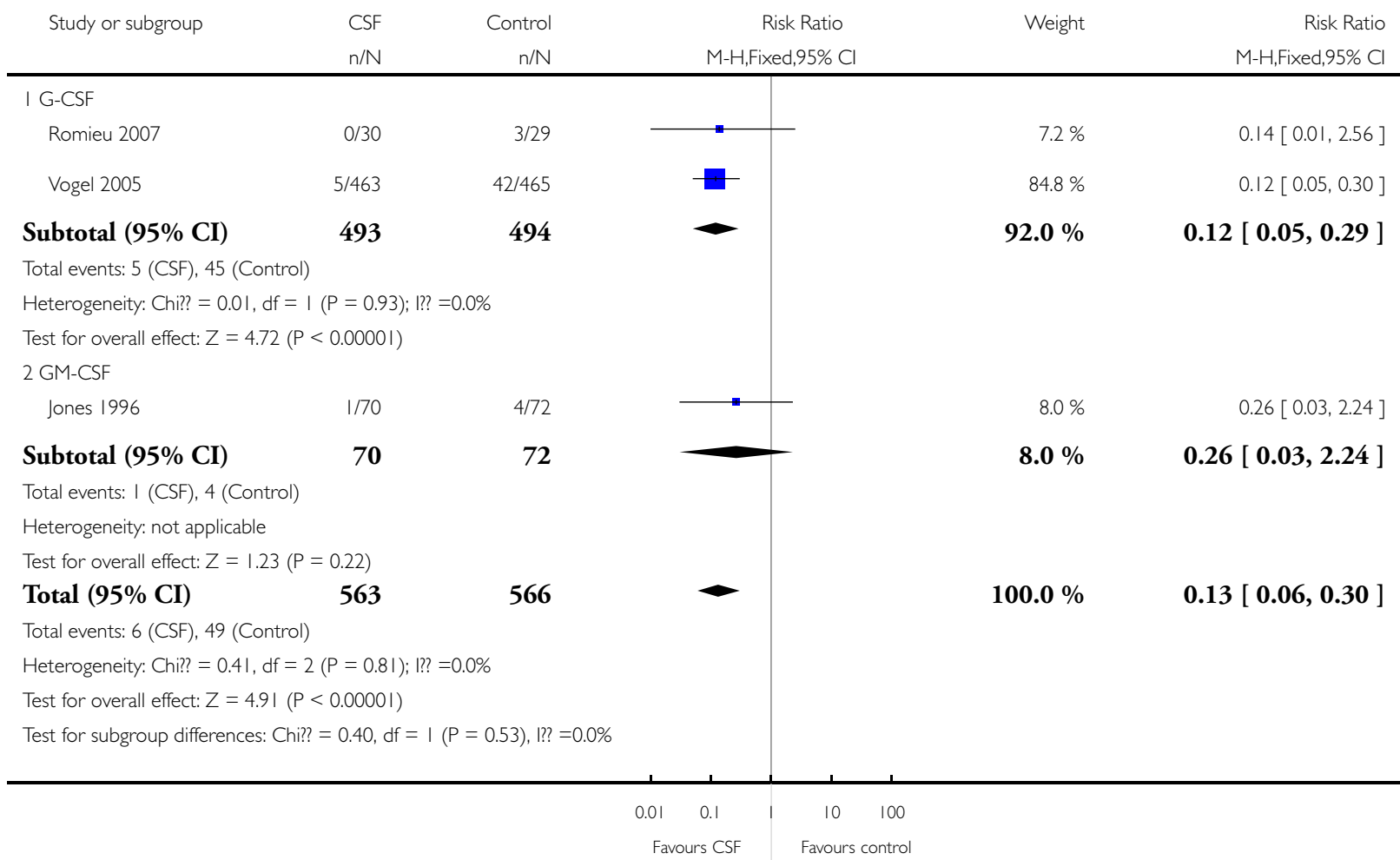

Primary prophylactic colony-stimulating factors for the prevention of chemotherapy-induced febrile neutropenia in breast cancer 


\section{Analysis 2.8. Comparison 2 Secondary Outcomes, Outcome 8 Antibiotics (total).}

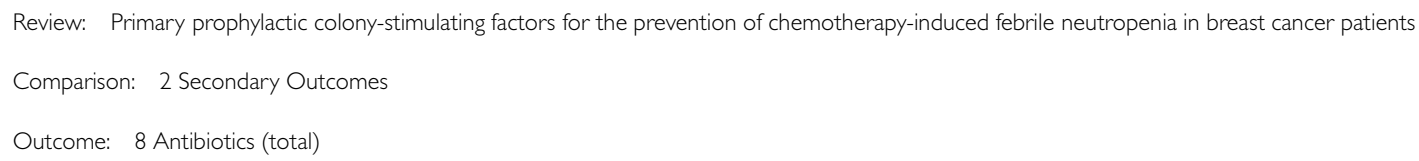

$\leftarrow$

Subtotal $(\mathbf{9 5 \%}$ CI)

$$
\text { 16/237 }
$$

$32 / 241$

700

706

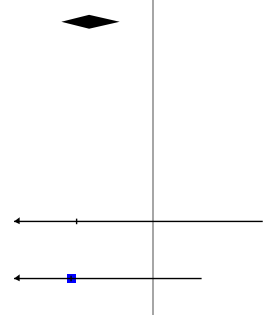

$1.4 \%$

$0.35[0.22,0.57]$

Total events: 21 (CSF), 60 (Control)

Heterogeneity: Chi? $=3.53, \mathrm{df}=1 \quad(P=0.06) ; 1 ? ?=72 \%$

Test for overall effect: $Z=4.22(P=0.000024)$

2 GM-CSF

Hansen 1995

0/II

1/9

Jones 1996

$1 / 70$

$4 / 72$

Subtotal $(\mathbf{9 5} \% \mathrm{CI})$

81

81

Total events: I (CSF), 5 (Control)

Heterogeneity: Chi? $=0.00, \mathrm{df}=1(\mathrm{P}=0.97) ; 1 ?$ ? $=0.0 \%$

Test for overall effect: $Z=1.47(P=0.14)$

Total $(\mathbf{9 5 \%}$ CI $)$

781

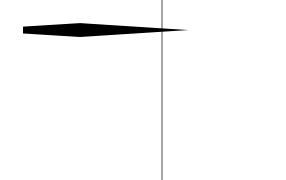

$2.5 \%$

$0.28[0.01,6.10]$

$6.0 \%$

$0.26[0.03,2.24]$

Total events: 22 (CSF), 65 (Control)

Heterogeneity: Chi? = 3.69, df = $3(P=0.30) ; 1 ?$ ? $=19 \%$

Test for overall effect: $Z=4.47(P<0.0000 \mathrm{I})$

Test for subgroup differences: Chi? $=0.10, \mathrm{df}=1(\mathrm{P}=0.75), 1 ? ?=0.0 \%$

$\begin{array}{lllllll}0.1 & 0.2 & 0.5 & 1 & 2 & 5 & 10\end{array}$

Favours CSF Favours control 


\section{Analysis 2.9. Comparison 2 Secondary Outcomes, Outcome 9 Antibiotics (all cycles).}

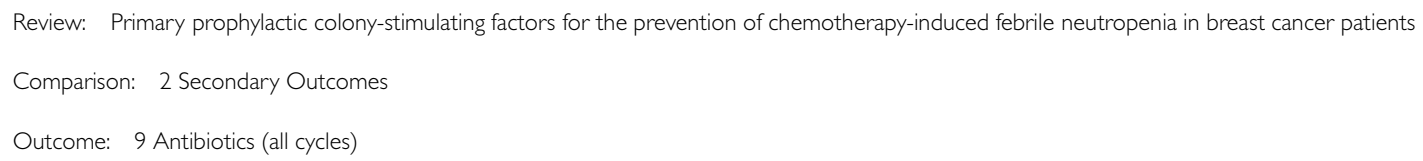

Subtotal $(95 \% \mathrm{CI})$

$$
\text { Hansen } 1995
$$

$$
0 / 11
$$

Subtotal $(\mathbf{9 5} \% \mathrm{CI})$

Total events: 0 (CSF), I (Control)

Heterogeneity: not applicable

Test for overall effect: $Z=0.8 \mathrm{I}(P=0.42)$

Total (95\% CI) $\quad 248$

\section{1}

1

Total events: 16 (CSF), 33 (Control)

Heterogeneity: Chi?? $=0.14, \mathrm{df}=1(P=0.7 \mathrm{I}) ; 1 ?$ ? $=0.0 \%$

Test for overall effect: $Z=2.44(P=0.015)$

Test for subgroup differences: Chi?? $=0.14, \mathrm{df}=1(P=0.7 \mathrm{I}), \mathrm{l} ? \mathrm{?}=0.0 \%$

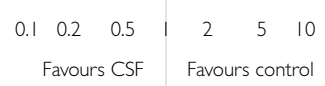

$4.9 \%$

$4.9 \%$

$100.0 \%$
$0.51[0.29,0.90$ ]

$0.28[0.01,6.10]$

$0.28[0.01,6.10]$

$0.50[0.28,0.87]$ 


\section{Analysis 2.10. Comparison 2 Secondary Outcomes, Outcome 10 Antibiotics (first cycle).}

Review: Primary prophylactic colony-stimulating factors for the prevention of chemotherapy-induced febrile neutropenia in breast cancer patients

Comparison: 2 Secondary Outcomes

Outcome: 10 Antibiotics (first cycle)

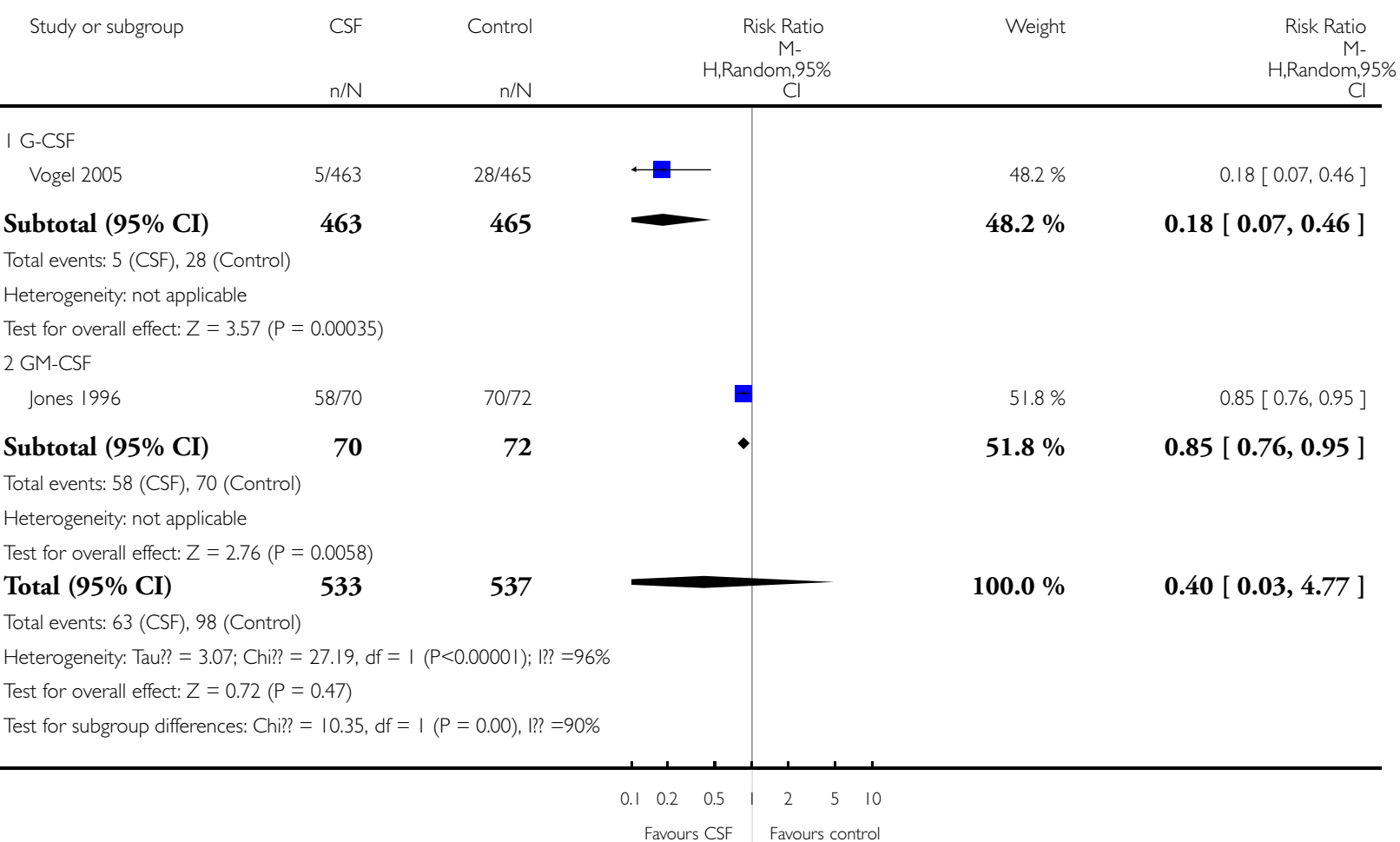

Primary prophylactic colony-stimulating factors for the prevention of chemotherapy-induced febrile neutropenia in breast cancer 


\section{Analysis 2.I I. Comparison 2 Secondary Outcomes, Outcome I I Chemotherapy, planned dose in time.}

Review: Primary prophylactic colony-stimulating factors for the prevention of chemotherapy-induced febrile neutropenia in breast cancer patients

Comparison: 2 Secondary Outcomes

Outcome: II Chemotherapy, planned dose in time

Study or subgroup CSF Control Risk Ratio $\quad$ C $\quad$ Weight

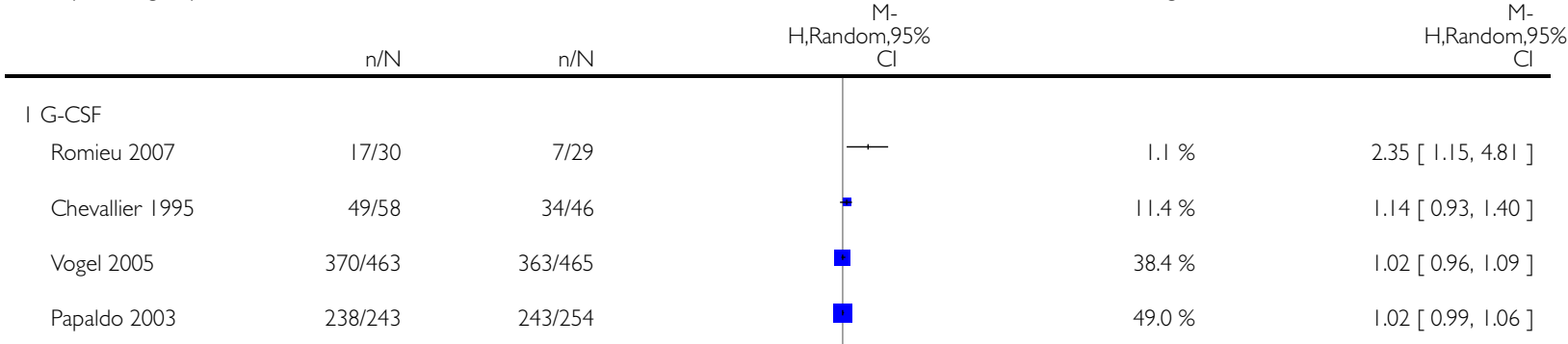

Total (95\% CI)

794

794

Total events: 674 (CSF), 647 (Control)

Heterogeneity: Tau?? = 0.00; Chi?? = 7.65, $d f=3(P=0.05) ;$ l? $=61 \%$

Test for overall effect: $Z=1.15(P=0.25)$

Test for subgroup differences: Not applicable

$100.0 \%$

$1.05[0.97,1.13$ ] 


\section{Analysis 2.12. Comparison 2 Secondary Outcomes, Outcome 12 Bone pain.}

Review: Primary prophylactic colony-stimulating factors for the prevention of chemotherapy-induced febrile neutropenia in breast cancer patients

Comparison: 2 Secondary Outcomes

Outcome: 12 Bone pain

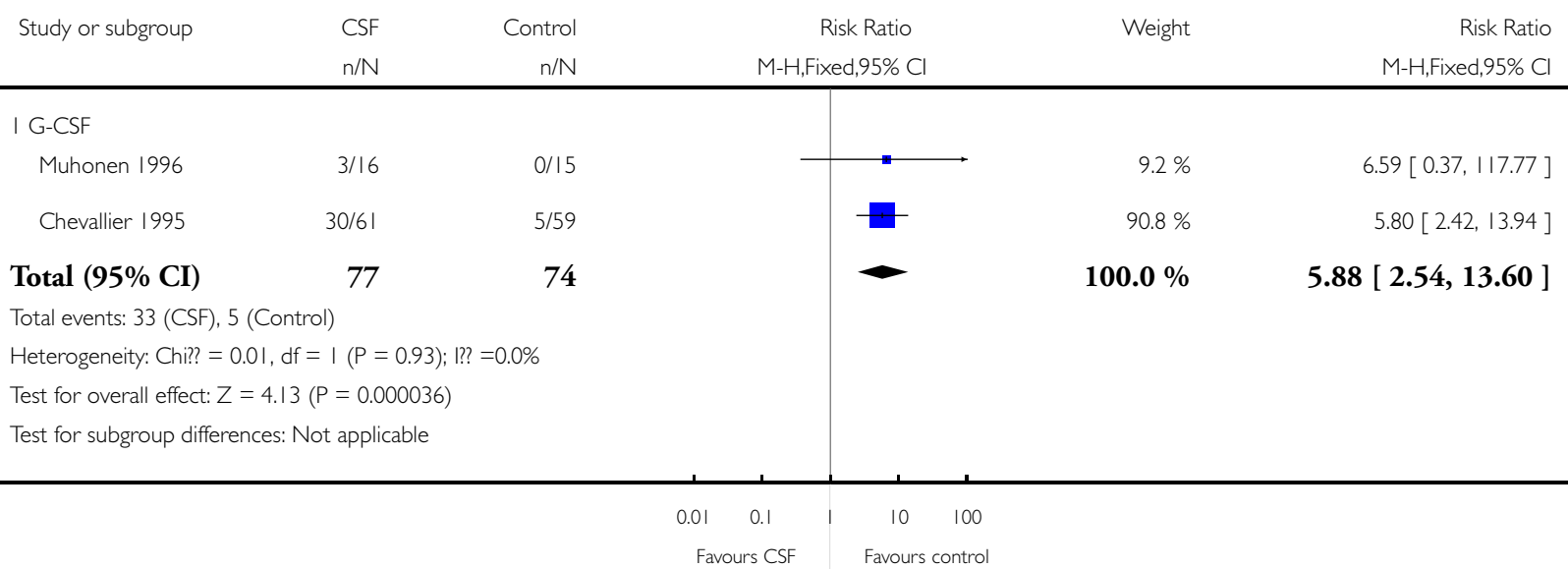




\section{Analysis 2.13. Comparison 2 Secondary Outcomes, Outcome 13 Injection-site reaction.}

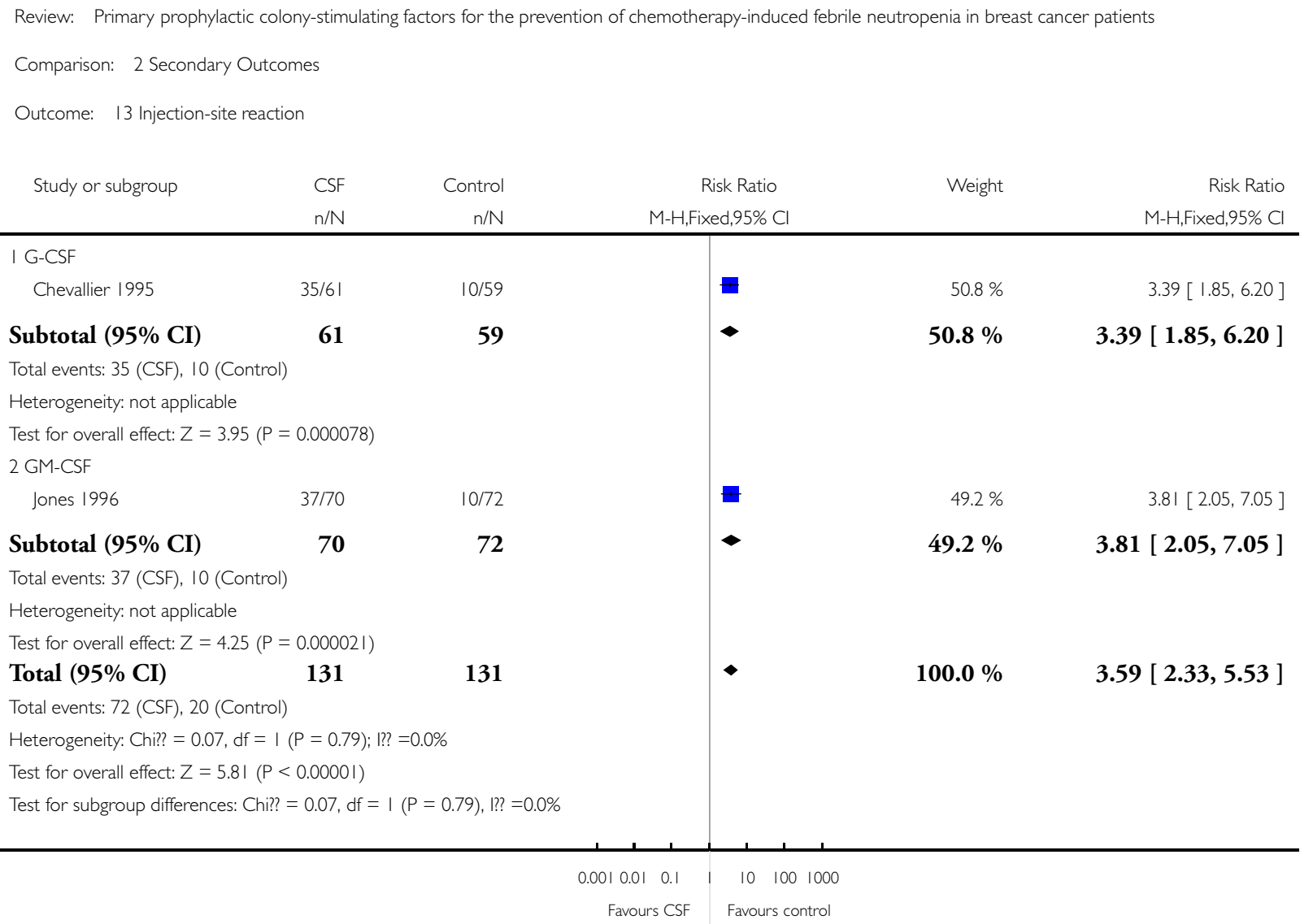

\section{ADDITIONAL TABLES}

Table 1. Characteristics of studies - chemotherapy regimen

\begin{tabular}{ll}
\hline Study & Chemotherapy \\
\hline Chevallier 1995 & $\begin{array}{l}\text { Agents (FEC-HD): } 5 \text {-fluorouracil: } 750 \mathrm{mg} / \mathrm{m}^{2}, \mathrm{~d} 1 \text {-4; epirubicin: } 35 \mathrm{mg} / \mathrm{m}^{2} \mathrm{~d} 2-4 \text {; cyclophosphamide: } 400 \mathrm{mg} / \\
\mathrm{m}^{2}, \mathrm{~d} 2-4 \\
\begin{array}{l}\text { Schedule: every } 3 \text { weeks } \\
\text { Cycles: } 4\end{array}\end{array}$ \\
\hline Jones 1996 & $\begin{array}{l}\text { Agents (FAC): } 5 \text {-fluorouracil: } 600 \mathrm{mg} / \mathrm{m}^{2}, \mathrm{~d} 1 ; \text { doxorubicin } 60 \mathrm{mg} / \mathrm{m}^{2} \mathrm{~d} 1 \text {; cyclophosphamide: } 750 \mathrm{mg} / \mathrm{m}^{2}, \mathrm{~d} 1 \\
\text { Schedule: every } 3 \text { weeks } \\
\text { Cycles: } 4\end{array}$
\end{tabular}

Primary prophylactic colony-stimulating factors for the prevention of chemotherapy-induced febrile neutropenia in breast cancer 
Table 1. Characteristics of studies - chemotherapy regimen (Continued)

\begin{tabular}{|c|c|}
\hline Del Giglio 2008 & $\begin{array}{l}\text { Agents: (TA) doxorubicin: } 60 \mathrm{mg} / \mathrm{m}^{2}, \mathrm{~d} 1 \text {, docetaxel: } 75 \mathrm{mg} / \mathrm{m}^{2}, \mathrm{~d} 1 \\
\text { Schedule: every } 3 \text { weeks } \\
\text { Cycles: } 4\end{array}$ \\
\hline Romieu 2006 & $\begin{array}{l}\text { Agents (FEC): } 5 \text {-fluorouracil: } 500 \mathrm{mg} / \mathrm{m}^{2}, \mathrm{~d} 1 \text {; epirubicin: } 100 \mathrm{mg} / \mathrm{m}^{2}, \mathrm{~d} 1 \text {; cyclophosphamide: } 500 \mathrm{mg} / \mathrm{m}^{2}, \mathrm{~d} 1 \\
\text { Schedule: every } 3 \text { weeks } \\
\text { Cycles: } 4-6 \text { cycles }\end{array}$ \\
\hline Papaldo 2003 & $\begin{array}{l}\text { Agents (EC): epirubicin: } 120 \mathrm{mg} / \mathrm{m}^{2}, \mathrm{~d} 1 \text {; cyclophosphamide: } 600 \mathrm{mg} / \mathrm{m}^{2}, \mathrm{~d} 1 \\
\text { Schedule: every } 3 \text { weeks } \\
\text { Cycles: } 4\end{array}$ \\
\hline Hansen 1995 & $\begin{array}{l}\text { Agents (HD-E/HD-C): cyclophosphamide: } 2.5 \mathrm{~g} / \mathrm{m}^{2}, \mathrm{~d} 1 \text { or epirubicin: } 130 \mathrm{mg} / \mathrm{m}^{2}, \mathrm{~d} 1 \\
\text { Schedule: every } 3 \text { weeks } \\
\text { Cycles: } 4\end{array}$ \\
\hline Vogel 2005 & $\begin{array}{l}\text { Agents (D): docetaxel: } 100 \mathrm{mg} / \mathrm{m}^{2}, \mathrm{~d} 1 \\
\text { Schedule: every } 3 \text { weeks } \\
\text { Cycles: } 4\end{array}$ \\
\hline Muhonen 1996 & $\begin{array}{l}\text { Agents (MMM): mitomycin: } 8 \mathrm{mg} / \mathrm{m}^{2}, \mathrm{~d} 1 \text {; mitoxantrone: } 8 \mathrm{mg} / \mathrm{m}^{2}, \mathrm{~d} 1 \text { and } 22 \text {; methotrexate: } 35 \mathrm{mg} / \mathrm{m}^{2} \mathrm{~d} 1 \text { and } \\
22 \\
\text { Schedule: every } 6 \text { weeks } \\
\text { Cycles: } 6\end{array}$ \\
\hline
\end{tabular}

d: day.

Table 2. Characteristics of studies - type of applied CSF

\begin{tabular}{|c|c|c|c|}
\hline Study & CSF & Type & Dosage and administration \\
\hline Chevallier 1995 & \multirow[t]{5}{*}{ G-CSF } & Lenograstim (filgrastim) rHuG-CSF & $5 \mu \mathrm{g} / \mathrm{kg} / \mathrm{d}(\mathrm{d} 6-15)$ \\
\hline Del Giglio 2008 & & XM02/Neupogen (filgrastim) r-metHuG-CSF & $5 \mu \mathrm{g} / \mathrm{kg} / \mathrm{d}(\mathrm{d} 2-6 / 15)$ \\
\hline Muhonen 1996 & & Filgrastim & $\begin{array}{l}5 \mu \mathrm{g} / \mathrm{kg} / \mathrm{d} \\
(\mathrm{d} 4-17 / \mathrm{d} 24-37)\end{array}$ \\
\hline Papaldo 2003 & & Filgrastim & $\begin{array}{l}\text { cohort 1: } 480 \mu \mathrm{g} / \mathrm{d}(\mathrm{d} 8-14) \\
\text { cohort 2: } 480 \mu \mathrm{g} / \mathrm{d}(\mathrm{d} 8,10,12,14) \\
\text { cohort 3: } 300 \mu \mathrm{g} / \mathrm{d}(\mathrm{d} 8-14) \\
\text { cohort 4: } 300 \mu \mathrm{g} / \mathrm{d}(\mathrm{d} 8,10,12,14) \\
\text { cohort 5: } 300 \mu \mathrm{g} / \mathrm{d}(\mathrm{d} 8,12)\end{array}$ \\
\hline Vogel 2005 & & Neulasta (pegfilgrastim) rHuG-CSF & $6 \mathrm{mg}(\mathrm{d} 2)$ \\
\hline
\end{tabular}

Primary prophylactic colony-stimulating factors for the prevention of chemotherapy-induced febrile neutropenia in breast cancer 
Table 2. Characteristics of studies - type of applied CSF (Continued)

\begin{tabular}{llll}
\cline { 3 - 3 } Romieu 2006 & & Pegfilgrastim & $6 \mathrm{mg}(\mathrm{d} 2)$ \\
\hline Hansen 1995 & GM-CSF & Molgramostim & $5 \mu \mathrm{g} / \mathrm{kg} / \mathrm{d}(\mathrm{d} 2-11)$ \\
\cline { 3 - 3 } Jones 1996 & Sargramostim & $250 \mu \mathrm{g} / \mathrm{m}^{2}(\mathrm{~d} 3-15)$
\end{tabular}

CSF: colony-stimulating factors; d: day of administration; G-CSF: granulocyte colony-stimulating factor; GM-CSF: granulocytemacrophage colony-stimulating factor; rHuG-CSF: recombinant human colony-stimulating factor

Table 3. Results - definition and measurement of febrile neutropenia

\begin{tabular}{|c|c|c|c|c|}
\hline \multirow[t]{2}{*}{ Study } & \multicolumn{2}{|c|}{ Definition } & \multicolumn{2}{|l|}{ Measurement } \\
\hline & $\begin{array}{l}\text { Fever } \\
\left({ }^{\circ} \mathrm{C}\right)\end{array}$ & Neutropenia (WHO grade) & $\begin{array}{l}\text { Fever } \\
\text { - time point } \\
\text { - time period } \\
\text { - measured by } \\
\text { - documented in }\end{array}$ & Neutropenia \\
\hline Chevallier 1995 & $\geq 38.2$ & III and IV & $\begin{array}{l}\text { - twice daily } \\
\text { - during CX and after discharge } \\
\text { - recorded by a nurse } \\
\text { - diary }\end{array}$ & $\begin{array}{l}\text { daily ( } 1 \text { st cycle) } \\
3 \text { times/week ( } 2 \text { nd to } 4 \text { th cycle) }\end{array}$ \\
\hline Jones 1996 & $\geq 38.2$ & IV & $\begin{array}{l}\text { - each morning } \\
\text { - while on study } \\
\text { - patients (ucl) } \\
\text { - diary }\end{array}$ & thrice/week \\
\hline Del Giglio 2008 & \multicolumn{2}{|c|}{$\begin{array}{l}2 \text { different definitions, unclear which was ap- } \\
\text { plied }\end{array}$} & $\begin{array}{l}\text { - daily } \\
\text { - from d1 until at least d15 } \\
\text { - n.r. } \\
\text { - n.r. }\end{array}$ & from $\mathrm{d} 2$ until at least $\mathrm{d} 15$ \\
\hline Romieu 2006 & $>38.0$ & IV & $\begin{array}{l}\text { - daily } \\
\text { - during CX until d30 after } \\
\text { study } \\
\text { - n.r. } \\
\text { - n.r. }\end{array}$ & $\begin{array}{l}3 \text { times/week until } \mathrm{ANC} \geq 2.0 \\
\times 10^{9} / \mathrm{L} \text { then weekly }\end{array}$ \\
\hline Papaldo 2003 & $\geq 38.2$ & IV & $\begin{array}{l}\bullet \text { n.r. } \\
\bullet \text { n.r. } \\
\text { - n.r. } \\
\bullet \text { n.r. }\end{array}$ & weekly \\
\hline Hansen 1995 & n.r. & n.r. & $\begin{array}{l}\text { - daily } \\
\text { - between each cycle }\end{array}$ & daily \\
\hline
\end{tabular}

Primary prophylactic colony-stimulating factors for the prevention of chemotherapy-induced febrile neutropenia in breast cancer 
Table 3. Results - definition and measurement of febrile neutropenia (Continued)

\begin{tabular}{|c|c|c|c|c|}
\hline & & & $\begin{array}{l}\bullet \text { n.r. } \\
\bullet \text { n.r. }\end{array}$ & \\
\hline Vogel 2005 & $\geq 38.2$ & $\begin{array}{l}\text { IV (on the same day of fever or } \\
\text { day after) }\end{array}$ & $\begin{array}{l}\text { - twice daily } \\
\text { - n.r. } \\
\text { - patient } \\
\text { - n.r. }\end{array}$ & weekly if febrile \\
\hline Muhonen 1996 & n.r. & n.r. & $\begin{array}{l}\cdot \text { n.r. } \\
\cdot \text { - n.r. } \\
\text { - n.r. } \\
\cdot \text { n.r. }\end{array}$ & n.r. \\
\hline
\end{tabular}

ANC: absolute neutrophil count; CX: chemotherapy; d: day of administration; n.r.: not reported.

Table 4. Results - rates of neutropenia/febrile neutropenia

\begin{tabular}{|c|c|c|c|c|c|c|c|}
\hline \multirow[t]{2}{*}{ Study } & \multirow[t]{2}{*}{ CSF } & \multicolumn{2}{|l|}{$\begin{array}{l}\text { Neutropenia } \\
\text { grade IV }\end{array}$} & \multicolumn{2}{|l|}{$\begin{array}{l}\text { Neutropenia } \\
\text { grade III-IV }\end{array}$} & \multicolumn{2}{|c|}{ Febrile neutropenia } \\
\hline & & Intervention & Control & Intervention & Control & Intervention & Control \\
\hline $\begin{array}{l}\text { Chevallier } \\
1995\end{array}$ & G-CSF & - & - & - & - & $\begin{array}{l}36 / 61 \\
(59 \%) \\
\text { E/Cy: } \\
47 / 240 \\
(19.6 \%)\end{array}$ & $\begin{array}{l}42 / 59 \\
(71.2 \%) \mathrm{ns} \\
\mathrm{E} / \mathrm{Cy}: \\
67 / 214 \\
(31.3 \%)\end{array}$ \\
\hline $\begin{array}{l}\text { Del Giglio } \\
2008 \\
(1 \text { st cycle })\end{array}$ & & - & - & - & - & $\begin{array}{l}34 / 276 \\
12.3 \%\end{array}$ & $\begin{array}{l}25 / 70 \\
(36.1 \%)^{*}\end{array}$ \\
\hline $\begin{array}{l}\text { Muhonen } \\
1996\end{array}$ & & $\begin{array}{l}4 / 16 \\
(25 \%)\end{array}$ & $\begin{array}{l}12 / 15 \\
(80 \%)^{*}\end{array}$ & - & - & - & - \\
\hline Papaldo 2003 & & $\begin{array}{l}13 / 237 \\
(5.4 \%)\end{array}$ & $\begin{array}{l}101 / 243 \\
(41.6 \%)\end{array}$ & $\begin{array}{l}68 / 237 \\
(28.6 \%)\end{array}$ & $\begin{array}{l}198 / 243 \\
(81.6 \%)^{*}\end{array}$ & $\begin{array}{l}3 / 237 \\
(1.2 \%)\end{array}$ & $\begin{array}{l}16 / 241 \\
(6.6 \%)^{*}\end{array}$ \\
\hline Vogel 2005 & & - & - & - & - & $\begin{array}{l}6 / 463 \\
(1 \%) \\
1 \text { st cycle: } \\
5 / 463 \\
<1 \%\end{array}$ & $\begin{array}{l}78 / 465 \\
(17 \%)^{*} \\
1 \text { st cycle: } \\
51 / 465 \\
11 \%\end{array}$ \\
\hline $\begin{array}{l}\text { Romieu } 2006 \\
\text { (1st cycle) }\end{array}$ & & $\begin{array}{l}23 / 30 \\
(77 \%)\end{array}$ & $\begin{array}{l}21 / 29 \\
(72 \%)\end{array}$ & - & - & $\begin{array}{l}1 / 30 \\
(3.3 \%)\end{array}$ & $\begin{array}{l}5 / 29 \\
(17.2 \%) \ddagger\end{array}$ \\
\hline
\end{tabular}

Primary prophylactic colony-stimulating factors for the prevention of chemotherapy-induced febrile neutropenia in breast cancer 
Table 4. Results - rates of neutropenia/febrile neutropenia (Continued)

\begin{tabular}{|c|c|c|c|c|c|c|c|}
\hline Hansen 1995 & GM-CSF & $\begin{array}{l}\text { E/Cy: } \\
24 / 39 \\
(62 \%)\end{array}$ & $\begin{array}{l}\text { E/Cy: } \\
29 / 31 \\
(94 \%)\end{array}$ & - & - & $\begin{array}{l}\text { E/Cy: } \\
8 / 39 \\
(21 \%)\end{array}$ & $\begin{array}{l}\text { E/Cy: } \\
10 / 31 \\
(32 \%)\end{array}$ \\
\hline $\begin{array}{l}\text { Jones } 1996 \\
\text { (1st cycle) }\end{array}$ & & $\begin{array}{l}43 / 70 \\
(61 \%)\end{array}$ & $\begin{array}{l}57 / 72 \\
(79 \%)\end{array}$ & - & - & $\begin{array}{l}6 / 70 \\
(9 \%) \\
1 \text { st cycle: } \\
1 / 70 \\
(1 \%)\end{array}$ & $\begin{array}{l}8 / 72 \\
(11 \%) \\
1 \text { st cycle: } \\
4 / 72 \\
(6 \%)\end{array}$ \\
\hline
\end{tabular}

* significant $(\mathrm{P}<0.05)$.

$\ddagger+$ stated as serious febrile neutropenia events.

CSF: colony-stimulating factor; E/Cy: events per cycle; G-CSF: granulocyte colony-stimulating factor; GM-CSF: granulocytemacrophage colony-stimulating factor; ns: not significant.

Table 5. Results - early mortality

\begin{tabular}{|c|c|c|c|c|}
\hline \multirow[t]{2}{*}{ Study } & \multirow[t]{2}{*}{ CSF } & \multirow[t]{2}{*}{ Reason } & \multicolumn{2}{|c|}{ Number of events } \\
\hline & & & Intervention & Control \\
\hline Chevallier 1995 & \multirow[t]{6}{*}{ G-CSF } & - & $0 / 61$ & $0 / 59$ \\
\hline Del Giglio 2008 & & $\begin{array}{l}\text { IG: ischemic stroke; CG: sepsis, } \\
\text { cardiorespiratory arrest }\end{array}$ & $\begin{array}{l}1 / 276 \\
(0.3 \%)\end{array}$ & $\begin{array}{l}2 / 70 \\
(2.9 \%)\end{array}$ \\
\hline Vogel 2005 & & $\begin{array}{l}\text { IG: } 5 \text {; CG: } 12 \text {, all attributed to } \\
\text { disease progression; CG: } 2 \text {, re- } \\
\text { lated to infectious events }\end{array}$ & $\begin{array}{l}5 / 463 \\
(1 \%)\end{array}$ & $\begin{array}{l}14 / 465^{*} \\
(3 \%)\end{array}$ \\
\hline Romieu 2006 & & CG: cardiac failure & $0 / 30$ & $1 / 29$ \\
\hline Hansen 1995 & & - & $0 / 11$ & $0 / 9$ \\
\hline Papaldo 2003 & & - & $0 / 254$ & $0 / 243$ \\
\hline Jones 1996 & \multirow[t]{2}{*}{ GM-CSF } & - & $0 / 70$ & $0 / 72$ \\
\hline Muhonen 1996 & & - & $0 / 16$ & $0 / 15$ \\
\hline
\end{tabular}

* - significant $(\mathrm{P}<0.05)$.

CG: control group; CSF: colony-stimulating factor; G-CSF: granulocyte colony-stimulating factor; GM-CSF: granulocyte-macrophage colony-stimulating factor; IG: intervention group. 
Table 6. Results - infection related mortality

\begin{tabular}{|c|c|c|c|c|}
\hline \multirow[t]{2}{*}{ Study } & \multirow[t]{2}{*}{ CSF } & \multirow[t]{2}{*}{ Reason } & \multicolumn{2}{|c|}{ Number of events } \\
\hline & & & Intervention & Control \\
\hline Chevallier 1995 & \multirow[t]{6}{*}{ G-CSF } & - & $0 / 61$ & $0 / 59$ \\
\hline Del Giglio 2008 & & during cycle 1: CG: 1 sepsis & $0 / 276$ & $\begin{array}{l}1 / 70 \\
(1.4 \%)\end{array}$ \\
\hline Vogel 2005 & & CG: 2 sepsis & $0 / 463$ & $\begin{array}{l}2 / 465 \\
(0.4 \%)\end{array}$ \\
\hline Romieu 2006 & & - & $0 / 30$ & $0 / 29$ \\
\hline Hansen 1995 & & - & $0 / 11$ & $0 / 9$ \\
\hline Papaldo 2003 & & - & $0 / 254$ & $0 / 243$ \\
\hline Jones 1996 & \multirow[t]{2}{*}{ GM-CSF } & - & $0 / 70$ & $0 / 72$ \\
\hline Muhonen 1996 & & - & $0 / 16$ & $0 / 15$ \\
\hline
\end{tabular}

Table 7. Results - duration of severe neutropenia (grade IV)

\begin{tabular}{|c|c|c|c|}
\hline \multirow[t]{2}{*}{ Study } & \multirow[t]{2}{*}{ CSF } & \multicolumn{2}{|c|}{ Duration of neutropenia grade IV (days) } \\
\hline & & Intervention & Control \\
\hline Chevallier 1995 & \multirow[t]{3}{*}{ G-CSF } & 2 & $6^{*}$ \\
\hline Romieu 2006 & & $\begin{array}{l}\text { 1st cycle: } \\
1(\mathrm{mn})\end{array}$ & $\begin{array}{l}\text { 1st cycle: } \\
3 \text { (mn) }\end{array}$ \\
\hline Del Giglio 2008 & & $\begin{array}{l}\text { 1st cycle: } \\
1.1(\mathrm{mn})\end{array}$ & $\begin{array}{l}\text { 1st cycle: } \\
3.9 \text { (mn) }\end{array}$ \\
\hline Hansen 1995 & \multirow[t]{2}{*}{ GM-CSF } & 4 (md) & 8 (md) \\
\hline Jones 1996 & & $\begin{array}{l}\text { 1st cycle: } \\
2 \text { (md) }\end{array}$ & $\begin{array}{l}\text { 1st cycle: } \\
7^{*}(\mathrm{md})\end{array}$ \\
\hline
\end{tabular}

* significant $(\mathrm{P}<0.05)$.

CSF: colony-stimulating factor; G-CSF: granulocyte colony-stimulating factor; GM-CSF: granulocyte-macrophage colony-stimulating factor; md: median; mn: mean. 
Table 8. Results - rates of patients with infections

\begin{tabular}{llll}
\hline Study & CSF & Intervention & Control \\
\hline Chevallier 1995 & G-CSF & $\begin{array}{l}47 / 61 \\
(77 \%)\end{array}$ & \begin{tabular}{l}
$\begin{array}{l}53 / 59 \\
(89.8 \%) \mathrm{ns}\end{array}$ \\
\cline { 3 - 4 }
\end{tabular} \\
\cline { 3 - 4 } Muhonen 1996 & $\begin{array}{l}6 / 16 \\
(37.5 \%)\end{array}$ & $\begin{array}{l}7 / 15 \\
(46.7 \%) \mathrm{ns}\end{array}$ \\
\hline Romieu 2006 (1st cycle) & GM-CSF & $\begin{array}{l}2 / 30 \\
(7 \%)\end{array}$ & $\begin{array}{l}2 / 29 \\
(7 \%) \mathrm{ns}\end{array}$ \\
\hline
\end{tabular}

CSF: colony-stimulating factor; G-CSF: granulocyte colony-stimulating factor; GM-CSF: granulocyte-macrophage colony-stimulating factor; ns: not significant.

Table 9. Results - hospitalization and administration of antibiotics

\begin{tabular}{|c|c|c|c|c|c|c|c|c|}
\hline \multirow[t]{2}{*}{ Study } & \multirow[t]{2}{*}{ CSF } & \multicolumn{3}{|c|}{ Hospitalization } & \multicolumn{4}{|c|}{ Administration of antibiotics } \\
\hline & & Intervention & Control & Decision & Mode & Intervention & Control & Decision \\
\hline $\begin{array}{l}\text { Papaldo } \\
2003\end{array}$ & \multirow[t]{3}{*}{ G-CSF } & - & - & - & i.v. & $\begin{array}{l}16 / 237 \\
(7 \%)\end{array}$ & $\begin{array}{l}32 / 241^{*} \\
(13 \%)\end{array}$ & Not stated \\
\hline Vogel 2005 & & $\begin{array}{l}6 / 463 \\
(1 \%) \\
1 \text { st cycle: } \\
5 / 463 \\
(1 \%)\end{array}$ & $\begin{array}{l}64 / 465 \\
(14 \%)^{*} \\
\text { 1st cycle: } \\
42 / 465 \\
(9 \%) \text { nsp }\end{array}$ & $\begin{array}{l}\text { In case of a } \\
\text { clinical diag- } \\
\text { nosis of FN }\end{array}$ & i.v. & $\begin{array}{l}7 / 463 \\
(2 \%) \\
1 \text { st cycle: } \\
1 \%\end{array}$ & $\begin{array}{l}48 / 465 \\
(10 \%)^{*} \\
1 \text { st cycle: } \\
6 \%\end{array}$ & In case of FN \\
\hline $\begin{array}{l}\text { Romieu } \\
2006\end{array}$ & & $\begin{array}{l}0 / 30 \\
(0 \%)\end{array}$ & $\begin{array}{l}3 / 29 \\
(10,3 \%)\end{array}$ & $\begin{array}{l}\text { In case of FN } \\
(\mathrm{N} 4 \text { and }>38 \\
\left.{ }^{\circ} \mathrm{C}\right)\end{array}$ & i.v. & - & - & - \\
\hline $\begin{array}{l}\text { Hansen } \\
1995\end{array}$ & \multirow[t]{2}{*}{ GM-CSF } & $\begin{array}{l}0 / 11 \\
(0 \%)\end{array}$ & $\begin{array}{l}1 / 9 \\
(11 \%) n s p\end{array}$ & Not stated & i.v. & $\begin{array}{l}0 / 11 \\
(0 \%)\end{array}$ & $\begin{array}{l}1 / 9 \\
(11 \%) \mathrm{nsp}\end{array}$ & Not stated \\
\hline Jones 1996 & & $\begin{array}{l}6 / 70 \\
(9 \%) \\
1 \text { st cycle: } \\
1 / 70 \\
(1 \%)\end{array}$ & $\begin{array}{l}8 / 72 \\
(11 \%) \\
1 \text { st cycle: } \\
4 / 72 \text { nsp } \\
(6 \%)\end{array}$ & In case of FN & $\begin{array}{l}\text { Ciprofloxa- } \\
\text { cin orally } \\
\text { twice daily } \\
(500 \mathrm{mg}) \\
\text { i.v. }\end{array}$ & $\begin{array}{l}\text { 1st cycle: } \\
58 / 70 \\
(83 \%) \\
1 / 70 \\
(1 \%)\end{array}$ & $\begin{array}{l}\text { 1st cycle: } \\
70 / 72 \\
(97 \%) \\
4 / 72 \\
(6 \%)\end{array}$ & $\begin{array}{l}\text { At the on- } \\
\text { set of N3 } \\
\text { until recov- } \\
\text { ery patients } \\
\text { received an- } \\
\text { tibiotics } \\
\text { (orally) } \\
\text { Hospital- } \\
\text { ized patients } \\
\text { received an- }\end{array}$ \\
\hline
\end{tabular}


Table 9. Results - hospitalization and administration of antibiotics (Continued)

tibiotics (i.v.

)

* = significant $(\mathrm{P}<0.05)$.

CSF: colony-stimulating factor; FN: febrile neutropenia; G-CSF: granulocyte colony-stimulating factor; GM-CSF: granulocytemacrophage colony-stimulating factor; i.v.: intravenous; N3: grade III neutropenia; N4: grade IV neutropenia; nsp: not specified.

Table 10. Results - administration of chemotherapies

\begin{tabular}{|c|c|c|c|}
\hline \multirow[t]{2}{*}{ Study } & \multirow[t]{2}{*}{ CSF } & \multicolumn{2}{|c|}{ Rates of patients who received the planned chemotherapy cycles at scheduled times and doses } \\
\hline & & Intervention & Control \\
\hline Chevallier 1995 & G-CSF & $\begin{array}{l}\text { Retreatment at the planned date for cycles } 2,3,4 \\
51 / 61(84 \%) \\
51 / 60(85 \%) \\
49 / 58(84 \%)\end{array}$ & $\begin{array}{l}46 / 57(81 \%) \\
33 / 52(63 \%) \\
34 / 46(74 \%)\end{array}$ \\
\hline Papaldo 2003 & & Epirubicin dose intensity: $98.1 \%$ & $95.5 \%$ \\
\hline Vogel 2005 & & Patients who received planned dose on time: $80 \%$ & $78 \%$ \\
\hline Romieu 2006 & & $\begin{array}{l}\text { RDI } 100 \%: 17(57 \%) \\
\text { RDI } 95 \% \text { to } 100 \%: 9(30 \%) \\
\text { RDI } 90 \% \text { to } 95 \%: 2(7 \%) \\
\text { RDI < } 90 \%: 2(7 \%)\end{array}$ & $\begin{array}{l}7(24 \%) \\
12(41 \%) \\
6(21 \%) \\
4(14 \%)\end{array}$ \\
\hline
\end{tabular}

CSF: colony-stimulating factor; G-CSF: granulocyte colony-stimulating factor; RDI: relative dose intensity.

Table 11. Results - adverse events

\begin{tabular}{|c|c|c|c|c|c|}
\hline \multirow[t]{2}{*}{ Study } & \multirow[t]{2}{*}{ CSF } & \multicolumn{2}{|l|}{ Bone pain } & \multicolumn{2}{|c|}{ Injection-site reactions } \\
\hline & & Intervention & Control & Intervention & Control \\
\hline Chevallier 1995 & G-CSF & $\begin{array}{l}30 / 61 \\
(49 \%)\end{array}$ & $\begin{array}{l}5 / 59 \\
(8 \%)\end{array}$ & $\begin{array}{l}35 / 61 \\
(57 \%)\end{array}$ & $\begin{array}{l}10 / 59 \\
(17 \%)\end{array}$ \\
\hline Muhonen 1996 & & $\begin{array}{l}3 / 16 \\
(19 \%)\end{array}$ & $\begin{array}{l}0 / 15 \\
(0 \%)\end{array}$ & - & - \\
\hline Papaldo 2003 & & $\begin{array}{l}101 / 237 \\
(42.6 \%)\end{array}$ & Not stated & - & - \\
\hline Vogel 2005 & & $\begin{array}{l}146 / 463 \\
(31 \%)\end{array}$ & $\begin{array}{l}126 / 465 \\
(27 \%)\end{array}$ & - & - \\
\hline
\end{tabular}


Table 11. Results - adverse events (Continued)

\begin{tabular}{l|l|l|l}
\hline Jones $1996 \quad$ GM-CSF & - & $\begin{array}{l}37 / 70 \\
(53 \%)\end{array}$ & $\begin{array}{l}10 / 72 \\
(14 \%)^{*}\end{array}$ \\
\hline
\end{tabular}

* significant $(\mathrm{P}<0.05)$.

CSF: colony-stimulating factor; G-CSF: granulocyte colony-stimulating factor; GM-CSF: granulocyte-macrophage colony-stimulating factor.

\section{A P P E N D I C ES}

\section{Appendix I. DIMDI search strategy}

(colony-stimulating factors OR

granulocyte colony-stimulating factor OR

granulocyte colony stimulating factor, recombinant OR

granulocyte-macrophage colony-stimulating factor OR

granulocyte macrophage colony-stimulating factors, recombinant $\mathrm{OR}$

filgrastim OR

granulocyte colony-stimulating factor OR

recombinant granulocyte colony stimulating factor $\mathrm{OR}$

$\mathrm{g} \operatorname{csf} \mathrm{OR}$

gcsf OR

granulocyte-macrophage colony-stimulating factor OR

gm csf OR

recombinant granulocyte macrophage colony-stimulating factor OR

gmcsf OR

pegfilgrastim OR

lenograstim $O R$

sargramostim OR

filgrastim OR

neupogen $\mathrm{OR}$

granocyte OR

neulasta OR

biograstim OR

ratiograstim $\mathrm{OR}$

XM02 OR

Immunex OR

Leukine OR

Leucomax OR

Molgramostin OR

Granulokin OR

Granulokine OR

Nivestim OR

Tevagrastim OR

Zarzio OR

SCH 39300 OR

Primary prophylactic colony-stimulating factors for the prevention of chemotherapy-induced febrile neutropenia in breast cancer 


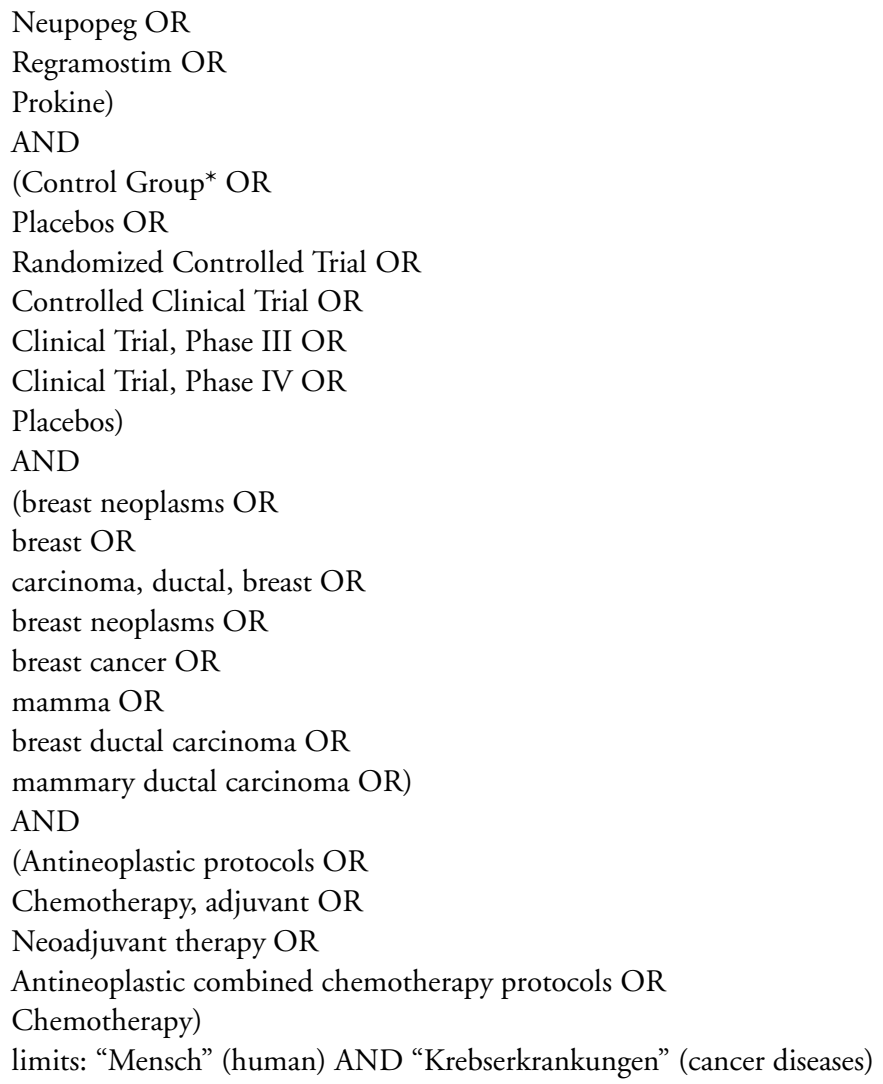

\section{Appendix 2. Clinicaltrials.gov and WHO ICTRP search strategy \\ WHO ICTRP “advanced search” strategy}

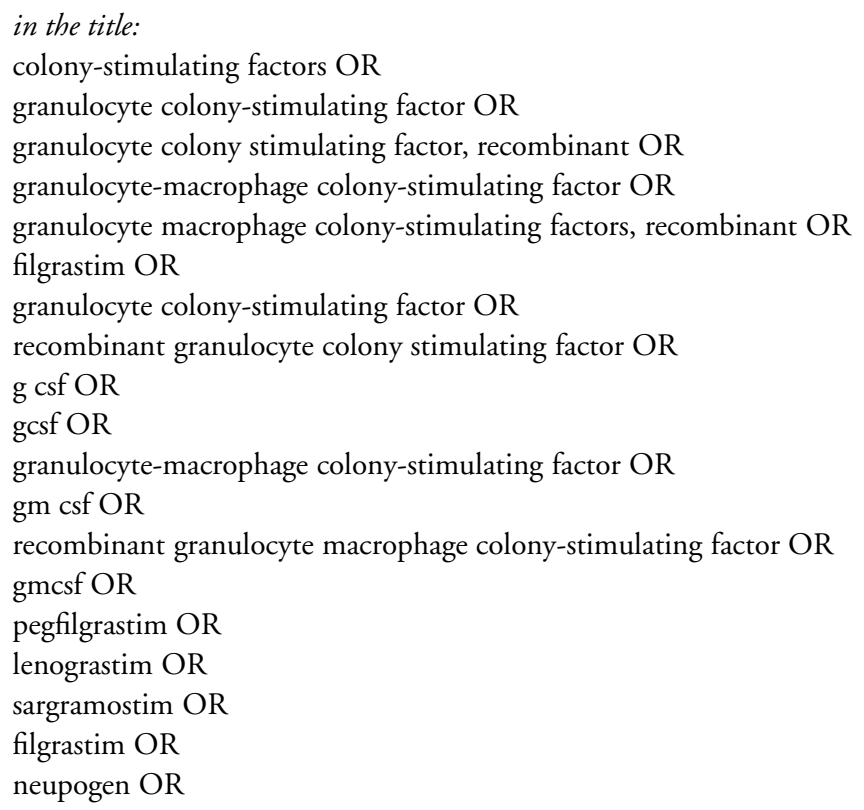

Primary prophylactic colony-stimulating factors for the prevention of chemotherapy-induced febrile neutropenia in breast cancer 
granocyte OR

neulasta OR

biograstim OR

ratiograstim $\mathrm{OR}$

XM02 OR

Immunex OR

Leukine OR

Leucomax OR

Molgramostin OR

Granulokin OR

Granulokine OR

Nivestim OR

Tevagrastim OR

Zarzio OR

SCH 39300 OR

Neupopeg OR

Regramostim OR

Prokine

in the condition:

breast neoplasms OR

breast OR

carcinoma, ductal, breast OR

breast neoplasms OR

breast cancer OR

mamma OR

breast ductal carcinoma OR

mammary ductal carcinoma

in the intervention: -

all recruitment status

all countries

every date of registration

Clinicaltrials.gov search strategy

(colony-stimulating factors OR

granulocyte colony-stimulating factor OR

granulocyte colony stimulating factor, recombinant $\mathrm{OR}$

granulocyte-macrophage colony-stimulating factor $\mathrm{OR}$

granulocyte macrophage colony-stimulating factors, recombinant $\mathrm{OR}$

filgrastim OR

granulocyte colony-stimulating factor $\mathrm{OR}$

recombinant granulocyte colony stimulating factor OR

$\mathrm{g} \operatorname{csf} \mathrm{OR}$

gcsf OR

granulocyte-macrophage colony-stimulating factor OR

gm csf OR

recombinant granulocyte macrophage colony-stimulating factor OR

gmcsf OR

pegfilgrastim OR

lenograstim OR

sargramostim OR

filgrastim OR

neupogen OR

granocyte OR

neulasta OR

Primary prophylactic colony-stimulating factors for the prevention of chemotherapy-induced febrile neutropenia in breast cancer 
biograstim OR

ratiograstim $\mathrm{OR}$

XM02 OR

Immunex OR

Leukine OR

Leucomax OR

Molgramostin OR

Granulokin OR

Granulokine OR

Nivestim OR

Tevagrastim OR

Zarzio OR

SCH 39300 OR

Neupopeg OR

Regramostim OR

Prokine) [ALL-FIELDS]

AND "Interventional" [STUDY-TYPES]

AND

(breast neoplasms OR

breast OR

carcinoma AND ductal AND breast OR

breast neoplasms OR

breast cancer OR

mamma OR

breast ductal carcinoma OR

mammary ductal carcinoma) [DISEASE]

\section{Appendix 3. Chinese Databases search strategy}

\section{VIP Database:}

集落刺激因子 $A N D$ 发热性中性粒细胞减少( ti) 0

集落刺激因子 AND发热性中性粒细胞减少 $(\mathrm{kw}) \mathbf{0}$

集落刺激因子 AND FN（ti) 0

藮落刺激因子 AND FN ( kw) 4

CSF AND 发热性中性粒细胞减少（， ti) 0

CSF AND 发热性中性粒细胞减少（ kw) 0

CSF AND FN ( ti) 19

CSF AND FN ( kw) 15

\section{CNKI}

集落刺激因子AND发热性中性粒细胞减少（ｔi) 0

集落刺激因子AND发热性中性粒细胞减少 $(\mathbf{k w}) \mathbf{1}$

集落刺激因子 $\mathrm{AND}$ 发热性中性粒细胞减少( mesh) 10

集落刺激因子 AND FN ( ti) 0

集落刺激因子 AND FN ( $\mathbf{k w}) \mathbf{0}$

荤落刺激因子 AND FN (mesh) 14

CSF AND 发热性中性粒细胞减少（ti) 1

CSF AND 发热性中性粒细胞减少（ kw) 0

CSF AND 发热性中性粒细胞减少（mesh） 10

CSF AND FN ( ti) 1

CSF AND FN ( $k w) ~ 0$

CSF AND FN ( mesh) 61

Primary prophylactic colony-stimulating factors for the prevention of chemotherapy-induced febrile neutropenia in breast cancer 
CBM Database

集落刺激因子 $\mathrm{AND}$ 发热性中性粒细胞减少( ti) 0

集落刺激因子AND 发热性中性粒细胞减少( $\mathbf{a b}$ ) 3

菒落刺激因子 AND FN ( ti) 0

集落刺激因子 AND FN ( ab) 5

CSF AND 发热性中性粒细胞减少（ti) 1

CSF AND 发热性中性粒细胞减少（ab) 4

CSF AND FN ( ti) 0

CSF AND FN ( ab) 17

\section{H I S T O R Y}

Protocol first published: Issue 3, 2009

Review first published: Issue 10, 2012

\section{CONTRIBUTIONSOFAUTHORS}

PR and MH had full access to all data in the review and take responsibility for the integrity of the data and the accuracy of the analysis.

Study concept and design: MH, SM, PR, MZ.

Inclusion and exclusion of studies: PR, SM, JL, JB, MH.

Acquisition of data: PR, SM.

Data entry and plausibility check: PR, SM, MH.

Analysis and interpretation of data: MH, PR, SM, JB, MZ.

Drafting of the manuscript: PR, MH with contributions from all other review authors.

Statistical analysis: MZ, PR, MH.

Study supervision: $\mathrm{MH}$.

The review was part of the doctoral thesis of PR.

\section{DECLARATIONSOF INTEREST}

The authors certify that they have no affiliations with any organization or entity with a direct financial interest in the subject matter of the review. All steps of the review process were completely independent from any work previously undertaken on this subject. 


\section{SOURCES OF SUPPORT}

\section{Internal sources}

- No sources of support supplied

\section{External sources}

- AG Biologische Krebstherapie, Deutsche Krebshilfe (70-301), Germany.

\section{DIFFERENCES BETWEEN PROTOCOLANDREVIEW}

The published protocol included 'mortality related to infections' as a primary outcome. We have since split up mortality to include: early mortality (during the study) and infection-related mortality (during the study) for clarity in the review. 